FELIPE MARINO MORENO

\title{
MACHINE LEARNING APPLIED TO SHIP MANEUVERING SIMULATIONS
}


FELIPE MARINO MORENO

\title{
MACHINE LEARNING APPLIED TO SHIP MANEUVERING SIMULATIONS
}

\author{
Master Thesis presented to the Escola \\ Politécnica, Universidade de São Paulo to \\ obtain the degree of Master of Science.
}


FELIPE MARINO MORENO

\title{
MACHINE LEARNING APPLIED TO SHIP MANEUVERING SIMULATIONS
}

\author{
Revised Version
}

Master Thesis presented to the Escola Politécnica, Universidade de São Paulo to obtain the degree of Master of Science.

Research Area:

Mechanical Engineering on Control and Automation

Advisor:

Prof. Dr. Eduardo Aoun Tannuri 
Autorizo a reprodução e divulgação total ou parcial deste trabalho, por qualquer meio convencional ou eletrônico, para fins de estudo e pesquisa, desde que citada a fonte.

Este exemplar foi revisado e corrigido em relação à versão original, sob responsabilidade única do autor e com a anuência de seu orientador.

São Paulo, de de

Assinatura do autor:

Assinatura do orientador:

\section{Catalogação-na-publicação}

Moreno, Felipe Marino

Machine Learning Applied to Ship Maneuvering Simulations / F. M.

Moreno -- versão corr. -- São Paulo, 2020.

$97 \mathrm{p}$.

Dissertação (Mestrado) - Escola Politécnica da Universidade de São Paulo. Departamento de Engenharia Mecatrônica e de Sistemas Mecânicos.

1.Machine Learning 2.Maritime Maneuvering Simulations 3.Cluster Analysis I.Universidade de São Paulo. Escola Politécnica. Departamento de Engenharia Mecatrônica e de Sistemas Mecânicos II.t. 


\section{ACKNOWLEDGMENTS}

Throughout the writing of this thesis I have received a great deal of support and assistance. I would first like to thank my advisor, Eduardo Aoun Tannuri, for the opportunity to carry this study and for his expertise, which was invaluable in the development of the methodologies present in this work.

I would like to thank Officers Carlos Eduardo do Nascimento, Rodrigo Negrizoli da Silva and deck cadet Gustavo França de Monteiro Mendonça for their participation in the Real-Time maneuvering simulations used to evaluate the methodology in this work. I would also like to thank Felipe Lopes de Souza for his contribution with ideas and insightful talks about machine learning and statistics.

In addition, I'm grateful to my colleagues and friends at TPN-USP, for their knowledge sharing and deliberations about various fields, as well as $\mathrm{CNPq}$ for the research grant.

Last, but not least, I would like to thank my family for their counsels and invaluable support. 


\section{RESUMO}

Com a expansão do poder computacional, simulações de manobras marítimas se tornaram uma importante ferramenta para se aumentar a segurança das operações realizadas no mar. Neste contexto, uma das categorias mais importantes de simulações realizadas pelo Tanque de Provas Numérico da USP (TPN-USP) são as em tempo real, ou seja na mesma escala de tempo de uma manobra real em um ambiente de realidade virtual. Tais simulações são utilizadas para se avaliar os riscos e a viabilidade de manobras marítimas, porém por elas serem demoradas poucos casos podem ser analisados por dia. Este trabalho visa a aplicação de aprendizado de máquina para criar uma ferramenta para o simulador marítimo do TPN-USP que irá ser utilizada para escolher quais condições ambientais de vento, corrente, ondas de mar local e swell serão utilizadas para essas simulações

Palavras-Chave - Aprendizado de Máquina, Simulação Marítima, Simulação Hidroviária, Cluster Analysis. 


\section{ABSTRACT}

With the increase of computational power, ship maneuvering simulations have become an important tool to improve the safety of the operations carried at the sea. In this context, one of the most important categories of simulations made by the Numerical Offshore Tank (TPN-USP) is the Real-Time simulations, carried out in a Virtual Reality environment at the same time scale as a real maneuver. These simulations are used to evaluate maritime maneuvers' risks and viability, but since they take a long time, only a few can be made per day. This work focuses on applying machine learning to create a tool for the TPN-USP maritime simulator that will be used to choose environmental conditions of wind, currents, local sea waves and swell for these simulations.

Keywords - Machine Learning, Maritime Simulation, Waterway Simulation, Cluster Analysis. 


\section{LIST OF FIGURES}

1 Real and simulated ship-to-ship operation. Source: TPN.

2 Mean quantization error for different clustering algorithms for trivariate waves. Source: CAMUS et al. (2011). . . . . . . . . . . . . . . . . . . . . 19

3 Clustering results for the waves at Santa Catarina coast. For the Spring season, the algorithm split part of group E in group F. Source: ARAÚJO et al. (2003). . . . . . . . . . . . . . . . . . . . . 20

4 Current clustering results for the West Florida shelf. It is possible to notice three different patterns in the clusters, one where the flux is mainly southeastward, one where the flux is mainly northwestward and another where the flux is transitional with low current velocities. Source: LIU; WEISBERG (2005). . . . . . . . . . . . . . . . . . 21

5 Clustered meteorological stations in the Alagoas state. Source: LYRA et

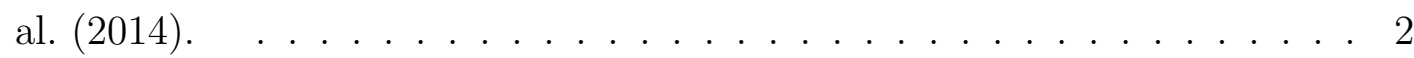

6 Clustered winds and waves for the Borssele Wind Farm Zone, Netherlands. Clusters 1, represented by the red symbols were obtained using the previous algorithm given by KANNER et al. (2017), while Clusters 2 was obtained using the newer algorithm. Source: KANNER et al. (2018). . . . . . . . . 24

$7 \quad$ Literature reviewed papers grouped by their objective and clustered environmental agents. The clustering can be used to reduce inputs for other simulations, to forecast weather and to find relations between the data or evaluate different clustering algorithms (analysis). . . . . . . . . . . .

8 Example of four simulators situated at TPN-USP. All simulators can run the same scenario at the same time, each one controlling one vessel. The Crane simulator (bottom right) can control either a tugboat or a crane. Source: TPN.

$9 \quad$ Reference frames for the Dyna simulator. Source: TPN.

10 Rudder forces. Source: TANNURI et al. (2014). . . . . . . . . . . . . . . 32

11 Line of sight basic diagram. . . . . . . . . . . . . . . . . . 34 
12 Example of a cluster analysis applied to a group of three two-dimensional Gaussian distributions.

13 Dendogram for the hierarchical clustering of five objects. Source: VALE (2005).

14 Comparison between Euclidian distance (a) and Dynamic Time Warping (b). The map shown in (c) is the warping path that correlates the points of both curves in (b), the two diagonal lines are constraints to the warping path. Source: ZHANG et al. (2015). . . . . . . . . . . . . . . . . . . 38

15 Dynamic Time Warping Paliwal window defined. Source: PALIWAL et al. (1982).

16 Methodology overview. . . . . . . . . . . . . . . . . 40

17 Autopilot overview. . . . . . . . . . . . . . . . . . . 41

18 Heading control system. . . . . . . . . . . . . . . . . . . . . 42

19 Exemplification of the $g\left(k, o_{i}\right)$ and $l\left(k, o_{i}\right)$ values. . . . . . . . . 45

20 Example of radial histogram plot for the entire dataset of the Tubarão port. Wind and current speeds are in meters per second, and waves height

21 Example of time-series plot for a group.

22 Left: Aerial view of the Tubarão port. Right: Tubarão port access channel. The B4 point indicates the point where the environmental conditions were obtained. Source: TPN . . . . . . . . . . . . . . . . . . . . . . 50

23 Directional histogram for wind, waves and currents in the studied site. . . 50

24 Currents velocity and direction maps for the Tubarão port. Source: TPN.

25 Wave significant height and direction maps for the Tubarão port. Source: TPN.

26 Silhouette coefficients for Tubarão simulations.

27 Mean environmental conditions for $k=2$ and cost function 4.5 for the Tubarão port.

28 Radial histograms for environmental conditions for $k=2$ and cost function 4.5 for the Tubarão port. 
29 Drift angle time-series for the first group for $k=2$ for the Tubarão port. The black curves represents the $5 \%$ simulations with largest average drift angle having the yellow curve as its medoid. Red curve is the group medoid. 56

30 Drift angle time-series for the second group for $k=2$ for the Tubarão port. The black curves represents the $5 \%$ simulations with largest average drift angle having the yellow curve as its medoid. . . . . . . . . . . . . . 56

31 Example of average environmental conditions for the cases with the $5 \%$ highest average drift angle for the Tubarão port. . . . . . . . . . . . . . . . 57

32 Time-lapse of selected maneuvers in Tubarão, with 3 minute sampling. The number denotes the group number, the letter "a" denotes the medoid for the entire group, and the letter "b" denotes the medoid for the $5 \%$ condition with highest drift.. Channel in yellow, start of channel in blue and end of channel in green. . . . . . . . . . . . . . . . 58

33 Suape port access channel. Source: TPN. . . . . . . . . . . . . . . 60

34 Silhouette coefficients for Suape port. . . . . . . . . . . . . . . 62

35 Mean environmental conditions for $k=2$ and cost function 4.6 for the Suape port. . . . . . . . . . . . . . . . . . 62

36 Radial histograms for environmental conditions for $k=2$ and cost function 4.6 for the Suape port.

37 Mean environmental conditions for $k=2$ and cost function 4.6 for the cases with $5 \%$ highest mean drifting for the Suape port simulations. . . . . . . . 64

38 Drifting time-series for the first group for $k=2$ for the Suape port. The black curves represents the $5 \%$ simulations with largest mean drift having the yellow curve as its medoid. Red curve is the group medoid. . . . . . . 65

39 Drifting time-series for the second group for $k=2$ for the Suape port. The black curves represents the $5 \%$ simulations with largest mean drift having the yellow curve as its medoid.

40 Time-lapse of selected maneuvers in the Suape port, with 2 minute sampling. The number denotes the group number, the letter "a" denotes the medoid for the entire group, and the letter "b" denotes the medoid for the $5 \%$ condition with highest drift. Channel in yellow, start of channel in blue and end of channel in green. 
41 Silhouette coefficients for Campos basin simulations with vessel in ballast condition.

42 Silhouette coefficients for Campos basin simulations with vessel in fully loaded condition. . . . . . . . . . . . . . . . . . . 69

43 Mean environmental conditions for groups in the Campos basin. . . . . . . 70

44 Mean environmental conditions for cases with $5 \%$ highest mean drifting for the groups in the Campos basin. . . . . . . . . . . . . . . . . . . . 70

45 Environmental conditions for groups in the Campos basin. . . . . . . . . . 72

46 Drifting time-series for the simulation in ballast condition in the Campos basin.

47 Drifting time-series for the simulation with the vessel fully loaded in the Campos basin.

48 Time-lapse of selected maneuvers in the Campos basin, with 2 minute sampling. The number denotes the group number, the letter "a" denotes the medoid for the entire group, and the letter " $b$ " denotes the medoid for the $5 \%$ condition with highest drift. Maximum allowable cross-track error, only the simulation between the blue and green lines is considered for the clustering. . . . . . . . . . . . . . . . . . . 74

49 Time-lapse of selected Tubarão maneuvers made by the Officer 1 . On the left is the simulation with moderate conditions 1a, on the right is the simulation with extreme conditions, 2c. . . . . . . . . . . . 79

50 Mean difficulty and drifting angle for simulations in Tubarão. . . . . . . . . 81

51 Time-lapse of selected Suape maneuvers made by Officer 1. On the top is the simulation with moderate conditions 1a', on the bottom is the simulation with extreme conditions, 2 c. . . . . . . . . . . . . . . 84

52 Mean difficulty and drifting angle for simulations in Suape. . . . . . . . . 85

53 Time-lapse of selected Campos basin maneuvers made by Officer 1 with the vessel fully loaded. On the top is the simulation with moderate conditions 1a, on the bottom is the simulation with extreme conditions, 2c. . . . . 88

54 Mean difficulty and drifting angle for simulations in the Campos basin, with the vessel fully loaded. 
55 Time-lapse of selected Campos basin maneuvers with the vessel in ballast condition. On the top is the simulation with moderate conditions 1a, on the bottom is the simulation with extreme conditions, 2c. . . . . . . . 92

56 Mean difficulty and drifting angle for simulations in the Campos basin, with the vessel in ballast condition. . . . . . . . . . . . . . . . . 93 


\section{LIST OF TABLES}

1 Parameters used for tuning the PID in equation $4.2 \ldots \ldots$. . . . . . . . 42

2 Example of the $D_{t u b}$ fields and structure. Hs denotes wave significant height, Tp wave peak period. . . . . . . . . . . . . . . . . 50

3 Valemax ship used for the simulations. Source: TPN. . . . . . . . . . . . 52

$4 \quad$ Available current and Wave maps directions for Tubarão port. . . . . . . . 52

$5 \quad$ Parameters used for the automatic pilot in the Tubarão simulations. . . . . 53

6 Processing time for each step of the methodology for this scenario ran on a computer with an i7-7700 3.6Ghz processor. . . . . . . . . . . . . . 53

$7 \quad$ Characteristics of the vessel used for Suape's simulations. Source: TPN. . . 59

8 Parameters used for the automatic pilot for the simulations with the vessel Aframax fully loaded. . . . . . . . . . . . . . . . . . . . . . . . 60

9 Criteria for classification of waves components into Swell or Local Sea waves. Source: HUANG et al. (2019) . . . . . . . . . . . . . . . . . . . . 61

10 REMO, Portuguese acronym for Oceanographic Modeling and Observation Network; ECMWF: European Centre for Medium-Range Weather Forecasts; and BOMOSHU: Brazil Offshore Metocean Storm Hindcast Update. Source: TANNURI et al. (2020) _ . . . . . . . . . . . . . . . 67

11 Parameters used for the automatic pilot for the simulations with the vessel Aframax in ballast condition. . . . . . . . . . . . . . . . . . . 68

12 Qualitative and quantitative difficulty grades used by the officers. . . . . . 75

13 Environmental conditions used for the Tubarão simulations with officers. The directions follow the convention used for this work (wind and waves incidence angle and currents emission angle) . . . . . . . . . . . . . . 77

14 Questionnaire answers for the Tubarão port simulations. The +2 denotes that the difficulty given by the officer was increased by two points due to the maneuver being carried without a safe distance from the margins. . . . 78

15 Officer classification of the simulated cases for the Tubarão port into bins. 78 
16 Correlations and statistical significance between the perceived maneuver difficulty and the simulations parameters for the Tubarão port. . . . . . . . 80

17 Environmental conditions used for the Suape simulations with officers. The arrow $(\nearrow)$ denotes the direction of the environmental agent. . . . . . . . . 82

18 Questionnaire answers for the Suape port simulations made by officers. . . 83

19 Officer 1 classification of the simulated cases for the Suape port. . . . . . . 84

20 Correlations and statistical significance between the perceived maneuver difficulty and the simulations parameters for the Suape port. . . . . . . . . 85

21 Environmental conditions used for the Campos simulations with officers. The arrow $(\nearrow)$ denotes the direction of the environmental agent. . . . . . 86

22 Questionnaire answers for the Campos Basin simulations made by the officers with the vessel fully loaded. . . . . . . . . . . . . . . . . . . 87

23 Officer 1 classification of the simulated cases for the Campos basin, vessel fully loaded. . . . . . . . . . . . . . . . . . . . . . . . . . 88

24 Correlations and statistical significance between the perceived maneuver difficulty and the simulations parameters for the Campos basin with the vessel fully loaded.

25 Environmental conditions used for the Campos simulations with officers. The arrow $(\nearrow)$ denotes the direction of the environmental agent. . . . . . 90

26 Questionnaire answers for the Campos Basin simulations made by the Officer 1 with the vessel in ballast condition. . . . . . . . . . . . . . . . . . . 91

27 Pilots classification of the simulated cases for the Campos basin simulations with the vessel in ballast condition. . . . . . . . . . . . . . . . . . . . . . . 91

28 Correlations and statistical significance between the perceived maneuver difficulty and the simulations parameters for the Campos basin with the vessel in ballast condition. . . . . . . . . . . . . . . . . . . . . . . 92 


\section{CONTENTS}

1 Introduction $\quad 15$

1.1 Motivation . . . . . . . . . . . . . . . 16

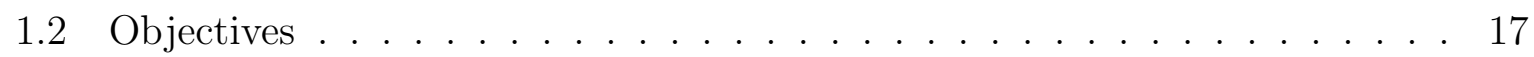

1.3 Text Structure . . . . . . . . . . . . . . . . . . . . 17

2 Literature Review $\quad 18$

2.1 Cluster Analysis applied to Waves . . . . . . . . . . . . . . . . . 18

2.2 Cluster Analysis applied to Ocean Currents . . . . . . . . . . . . . 20

2.3 Cluster Analysis applied to Wind and Meteorological Data . . . . . . . . . 21

2.4 Cluster Analysis applied to Combined Ocean Conditions . . . . . . . . . . 23

2.5 Literature Review Conclusions . . . . . . . . . . . . . . . . . 25

3 Theoretical Background $\quad 27$

3.1 Ship Maneuvering Simulations . . . . . . . . . . . . . . . . 27

3.1.1 Mathematical Model . . . . . . . . . . . . . . . 28

3.1 .2 External Forces . . . . . . . . . . . . . . . . 30

Environmental Forces . . . . . . . . . . . . 30

Actuator forces ..................... 32

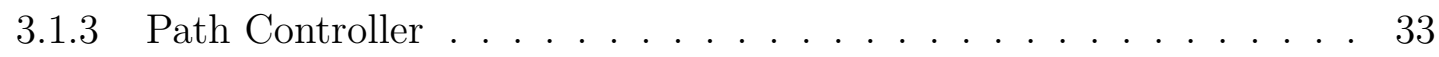

3.2 Unsupervised Machine Learning . . . . . . . . . . . . . . . . . . . . 34

3.3 Dissimilarity of Time-Series . . . . . . . . . . . . . . . 37

4 Methodology for obtaining a reduced set of environmental conditions 40

4.1 Method Overview . . . . . . . . . . . . . . . 40

4.1.1 Preparing the scenario . . . . . . . . . . . . . . . . 40 
$4.1 .2 \quad$ Fast-Time Simulations . . . . . . . . . . . . . . . . . . . . 41

4.1 .3 Cluster Analysis . . . . . . . . . . . . . . . . . . . . . . 43

4.1 .4 Analysis . . . . . . . . . . . . . . . . . . . 46

5 Case studies $\quad 49$

5.1 Tubarão Port . . . . . . . . . . . . . . . . . . . . . . . . 49

5.2 Suape Port . . . . . . . . . . . . . . . . . . . . . 58

5.3 Campos Basin . . . . . . . . . . . . . . . . . 66

6 Experimental Simulations $\quad 75$

6.1 Tubarão Port . . . . . . . . . . . . . . . . . . 76

6.2 Suape Port . . . . . . . . . . . . . . . . . . . . . . 81

6.3 Campos Basin: Fully Loaded Vessel . . . . . . . . . . . . . . . . . . . . 86

6.4 Campos Basin: Ballast Vessel . . . . . . . . . . . . . . . . . . . . 90

$\begin{array}{lll}7 & \text { Conclusion and Next Steps } & 94\end{array}$

$\begin{array}{ll}\text { References } & 95\end{array}$ 


\section{INTRODUCTION}

Ship maneuvering simulations are an important component for the safety and risk management of operations carried at sea. In this environment, the behavior of the vessels can be predicted under controlled conditions that simulate real-world scenarios, without exposing to risks the crew and material assets.

In this context, the category of ship simulations that better represent reality is called Real-Time ship maneuvering simulations, as shown in figure 1. These simulations are commanded by real pilots in a virtual reality environment adapted to emulate a ship's bridge. The simulation's time scale is the same as a real maneuver, in such a way that each simulated maneuver takes about 1.5 hours. They are used for multiple purposes, such as analysis of special maneuvers (for example, ship-to-ship direct oil transfer), feasibility assessment for larger vessels to access an existing port, and the study of new infrastructures such as expansions of terminals (new berths) or construction of new ports. During the simulation, important data is recorded, such as the ship's position, speeds, engine power used, the tension in lines, tug's usage etc.

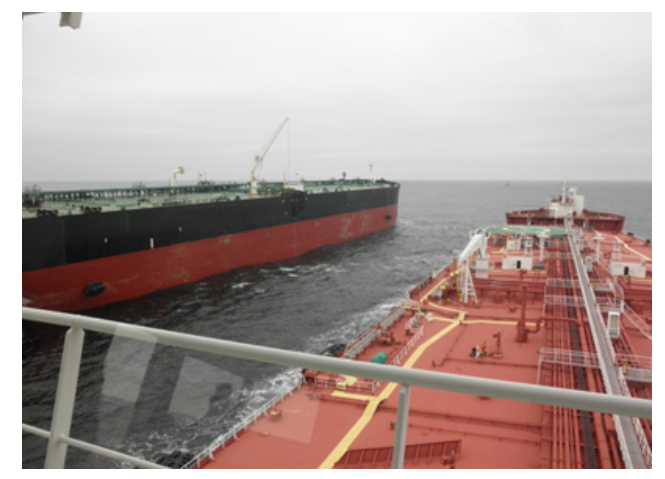

(a) Ship-to-ship offloading operation.

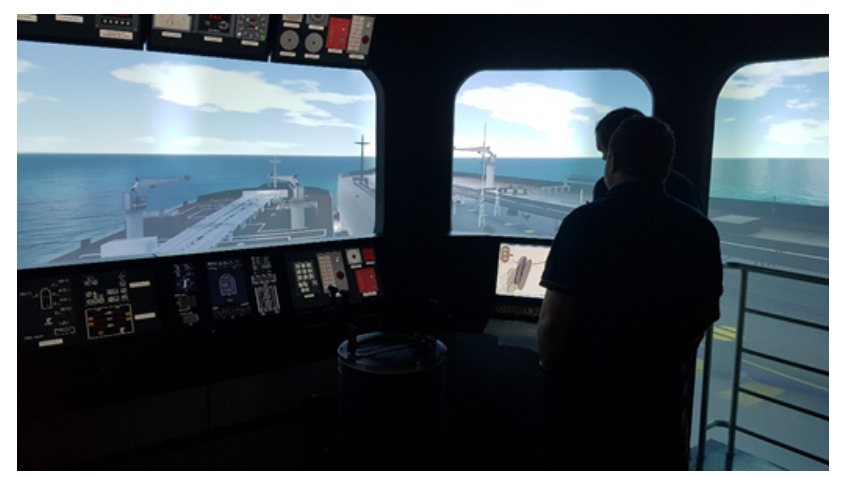

(b) Same operation being simulated at TPN-USP.

Figure 1: Real and simulated ship-to-ship operation. Source: TPN.

When simulating a port, it is crucial to represent the environmental effects caused by the wind, waves, and currents realistically. These In order to account for these effects, it is necessary to know the characteristics and parameters of the environmental agents in the 
area. One possible way to obtain this information is to ask someone who has experience navigating in the area to provide this information. Still, this option is not ideal since relevant parameters might be unintentionally omitted.

It is also possible to obtain these parameters by measuring directly the environmental agents employing buoys and other measurement devices. Such devices allow the systematic measurement of the environmental conditions and produce large amounts of data. But since the simulations are carried at real time, there is no time to simulate all the different environmental conditions obtained. From this situation emerges the problem of how to select the environmental conditions that should be used for the simulations.

In order to solve this problem, there is the need to reduce the large number of environmental data points $(n)$ into a smaller set of points $(q)$ that will be used for the simulations. The reduced set of points shall be much smaller than the original dataset $(q \ll n)$ while still representing the simulated site with good accuracy. The techniques that allow this reduction are called cluster analysis.

This work proposes to use cluster analysis to reduce the dataset with measurements of wind, ocean current and waves by grouping them accordingly to the effects felt by the ship. The environmental conditions that causes similar effects on the vessel will be represented by only one environmental condition in the Real-Time simulation.

This procedure will be used previously to the Real-Time ship maneuvering simulations, to select the most representative environmental conditions for the specific combination of ship and area to be tested.

\subsection{Motivation}

In the TPN's database there are some large datasets (each one containing between 7000 and 20000 simultaneous waves/winds/currents conditions) of environmental conditions for some regions of the Brazilian shore. At the same time the Real-Time simulations can benefit from an objective selection of environmental conditions in order to extract the most from each simulation, since only a very few of these simulations can be made per day.

This volume of data opens the possibility to apply data-driven methods, such as cluster analysis to extract useful metocean conditions for these simulations, reducing the large amounts of environmental conditions present in the database to a few that best represent the simulated site, and thus maximize the value of each Real-Time simulation. 
Since the vessel behavior under the environmental agents is more important than the environmental agents per se, it was decided that the cluster analysis shall consider the vessel behavior instead of the absolute intensity and direction of the environmental agents. Meaning that all environmental conditions that affect the vessel in a similar manner and intensity can be considered effectively the same and be represented by only one representative environmental condition.

\subsection{Objectives}

The objective of this work is to develop a systematic procedure for reducing a large database of environmental conditions, containing values of wind/wave/currents, to a small set of representative environmental conditions to be used for Real-Time ship maneuvering simulations.

\subsection{Text Structure}

This text starts with a literature review in chapter 2, where similar works are briefly discussed. In the chapter 3, a briefly theoretical review of the key concepts used for this work is given. The revision comprehends concepts from the machine learning field, vessel dynamics and the simulation environment where the machine learning will be applied.

The chapter 4 presents the techniques developed for selection of environmental conditions and the chapter 5 presents the techniques applied for four different scenarios in three different regions. The chapter 6 shows experimental simulations made with human officers in order to evaluate the methodology.

Finally, on chapter 7, the conclusion and next steps of this thesis will be presented. 


\section{LITERATURE REVIEW}

Cluster analysis is a group of techniques used to group similar entities accordingly to a specified metric. Different methods were developed to classify the data in clusters, mainly by adopting optimization formulation. A fundamental description of cluster analysis can be found in (BISHOP, 2006) and (HASTIE et al., 2008).

The cluster analysis started to attract research attention in the 60's with the advent of high speed computers, and became a common tool in many fields of research. Therefore the application of cluster analysis as a mean to reduce the number of environmental data is not new, many researchers have applied these methods with satisfactory results. In this section it will be discussed references that employ cluster analysis to cluster different environmental data, divided into four topics accordingly to the environmental agent being clustered.

\subsection{Cluster Analysis applied to Waves}

One case of cluster analysis application is the use of k-means to group directional wave spectrum for structure simulations in the Campos basin. Although it was possible to represent the vessel response with a good approximation by using 100 groups of wave spectra, it was also noted that for multimodal seas the k-means can not represent well small, but important, groups of wave spectra. (VOGEL et al., 2016)

Another application of cluster analysis is made by CAMUS et al. (2011) to cluster ocean waves mean period, significant height and direction. That work focuses on the comparison between K-means (KMA), Self Organizing Maps (SOM) and the Maximum Dissimilarity Algorithm (MDA) to cluster the data. It was found that the K-means offer the lowest quantization error when compared to the other methods, specially for lower number of groups $(k \leq 200)$, as can be seen in figure 2 . 


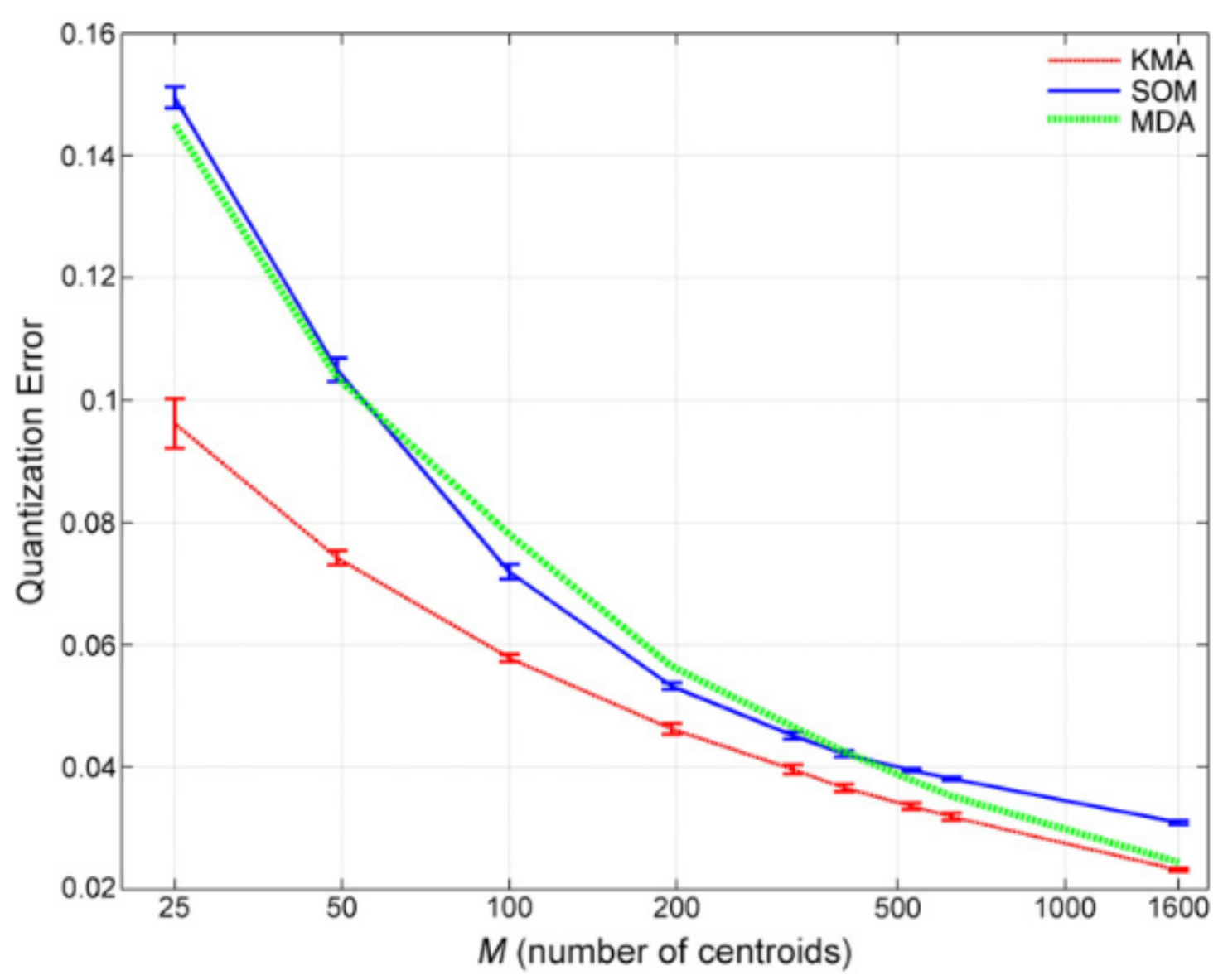

Figure 2: Mean quantization error for different clustering algorithms for trivariate waves. Source: CAMUS et al. (2011).

An application of hierarchical clustering is provided by a tool made by EUÁN; SUN (2019) for the classification of directional spectra of waves. Since the directional spectra is a bi-dimensional function, the distance is computed as the integral of modulus differences between the spectra for the entire function domain.

Another cluster application for ocean waves is made by ARAÚJO et al. (2003) for the coast of Santa Catarina, Brazil, where hierarchical clustering using Mahalanobis distance is used in order to group the waves accordingly to their dominant direction and peak period. This allowed the identification of five different wave systems in the region, each one associated to a different cause, as shown in figure 3. 

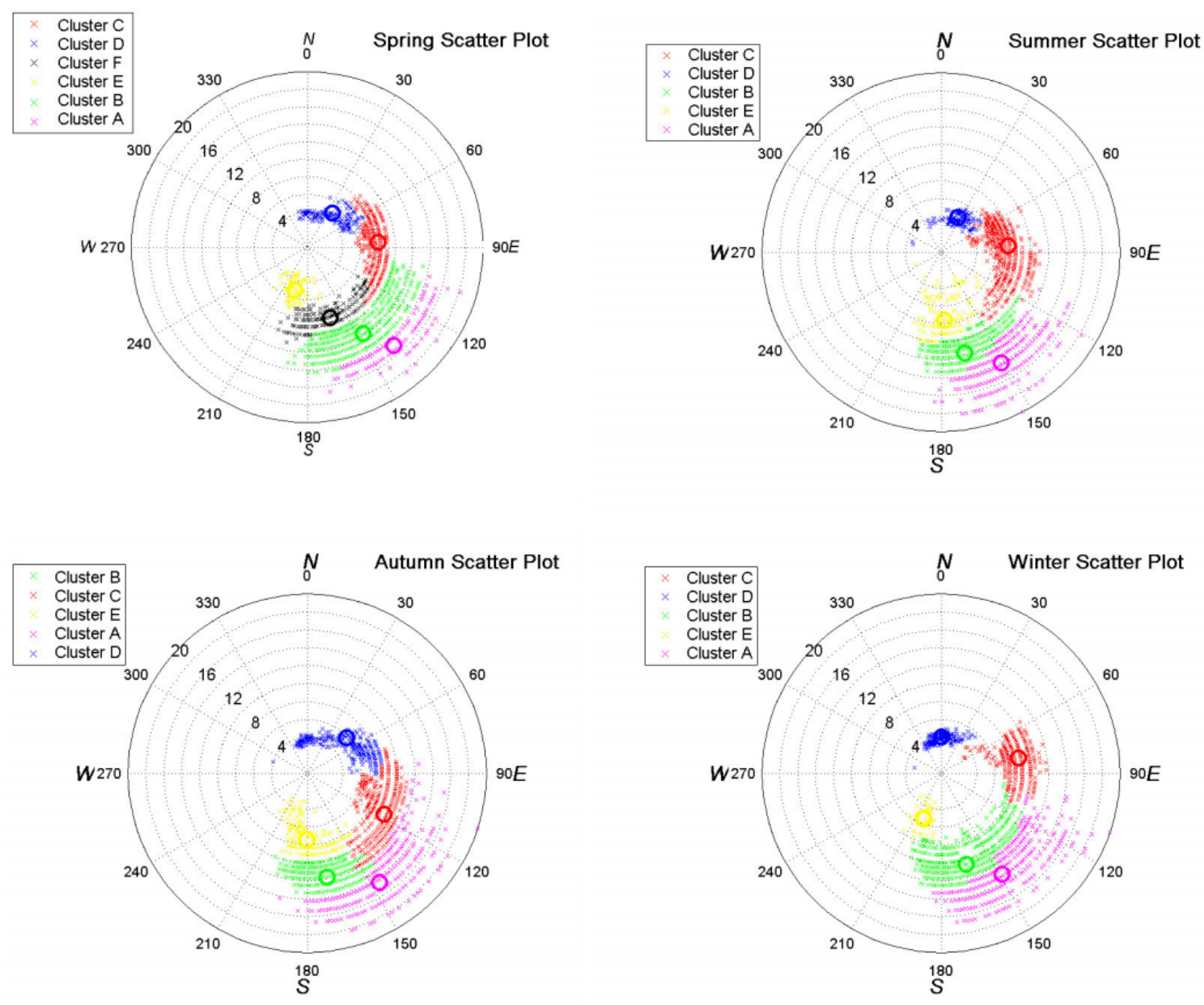

Figure 3: Clustering results for the waves at Santa Catarina coast. For the Spring season, the algorithm split part of group E in group F. Source: ARAÚJO et al. (2003).

\subsection{Cluster Analysis applied to Ocean Currents}

One application of environmental cluster analysis was employed to group current profiles to simplify fatigue simulations for risers. In this work, Self Organizing Maps were used and compared with Empirical Orthogonal Functions and classical Current Profile Characterization. The three methods were compared and refined. All three methods allow the correct fatigue analysis when they have at least 500 different groups, but due to confidentiality reasons a deeper comparison between these methods was not divulged. (PREVOSTO et al., 2012)

Another application of cluster analysis is made by LIU; WEISBERG (2005), where a Self-Organizing Map is used to cluster the current patterns in West Florida, U.S.A., shelf. This method was compared to the Empirical Orthogonal Function, and it had some advantages, such as the extraction of asymmetric patterns and handling of missing 
data, while having the disadvantage that the arrangement of the neurons is user defined, needing some tweaking in order to obtain the best results. The final 12 clusters obtained by SOM, applied to currents in three depths for 11 buyoys is shown in figure 4 .
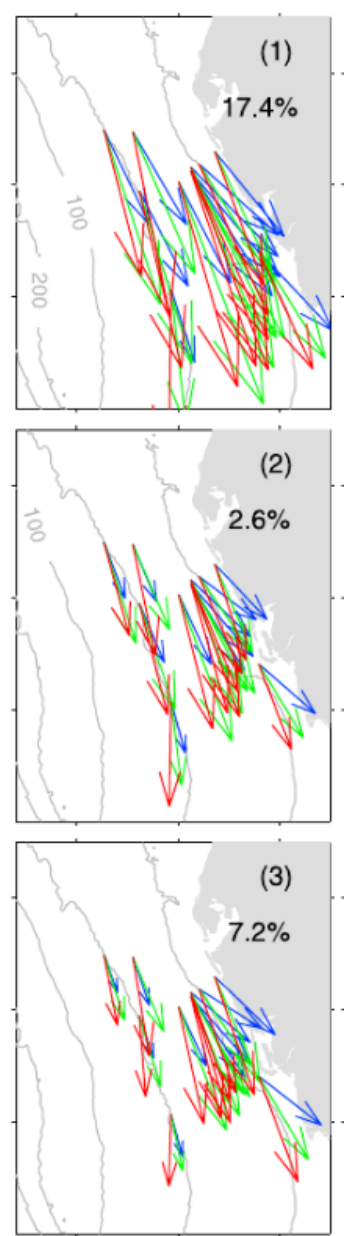
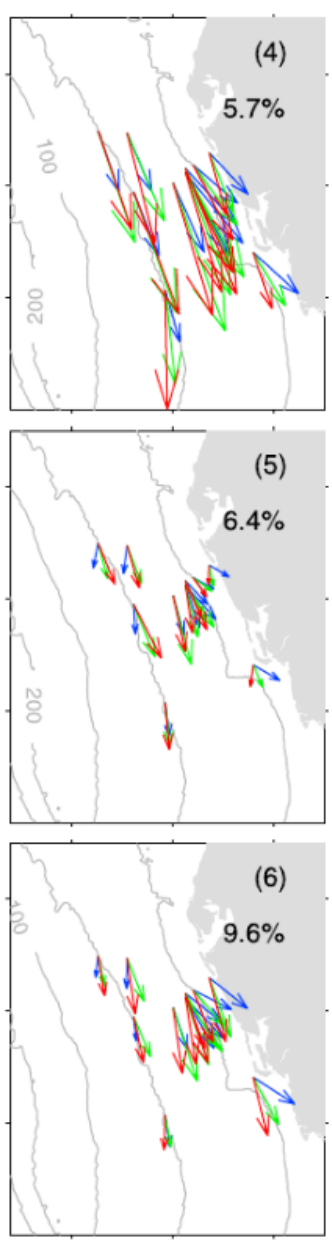
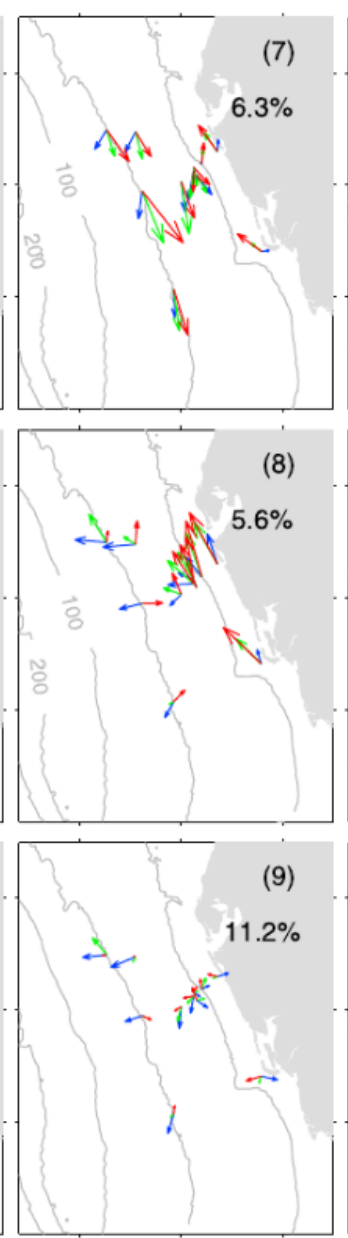
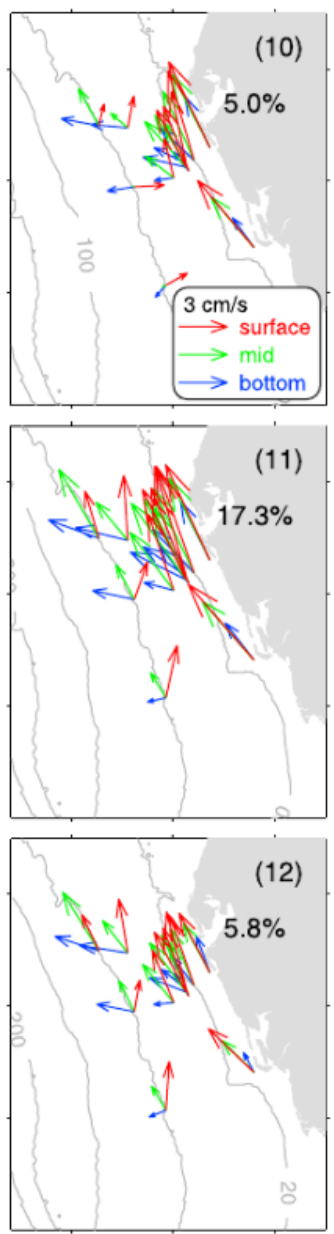

Figure 4: Current clustering results for the West Florida shelf. It is possible to notice three different patterns in the clusters, one where the flux is mainly southeastward, one where the flux is mainly northwestward and another where the flux is transitional with low current velocities. Source: LIU; WEISBERG (2005).

\subsection{Cluster Analysis applied to Wind and Meteoro- logical Data}

Cluster analysis has achieved success in others related fields, such as to group climatological patterns in the central and eastern North America carried by GONG; RICHMAN (1995) using rainfall as the clustering parameter. In this work 8 cluster analysis algorithms were used with 3 different dissimilarity measures, and it was found that the cluster analysis accuracy increases linearly to logarithmically with relation to the sample size. 
In the work developed by LYRA et al. (2014), cluster analysis is used to segment the regions of the Alagoas state, situated at Northeast of Brazil. The cluster analysis aimed to separate the groups accordingly to their pattern of monthly rainfall. It was found that the cluster analysis yielded groups consistent with climatological studies that associates the enhancement or suppression of rainfall in the studied site by weather events. The cluster outcome is shown in figure 5 .

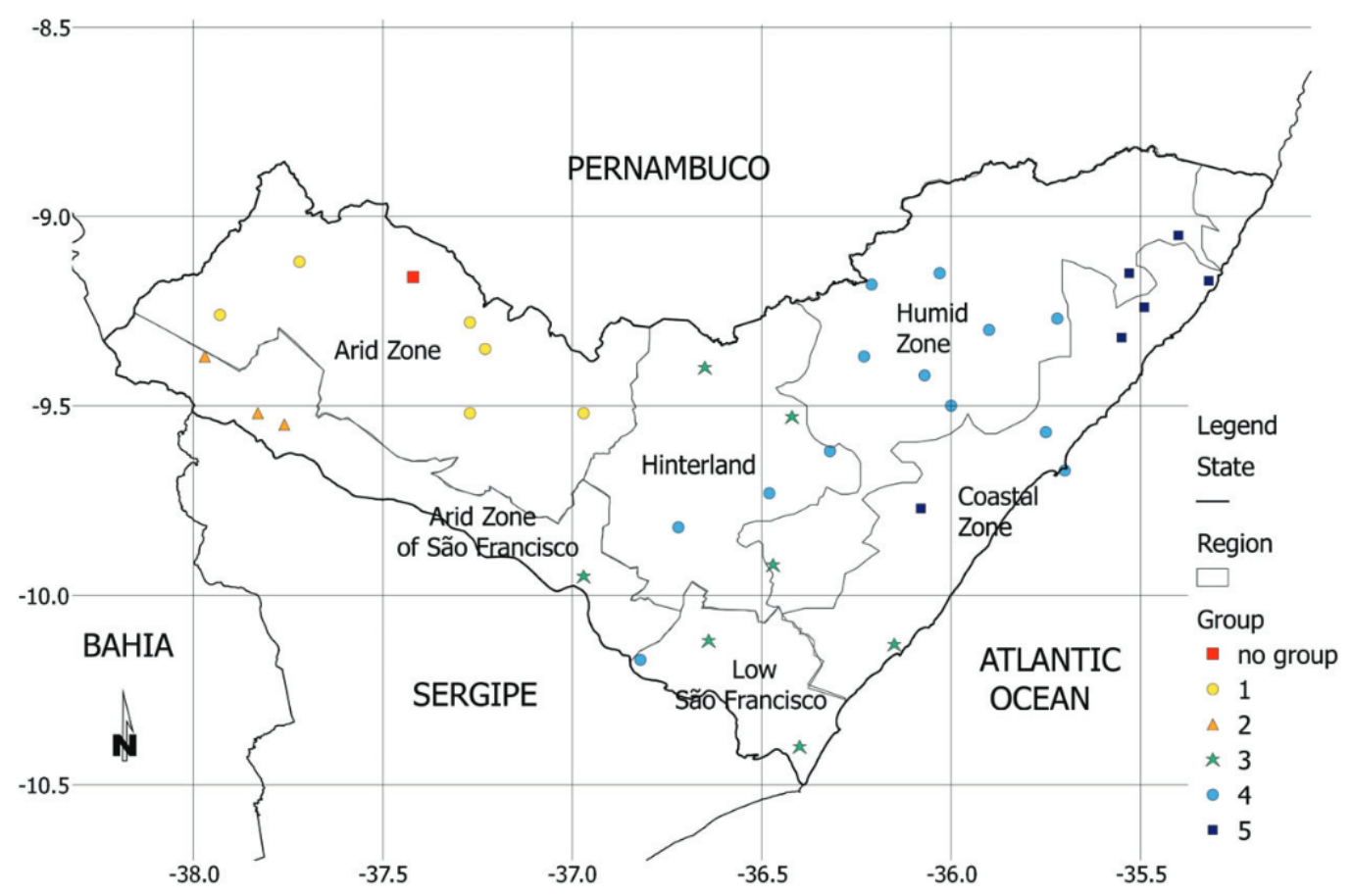

Figure 5: Clustered meteorological stations in the Alagoas state. Source: LYRA et al. (2014).

Another use of cluster analysis is presented by LECKEBUSCH et al. (2008), where kmeans is used in order to cluster weather patterns into different classes, and to study their statistical distribution in different scenarios considering climatic changes simulations.

One application of k-means associated with k-nearest neighbours is presented by CARAWAY et al. (2014) in weather generation, where the sites are at first clustered by their seasonal precipitation in order to smooth and reduce the data, $\mathrm{k}-\mathrm{NN}$ is used in association with different Markov chains approaches in order to generate the weather for a desired simulation time window. 


\subsection{Cluster Analysis applied to Combined Ocean Con- ditions}

Previous work about the clustering of environmental conditions for maneuvering simulations was developed by the author of this thesis and others (MORENO et al., 2018). The cluster was based on the mean forces caused by the waves, currents and wind on the ship. The resulting clusters were evaluated in ship maneuvering simulations commanded by an officer. The officer's analysis demonstrated that the proposed clusters were not representative, with no clear difference of the vessel behavior when subjected to different cluster groups.

Onother work that considers two different environmental agents for the cluster analysis is the one developed by KANNER et al. (2017). In this work the cluster analysis is applied to reduce the number of fatigue simulations for wind turbines. The method developed by the author consists in the normalization of the data, constituted of wind, wave and current parameters, and the development of a modified k-means algorithm that starts with centroids in a rectangular grid. It was observed that reducing the original dataset, containing 20 years of measurements taken every 3 hours, to 200 cases was enough to achieve a good accuracy when compared to simulations carried with the entire dataset.

A follow-up work is presented by KANNER et al. (2018) where a Maximum Dissimilarity Algorithm (MDA) is used for the same application. It was found that the MDA gives better approximations for the simulations, allowing a reduction of $75 \%$ in the number of clusters when compared to the previous work while maintaning the same error. The results for 100 clusters made for waves and winds using both this newer algorithm and the older one are shown in figure 6 . 


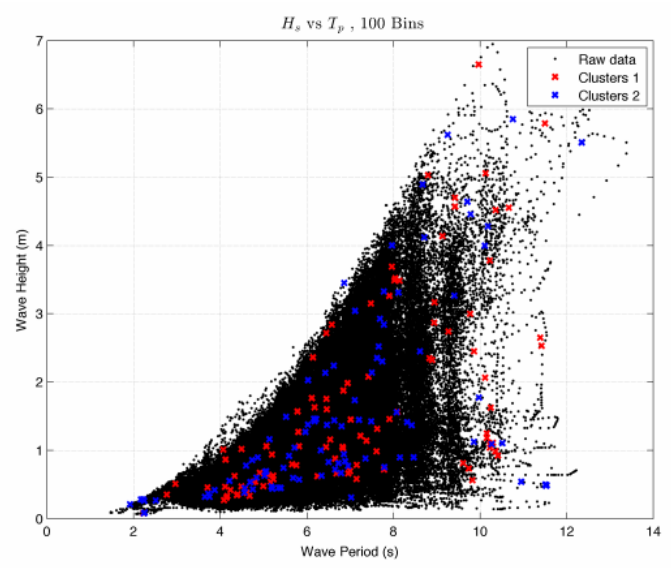

(a) Wave height $H_{s}$ versus wave period $T_{p}$.

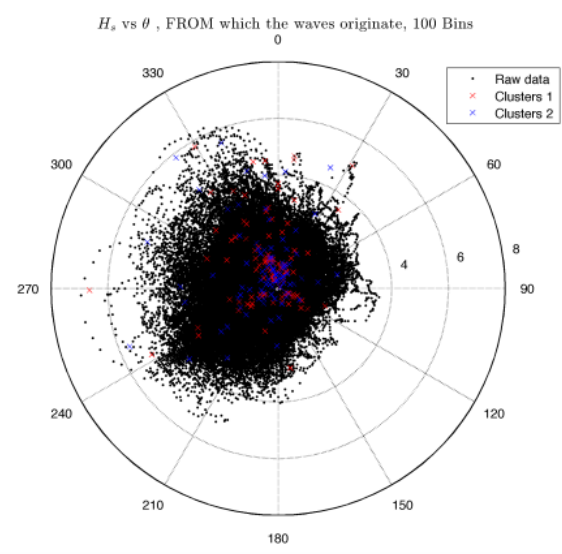

(c) Wave height versus wave direction.

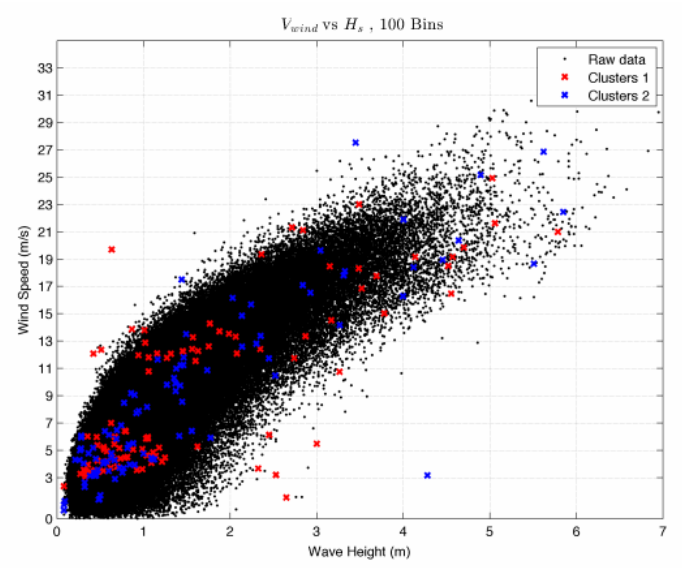

(b) Wind speed versus wave height.

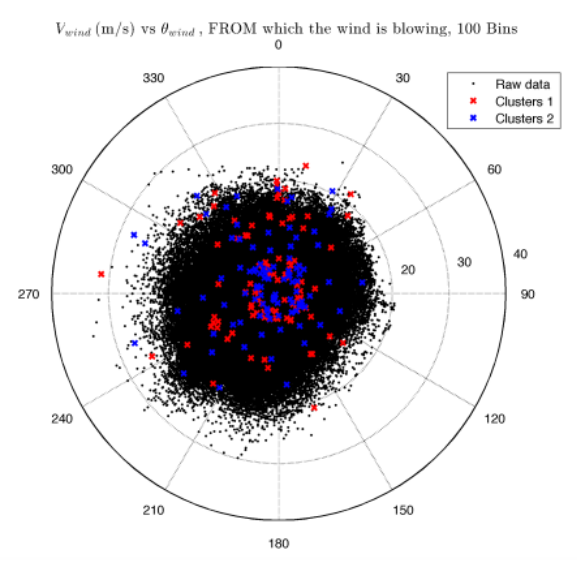

(d) Wind speed versus wind direction.

Figure 6: Clustered winds and waves for the Borssele Wind Farm Zone, Netherlands. Clusters 1, represented by the red symbols were obtained using the previous algorithm given by KANNER et al. (2017), while Clusters 2 was obtained using the newer algorithm. Source: KANNER et al. (2018).

A similar work is developed by GIBSON; CHRISTOU (2019), where a reduced set of water speeds from waves and currents is obtained by different algorithms for riser crossflow fatigue simulations. By using simulations made with the entire environmental dataset as a benchmark it was found that the simulations made using number of groups greater than 150 all the algorithms converged to the benchmark within a $10 \%$ error margin. It was also found that a direct division of the total water speed into segments provided better convergence than the clustering algorithms applied to the multivariate dataset, this can be explained by the fact that the cross-flow fatigue is strongly correlated to the total water speed.

In the work developed by DONG et al. (2016), cluster analysis is used in association with artificial neural networks (ANN) to predict the wind power day-ahead. At first a $\mathrm{k}$-means algorithm is used to separate the weather data into a small number of groups, 
by grouping winds and temperature parameters. To find the number of groups the Elbow Criterion is used. To forecast the wind power, it is verified which cluster is most similar to the prediction day and an ANN is trained in that cluster. It was perceived an increase in accuracy by $11.45 \%$ relative to the persistence model, which is usually used as reference model for prediction.

\subsection{Literature Review Conclusions}

Most of the papers found for this review focus on clustering individual environmental agents, such as currents, waves, wind, rainfall, etc. Some works such as the ones from section 2.4 are closer to the problem presented by this paper, in a sense that they combine distinct environmental agents in their clustering. An overview of papers accordingly to their main objective and clustered environmental agents is given in figure 7 .

\begin{tabular}{|c|c|c|c|c|}
\hline Objective & Waves & Currents & $\begin{array}{l}\text { Wind \& } \\
\text { Meteorological }\end{array}$ & Combinated \\
\hline $\begin{array}{l}\text { Input reduction } \\
\text { for simulations }\end{array}$ & Vogel et al. 2016 & Prevosto et al. 2012, & & $\begin{array}{l}\text { Kanner et al. 2017, } \\
\text { Kanner et al. 2018, } \\
\text { Gibson; Christou 2019, } \\
\text { Moreno et Al. } 2018\end{array}$ \\
\hline Forecasting & & & $\begin{array}{l}\text { Leckebusch et al. } 2008 \text {, } \\
\text { Caraway et al. } 2014\end{array}$ & Dong et al. 2016 \\
\hline Analysis & $\begin{array}{l}\text { Araújo et al. 2003, } \\
\text { Camus et al. 2011, } \\
\text { Euán; Sun, } 2019\end{array}$ & Liu; Weisberg 2005 & $\begin{array}{l}\text { Lyra et al. 2014, } \\
\text { Gong; Richman } 1995\end{array}$ & \\
\hline
\end{tabular}

Figure 7: Literature reviewed papers grouped by their objective and clustered environmental agents. The clustering can be used to reduce inputs for other simulations, to forecast weather and to find relations between the data or evaluate different clustering algorithms (analysis).

When clustering variables of different nature, the problem of magnitude arises, since the value differences between different variables might not be directly comparable, i.e.: a difference of $1 \mathrm{~m} / \mathrm{s}$ in the wind speed can be much less important than a difference of $1 \mathrm{~m} / \mathrm{s}$ in the current speed, despite the numerical value being the same.

Most papers try to circumvent this problem by dividing each variable by its maximum in the dataset, thus normalizing the data between -1 and 1 . The paper made by GIBSON; CHRISTOU (2019), circumvent this problem by converting the waves to cyclic current speeds, which are directly comparable to the ocean current speeds.

Some of the papers employ strategies in order to reduce the number of variables to be 
clustered, such as Principal Component Analysis, where the database is first converted to a base with lower dimensionality. This can be useful, since spaces with high dimensionality need more data points in order to have the same density as spaces with lower dimensionality, what is known as the "Curse of Dimensionality". (BELLMAN ,1961)

The work presented in this Master Thesis has the challenge of clustering a dataset of four qualitatively different environmental agents (wind/currents/sea waves/swell) containing between 7 and 10 variables in total.

It is expected that the strategy of using the effects felt by the vessel as variables for the clustering instead of using the environmental conditions themselves can address to a certain degree those points found during the literature review, since when the environmental variables are transformed into vessel effect variables, they become directly comparable. 


\section{THEORETICAL BACKGROUND}

In the next sections an overview about the theory used for this dissertation is provided. This overview is focused on the themes below, in the order they are used in the methodology:

- Ship Maneuvering Simulations: It explains the simulation environment and the mathematical models used for the simulations.

- Path Controller: It Explains how a Line-of-Sight strategy can be used to keep a vessel under a desired path.

- Dissimilarity Between Time-Series: It explains how the distance between timeseries is obtained by Dynamic Time Warping.

- Unsupervised Machine Learning: It explains the clustering algorithms used to separate the data into groups.

\subsection{Ship Maneuvering Simulations}

The simulations carried at the laboratory are divided in three groups:

- Real-Time simulations: those simulations receive this name because they are run at the same speed as the real maneuvers. They are carried in an environment that emulates a real ship command bridge, as shown in figure 8, with participation of pilots and officers, generally with the aim to evaluate operations. Since these simulations take a longer time than the others types of maneuvering simulations, only a very limited number of these simulations can be made per day.

- Fast-Time simulations: those dynamic simulations are applied to evaluate a larger number of scenarios in a reasonable time. These simulations are used to 

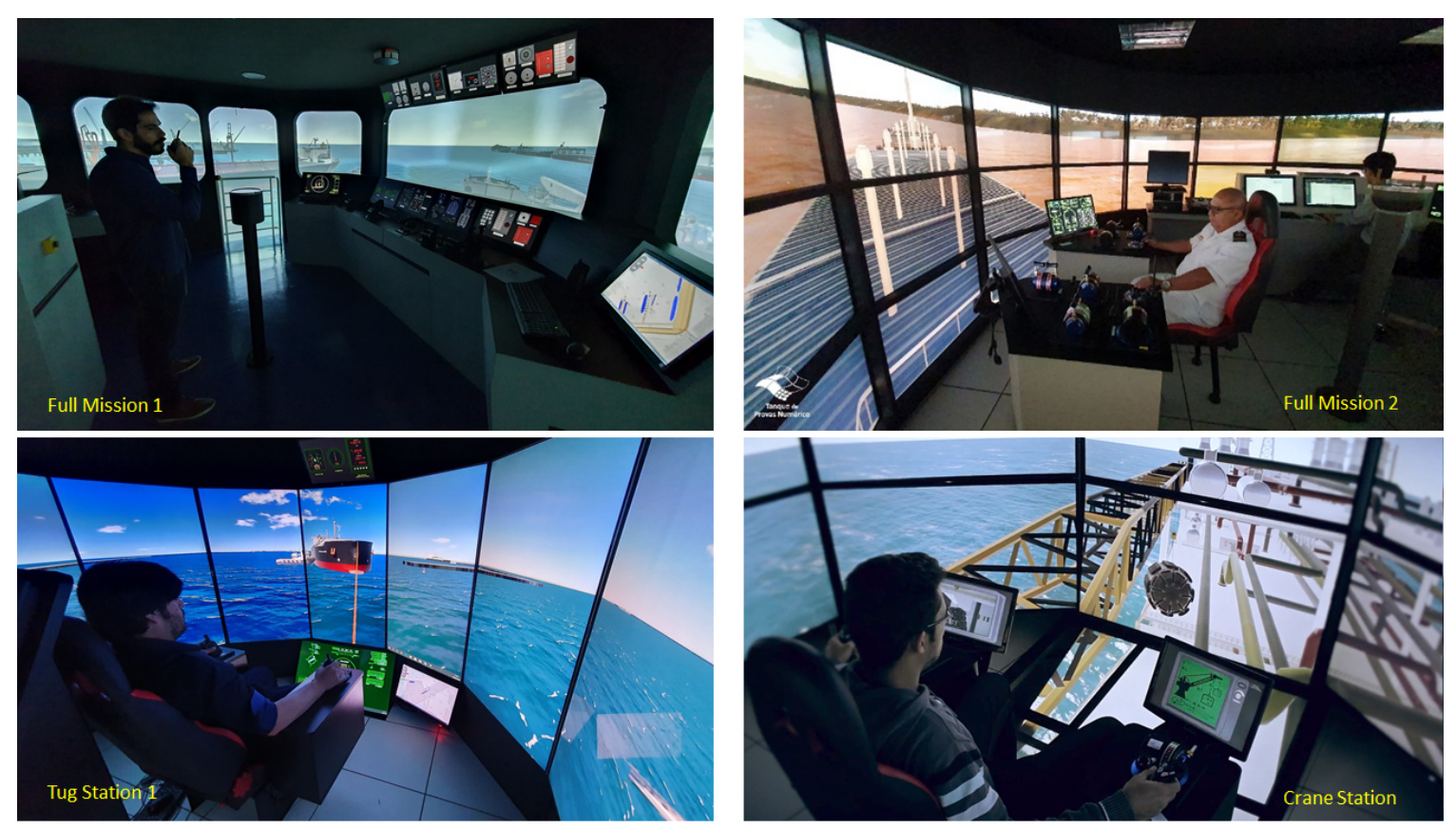

Figure 8: Example of four simulators situated at TPN-USP. All simulators can run the same scenario at the same time, each one controlling one vessel. The Crane simulator (bottom right) can control either a tugboat or a crane. Source: TPN.

evaluate control systems, stability and equilibrium points of operation for coupled systems under a larger number of environmental conditions.

- Time independent simulations: this category encompasses static simulations, usually made with simplified models that considers only constant parcels. These simplified simulations are often used to quickly obtain preliminary results or static equilibrium configuration of the vessels, and thus are refined by fast-time or realtime simulations.

Both the real-time and fast-time simulations runs on a high precision 6 DOF simulator named Dyna. The Dyna simulator calculates and integrates all physical effects, such as wind and current drags, wave forces, fluid coupling. Since this work focus on Fast-Time simulations, a brief explanation of its main aspects is available in the next subsections.

\subsubsection{Mathematical Model}

The mathematical model used represents the 6 DOF vessel subjected to external forces, such as environmental forces, propellers, rudders and tugboats. The 6 DOF vessel dynamics differential equations are solved by using explicit $4^{\text {th }}$ order Runge-Kutta integration method considering the vessel interactions with the fluid and external forces applied to the hull. 
The Earth Fixed Global Reference Frame (GRF) coordinate system is represented by oxyz. The Local Reference Frame (LRF) by $o_{L} x_{L} y_{L} z_{L}$ is attached to the and centered in its midship position, it moves and rotates around $z_{L}$ axis with the body. Figure 9 shows the geometry of the reference frames in the horizontal plane. The vector $\eta=\left[\begin{array}{lll}x & y & \psi\end{array}\right]^{T}$ represents the vessel's midship and its heading in the GRF. In this representation $x$ is the easting, $y$ is the northing and $\psi$ is the heading.

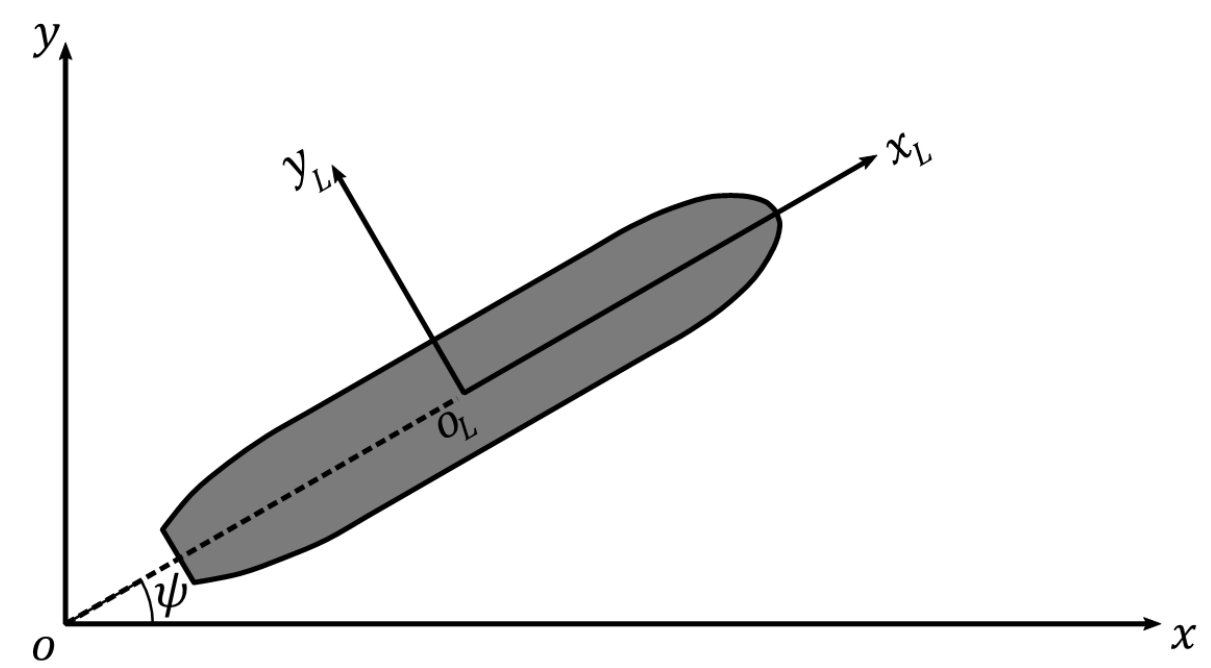

Figure 9: Reference frames for the Dyna simulator. Source: TPN.

The application of floating rigid body dynamics equations defines the low-frequency equation of motion, accounting for hydrodynamic inertial effects and external forces, as shown in equation 3.1.

$$
\begin{aligned}
& {\left[\begin{array}{ccc}
m-X_{\dot{u}} & 0 & 0 \\
0 & m-Y_{\dot{v}} & m x_{G}-Y_{\dot{r}} \\
0 & m X_{G}-Y_{\dot{r}} & I_{z}-N_{\dot{r}}
\end{array}\right]\left[\begin{array}{c}
\dot{u} \\
\dot{v} \\
\dot{r}
\end{array}\right]+} \\
& {\left[\begin{array}{ccc}
0 & -m r & -m x_{G} r+Y_{\dot{v}} v+Y_{\dot{r}} r \\
m r & 0 & -X_{\dot{u}} u \\
m x_{G} r-Y_{\dot{v}} v-Y_{\dot{r}} r & X_{\dot{u}} u & 0
\end{array}\right]\left[\begin{array}{l}
u \\
v \\
r
\end{array}\right]+} \\
& \left(X_{\dot{u}}-Y_{\dot{v}}\right)\left[\begin{array}{ccr}
0 & r & 0 \\
r & 0 & 0 \\
-v & u_{c}-u & 0
\end{array}\right]\left[\begin{array}{c}
u_{c} \\
v_{c} \\
0
\end{array}\right]=F_{\text {rudder }}+F_{\text {prop }}+F_{\text {tugs }}+F_{\text {curr }}+F_{\text {wind }}+F_{\text {wave }}
\end{aligned}
$$

The vectors $\nu=\left[\begin{array}{lll}u & v & r\end{array}\right]^{T}$ and $\dot{\nu}=\left[\begin{array}{ccc}\dot{u} & \dot{v} & \dot{r}\end{array}\right]^{T}$ are the midship velocity and acceler- 
ation in the LRF, respectively. The parameter $m$ is the vessel's mass, $I_{z}$ is its moment of inertia around $z_{L}$, and $x_{G}$ is the location of its center of mass respective to the midship position in the LRF. The hydrodynamic derivatives $X_{\dot{u}}, Y_{\dot{v}}, Y_{\dot{r}}$ and $N_{\dot{r}}$ are the terms of the added mass matrix $M_{A}$ represented in equation3.2.

$$
M_{A}=-\left[\begin{array}{ccc}
X_{\dot{u}} & 0 & 0 \\
0 & \mathrm{Y}_{\dot{v}} & Y_{\dot{r}} \\
0 & \mathrm{Y}_{\dot{r}} & N_{\dot{r}}
\end{array}\right]
$$

This model assumes a slowly varying and irrotational ocean current velocity, that can be decomposed in the LRF as $\nu_{c}=\left[\begin{array}{lll}u_{c} & v_{c} & 0\end{array}\right]^{T} . F_{\text {rudder }}, F_{\text {prop }}$ and $F_{\text {tug }}$ are the vectors of rudder, propeller and tug induced forces, $F_{\text {curr }}, F_{\text {wave }}$ and $F_{\text {wind }}$ are the vectors of environmental forces due to oceanic currents, waves, and the wind.

\subsubsection{External Forces}

\section{Environmental Forces}

This section contains basic models to obtain the forces $F_{\text {curr }}, F_{\text {wave }}$ and $F_{\text {wind }}$ used in equation 3.1.

The forces induced by the wind and currents are proportional to the vessel area exposed to the agent and to the square of their relative speed to the ship hulk. The wind velocity can be divided into a slowly varying parcel and a high frequency parcel denominated wind gusts (TANNURI, 2002). The forces induced by the waves can be described by a sum of parcels with increasing order in relation to the wave height, being generally considered only the first two parcels:

- First order: They are proportional to the incident wave height. These forces are induced by the individual effect of each wave that encounters the ship's hulk. They excite the vessel at the same frequency of the wave and have a zero mean force. The first order effect is the largest in absolute value

- Second order: These effects are proportional to the height of the wave squared. They are induced by the interaction of waves and cause forces with frequencies that are the sum and difference of the incident waves. They are responsible for the effects of slow drift. 
The external forces acting the ship can be divided into two parcels, a constant one, and a varying one. In the case of wind and currents the constant parcel is defined as the drag and the varying parcel can be due to fluctuations in the speed of the fluid. In the case of waves, the varying part is due to the effects of first, second and higher order wave effects and the constant part is the average of the second-order forces, that have a non zero mean.

The forces of current drag can be calculated by dimensionless coefficients as shown in equations 3.3. In this equation $X_{c}, Y_{c}$ and $N_{c}$ are respectively the surge force, sway force and yaw moment felt by the vessel, and $L$ is the vessel overall length, $T$ is the vessel draft, $V_{c}$ is the relative speed of the current respective to the vessel's hull, $\rho$ is the water density. $C_{C x}(\beta), C_{C y}(\beta), C_{C z z}(\beta)$ are dimensionless coefficients obtained from experiments, these coefficients are dependent on the vessel's hull geometry and the relative current angle of incidence $\beta$.

$$
\left\{\begin{array}{l}
X_{c}=\frac{1}{2} \rho C_{C x}(\beta) L T V_{c}^{2} \\
Y_{c}=\frac{1}{2} \rho C_{C y}(\beta) L T V_{c}^{2} \\
N_{c}=\frac{1}{2} \rho C_{C z z}(\beta) L^{2} T V_{c}^{2}
\end{array}\right.
$$

A similar formulation is adopted for calculating the wind forces in 3.4, where $X_{w}$ is the surge force induced by the wind, $Y_{w}$ is the sway force and $N_{w}$ is the yaw moment. $A_{L}$ is the projected lateral area of the vessel exposed to the wind, $A_{F}$ is the projected frontal area of the vessel exposed to the wind, $V_{w}$ is the relative speed of wind in relation to the vessel, $\rho_{a}$ is the air density, $L$ is the vessel length and $C_{W x}(\beta), C_{W y}(\beta)$ and $C_{W z z}(\beta)$ are dimensionless coefficients dependant on the incidence angle of the wind.

$$
\left\{\begin{array}{l}
X_{w}=\frac{1}{2} \rho_{a} C_{W x}(\beta) A_{F} V_{w}^{2} \\
Y_{w}=\frac{1}{2} \rho_{a} C_{W y}(\beta) A_{L} V_{w}^{2} \\
N_{w}=\frac{1}{2} \rho_{a} C_{W z z}(\beta) A_{L} L V_{w}^{2}
\end{array}\right.
$$

The wave slow drift forces can be calculated by the formulas in 3.5, where $X_{w v}$ is the surge force, $Y_{w v}$ is the sway force, $N_{w v}$ is the yaw moment, $S(\omega)$ is the wave spectrum at frequency $\omega$ and $D_{x}(\omega, \beta), D_{y}(\omega, \beta), D_{z z}(\omega, \beta)$ are coefficients dependent on the wave incidence angle, $\beta$, and the wave frequency $\omega$. These coefficients are obtained from the WAMIT software. 


$$
\left\{\begin{array}{l}
X_{w v}=2 \int_{0}^{\infty} S(\omega) D_{x}(\omega, \beta) d \omega \\
Y_{w v}=2 \int_{0}^{\infty} S(\omega) D_{y}(\omega, \beta) d \omega \\
N_{w v}=2 \int_{0}^{\infty} S(\omega) D_{z z}(\omega, \beta) d \omega
\end{array}\right.
$$

\section{Actuator forces}

This section contains basic models used to obtain the forces $F_{\text {rudder }}$ and $F_{\text {prop }}$ used in equation 3.1.

The model used for rudder forces, as shown in image 10, is based on the equation 3.6 (MOLLAND; TURNOCK, 2007), where $F_{L}(r)$ is the rudder lift force, $F_{D}(r)$ is the rudder drag force, $\rho$ is the water density, $A_{r}$ is the submerged rudder area, $V_{r}$ is the relative water speed respective to the rudder, $C_{L}(r)$ and $C_{D}(r)$ are a dimensionless coefficients that vary with the rudder angle relative to the free flow fluid direction $(r)$.

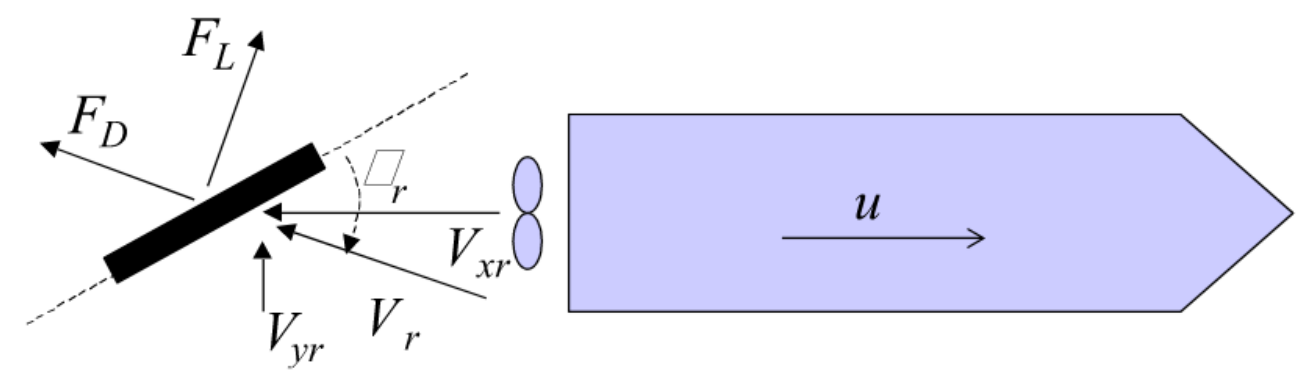

Figure 10: Rudder forces. Source: TANNURI et al. (2014).

$$
\left\{\begin{array}{l}
F_{L}(r)=0.5 \rho A_{r} C_{L}(r) V_{r}^{2} \\
F_{D}(r)=0.5 \rho A_{r} C_{D}(r) V_{r}^{2}
\end{array}\right.
$$

The flow downstream the propeller, $V_{x r}$ is obtained from an argument of conservation of moment, adapted from MOLLAND; TURNOCK (2007) and shown in equation 3.7, where $V_{i}$ is the longitudinal inlet water speed in the propeller, $D_{p}$ is the propeller diameter, $X$ is the longitudinal distance between the propeller and the rudder axis and $T_{\text {prop }}$ is the propeller trust. (TANNURI et al. , 2014)

$$
V_{x r}=V_{i}+\left(0.5+\frac{0.5}{1+0.15 X / D_{p}}\right)\left(\sqrt{V_{i}^{2}+\frac{8 T_{\text {prop }}}{\rho \pi D_{p}^{2}}}-\operatorname{sign}\left(V_{i}\right) V_{i}\right)
$$

The model used for the propeller trust is presented in equation 3.8, where $n$ is the 
thruster rotations per second, $p=$ pitch $/ D_{p}, J=v / n D_{p}$ is the advance ratio, $v$ is the water velocity incident in the thruster, and $k_{t}(J, p)$ is a thrust coefficient (FILHO et al., 2014).

$$
T_{\text {prop }}=\rho|n| n D_{p}^{4} k_{t}(J, p)
$$

\subsubsection{Path Controller}

Most simulated vessels have only a rudder and a propeller available to control its position. Since these two actuators can't fully control the vessel's three degrees of freedom in the horizontal plane a path-following strategy is employed. This strategy is used in order to control the cross-track error.

One of the strategies available for straight line navigation is the Line-of-Sight. In this strategy, the desired trajectory is defined by sequential waypoints $\left(\left[w_{1}, w_{2}, \ldots, w_{n}\right]\right)$ and line segments connecting these waypoints. The vessel while navigating from one waypoint to the next one will do so by staying close to the line segment that connects both waypoints. Once the vessel gets close enough to a target waypoint $w_{i}$, the next waypoint $w_{i+1}$ will become the target.

One example of Line-of-Sight is shown in figure 11 for two waypoints. In order to keep the vessel navigating in the line a desired Course Over Ground (COG), $\psi_{\text {cog }}$ is defined in a way that the vessel's trajectory converges to the desired path, minimizing the cross-track error $e_{L}$. One possibility is to define $\psi_{c o g}$ as in equation 3.9 , where both proportional, $K_{v}$, and integral gains, $K_{i}$ are used.

$$
\psi_{\text {cog }}=\psi_{c}+\arctan \left(K_{v} e_{L}+K_{i} \int e_{L} d t\right)
$$

Since the vessel's COG is different from its heading $\psi_{p}$, the equation 3.10, extracted from FOSSEN (2002) is used to obtain a desired heading $\psi_{d}$ that compensates the vessel's drift.

$$
\psi_{d}=\psi_{\operatorname{cog}}-\arctan \left(\frac{v}{u}\right)
$$




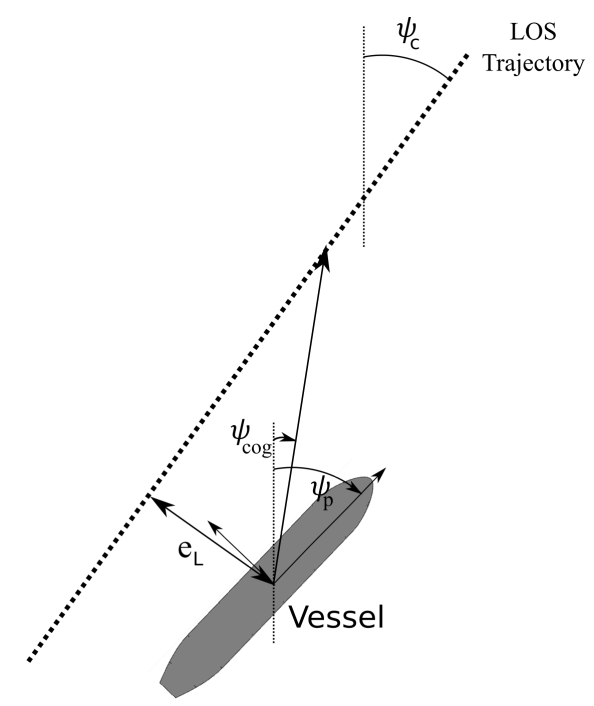

Figure 11: Line of sight basic diagram.

\subsection{Unsupervised Machine Learning}

Machine learning is a field of Artificial Intelligence that focus on the learning of patterns present in data. It can be divided into three broad categories: supervised learning, unsupervised learning and reinforcement learning. This work only uses unsupervised machine learning.

The unsupervised learning algorithms have as input a set of unlabeled data and as output they should provide relevant patterns of the structure the data. Under the unsupervised learning techniques there is a group referred as Cluster Analysis or Clustering, which as the name suggests tries to group the unlabeled data into groups based on their similarities. An example of clustering can be seen in figure 12 .

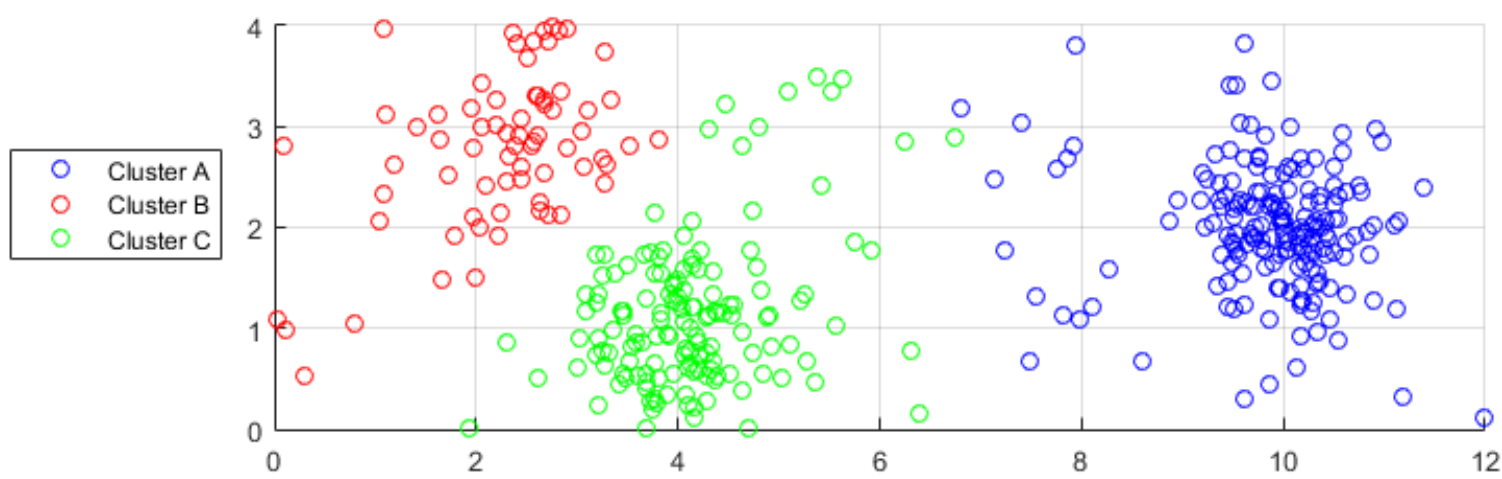

Figure 12: Example of a cluster analysis applied to a group of three two-dimensional Gaussian distributions.

To allow the grouping, it is needed to define both the variables of interest and a measure of distance between elements of the data. Ideally the measure distance defined 
should allow the data to be clearly separated into groups, where all distances between elements of the same group are much smaller than the distance between elements of different groups.

In some cases it is impossible to find clearly separated groups in the data like the ones shown in figure 12, and the data appears to have only one big cluster of points close together. In this case, some methods of clustering can be used to divide this large cluster in a few subclusters with similar number of elements.

The family of Cluster Analysis algorithms can be further divided into four subgroups:

- Hierarchical methods: Those methods are based on the proximity between neighboring elements of the data. The points are first united with their closest neighbors in small groups, and those groups are further united into bigger groups in a recursive way. It is also possible to start with only one group containing all elements and partition it into smaller groups recursively. After the clustering, it is generated a dendrogram of the process and accordingly to the project requisites it is extracted the desired groups. An example of dendrogram is shown in figure 13.

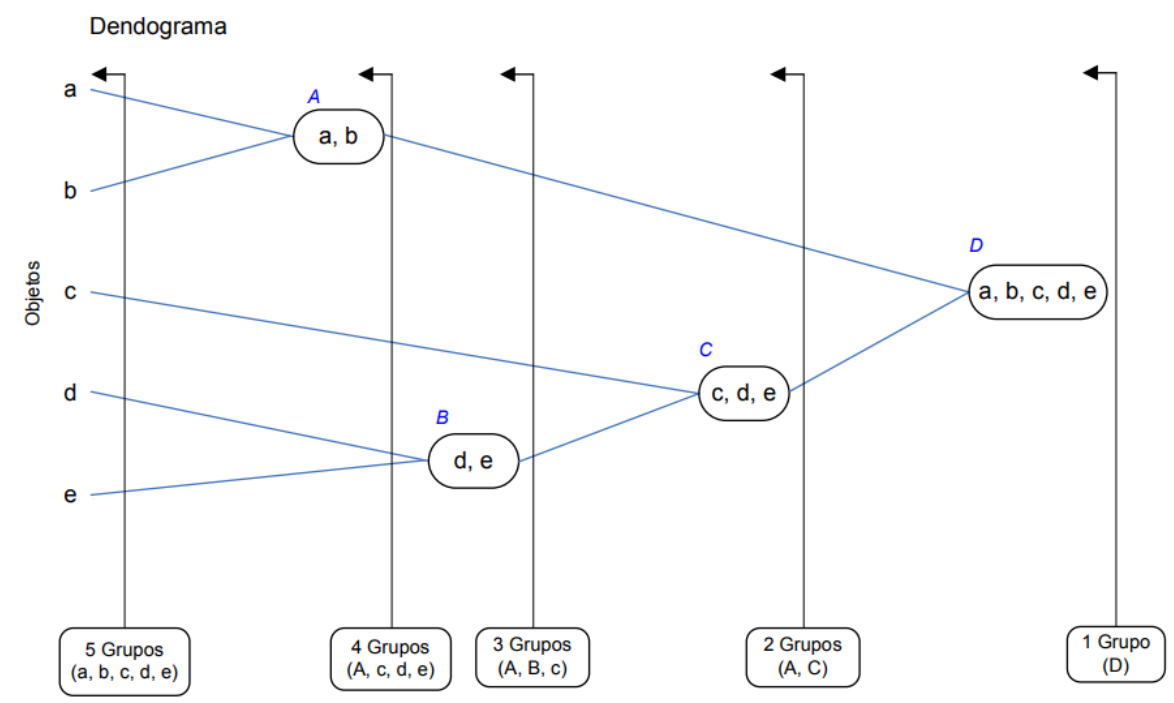

Figure 13: Dendogram for the hierarchical clustering of five objects. Source: VALE (2005).

- Centroid based methods: Those methods are based on the supposition that every group in the data has a centroid. Those centroids are chosen by iterative algorithms where the objective is to minimize some function that evaluates the distance between group members and their centroid. The most famous algorithm of this kind is the k-means, where the minimized function is the residual squared sum (RSS) of distances, as show in equation 3.11 for an Euclidean metric. $x_{j}$ denotes 
the $\mathrm{j}$-th data element and $u_{x}$ is the respective centroid of the group $x_{j}$. The total number of groups in the data must be defined a priori.

$$
R S S=\sum_{j=1}^{n}\left\|\vec{x}_{j}-\vec{\mu}\left(x_{j}\right)\right\|^{2}
$$

One possible algorithm to minimize the sum of squared distances is given below:

1. Assign the centroids to random or pseudo-random positions

2. Assign each one of the data elements to the group of their closest centroid

3. Calculate the mean positions of all the elements in each group

4. Move each one of the centroids to the mean positions found in step three for their groups

5. Repeat steps 2-4 until there is no change in the groups or a maximum number of iterations is reached

The method exposed above finds a local minimum of the RSS function. There are faster algorithms that are used to minimize 3.11, but all the algorithms still have the problem of convergence to local minima. To avoid converging to a shallow minimum, the process is repeated with different centroid starting points and only the best run is kept.

- Distribution based methods: Those methods are based on the supposition that the data is composed of a mixture of probability distribution, and for every element of the data there is assigned a probability of it being part of any of the groups existing in the data. The generally chosen distribution is the Gaussian, where there is an algorithm similar to the k-means. In this case it should be found the center of distribution, $\mu_{j}$, and a matrix of covariances $\Sigma_{j}$ for every group in the data. The parameters of the $\mathrm{j}$-th group is denoted as $\vartheta_{j}$ and the set of all parameters of all groups is denoted by $\Theta$.

The function that must be maximized in this case is the Likelihood function, that measures the probability that all the elements of the data $\chi$ were generated by a distribution mixture with parameters $\Theta$ :

$$
p(\chi \mid \Theta)=\prod_{k=1}^{n} p\left(x_{k} \mid \Theta\right)=\prod_{k=1}^{n}\left(\sum_{j=1}^{q} \alpha_{j} p\left(x_{k} \mid \vartheta_{j}\right)\right)
$$


Where $n$ is the number of elements in the data, $q$ is the number of groups in the data and $\alpha_{j}$ is the weight given to each one of the distributions, conforming to $\sum_{j=1}^{q} \alpha_{j}=1$.

- Density based methods: On those methods, the groups are defined as the regions with higher density of elements and elements in regions of low density are classified as noise. One of those methods is the DBSCAN (Density Based Spatial Clustering of Applications with Noise (ESTER et al., 1996)) This algorithm is based in the principle that to exist a group, there should exist a minimum number of $\operatorname{points}\left(N_{\epsilon}\right)$ inside a determined radius $(\epsilon)$ centered in every element that isn't on the border of the group. $N_{\epsilon}$ and $\epsilon$ are chosen a priori.

\subsection{Dissimilarity of Time-Series}

This section explains the Dynamic Time Warping algorithm (DTW), used to obtain a dissimilarity value between pairs of time-series, even when the series don't have the same length.

The DTW has the advantage of dynamically compensating for distortions in the time-scale, by creating a warping path, as shown in figure 14. This warping path can be constrained by a window in order to avoid situations where a large portion of points of one curve are associated to just a few points to the other. 


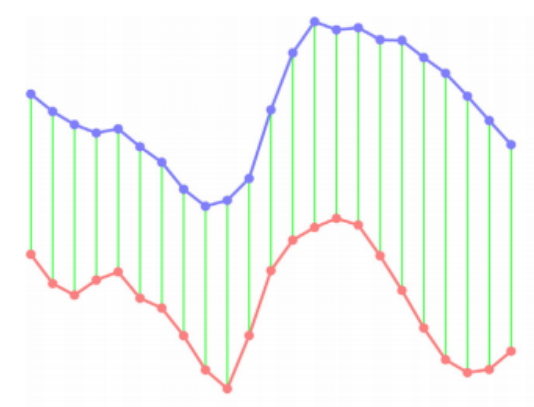

(a) Euclidean

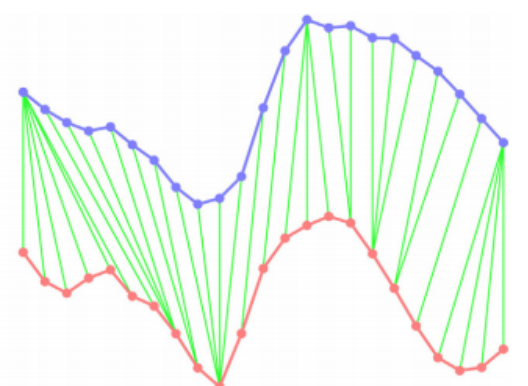

(b) DTW

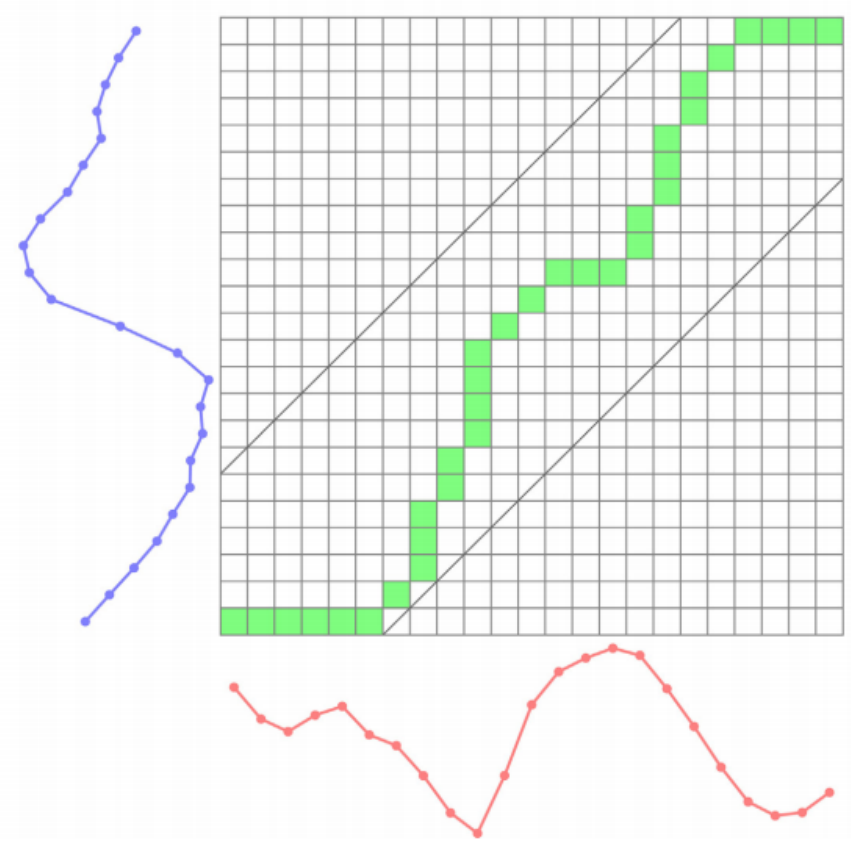

(c) warping path

Figure 14: Comparison between Euclidian distance (a) and Dynamic Time Warping (b). The map shown in (c) is the warping path that correlates the points of both curves in (b), the two diagonal lines are constraints to the warping path. Source: ZHANG et al. (2015).

One possible window is the Paliwal window exemplified in figure 15 and is defined by equation 3.13, where $i$ is the $i^{\text {th }}$ element of the first time-series of length $I$ and $j$ is the $j^{\text {th }}$ element of the second time series of length $J . r$ is the window width. (PALIWAL et al., 1982) 


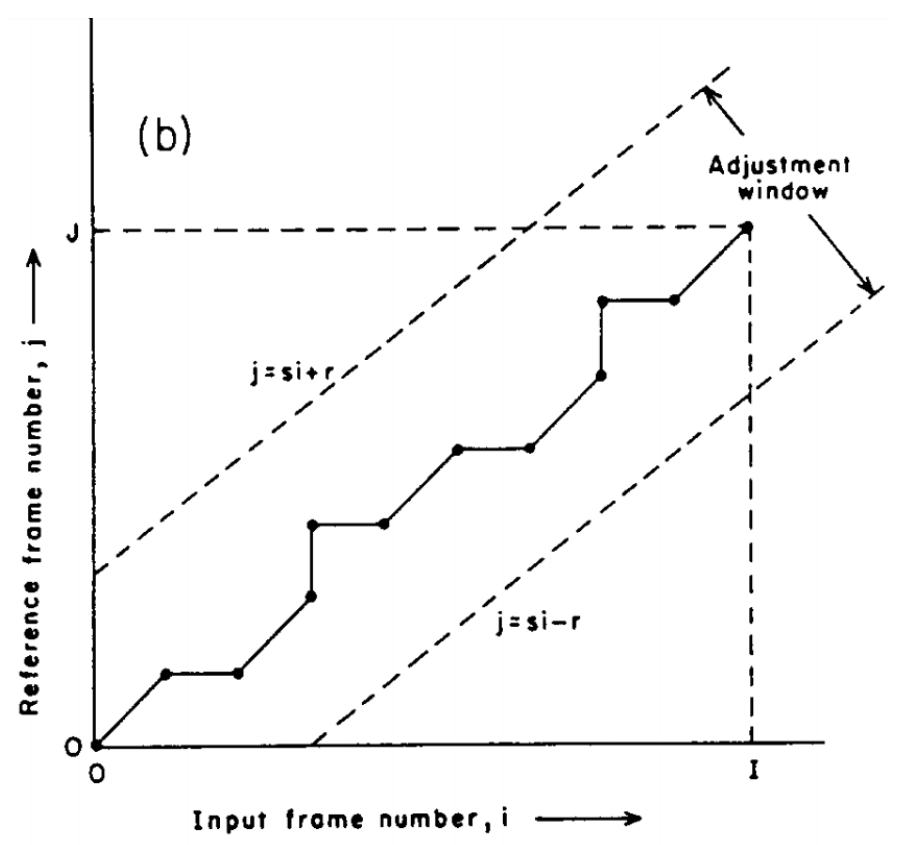

Figure 15: Dynamic Time Warping Paliwal window defined. Source: PALIWAL et al. (1982).

$$
\left(i-j \frac{I}{J}\right) \leq r
$$




\section{METHODOLOGY FOR OBTAINING A REDUCED SET OF ENVIRONMENTAL CONDITIONS}

In this chapter the methodology developed to obtain the reduced sets of environmental data is divided into four linear steps and explained. For the application of this methodology, see chapter 5, where it is applied for the Tubarão and Suape ports and the Campos basin localized in the states of Espírito Santo, Pernambuco and Rio de Janeiro respectively.

\subsection{Method Overview}

For this methodology the variable selected for the cluster analysis is the time-series of the vessel drifting. The figure 16 indicates the steps used in the current methodology to reduce the environmental conditions, each step will be explained in the subsections below.

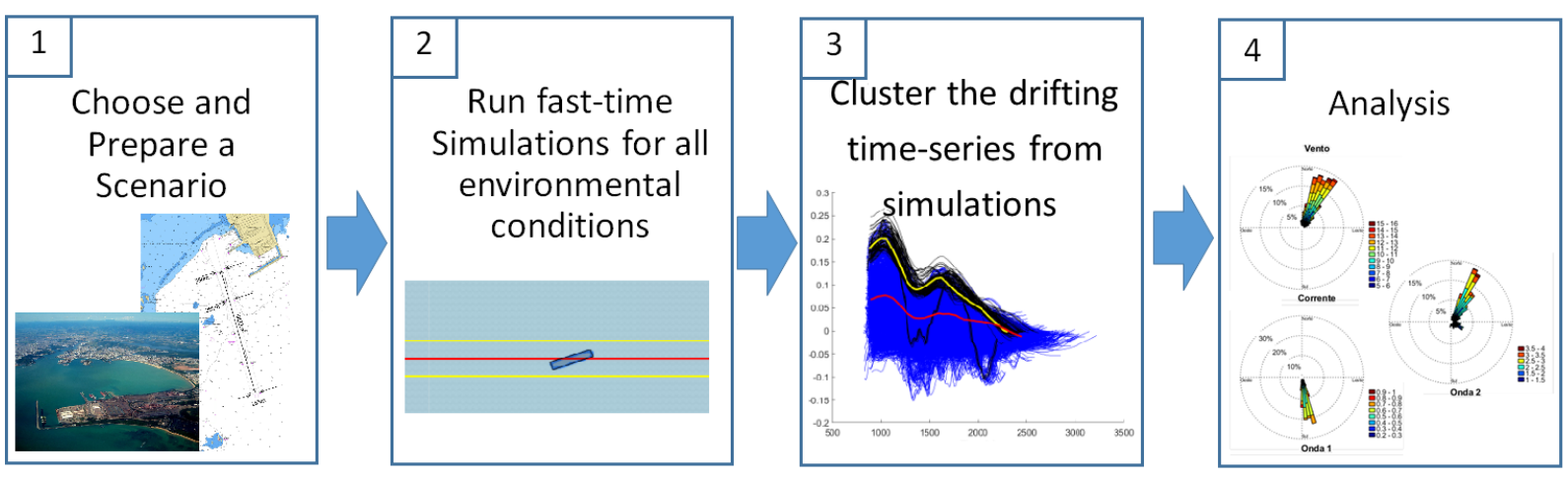

Figure 16: Methodology overview.

\subsubsection{Preparing the scenario}

In order to use this methodology, we first need to characterize the maneuver and the region of interest. To characterize the maneuver it is defined a desired path for the vessel 
by the user, as well as the vessel type and ballast level. To characterize the region of interest a historical series of wind, waves and currents is needed, as well as directional maps that show how the current and waves behave in the region of interest.

\subsubsection{Fast-Time Simulations}

Once the maneuvering scenario is ready, an automatic pilot drives the vessel, from the starting point to the destination point. One simulation is carried for each environmental condition available, and time-series of the vessel's heading, drift, position, velocities, and rudder commands are recorded.

The auto-pilot consists of a Proportional Integral Derivative (PID) controller associated with a line-of-sight for course navigation and a simple controller for speed control. The PID controller actuates the rudder in order to track a heading set-point. The heading is obtained through the line-of-sight algorithm. An overview of the auto-pilot control is shown in figure 17.

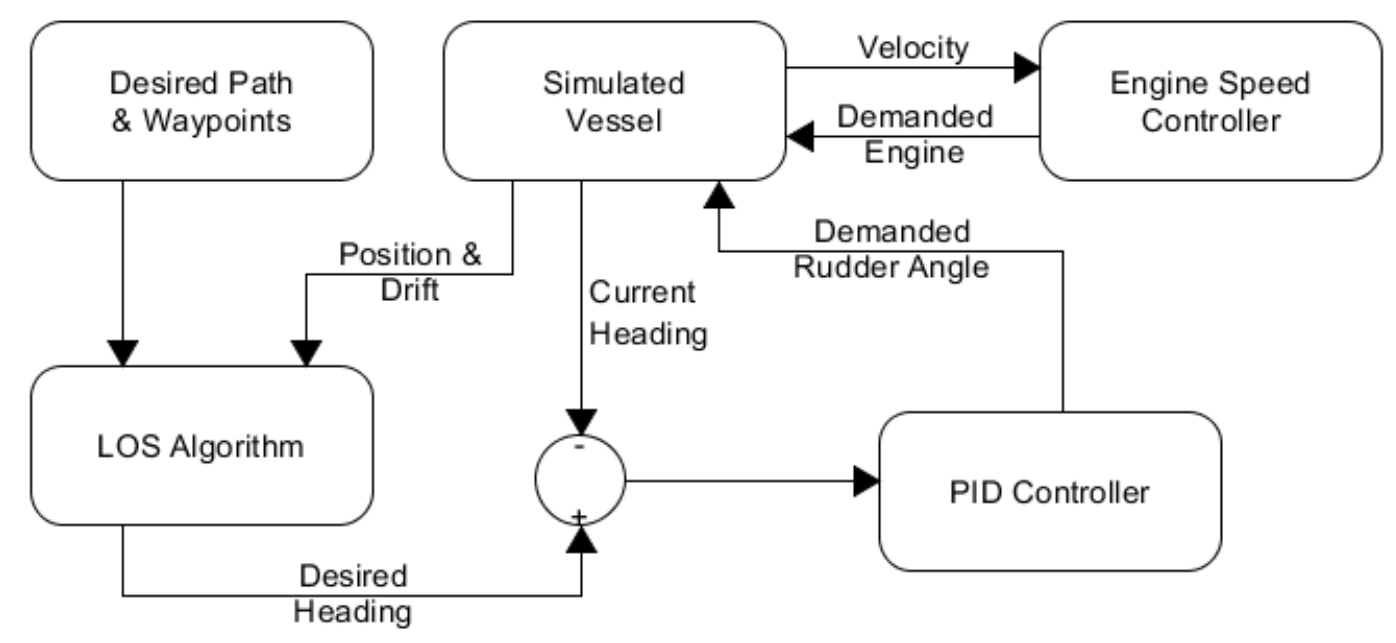

Figure 17: Autopilot overview.

The rudder control design is based on a simplified model of vessel's heading dynamics, equation 4.1, where linear damping and couplings are not considered. In that equation $r$ is the rate of turn, $I_{z}$ is the vessel's moment of inertia along the local $z$ axis, $-N_{\dot{r}}$ is the respective added mass, $F_{\text {rudder }}$ is the rudder forces generated and $F_{\text {curr }}, F_{\text {wind }}$ and $F_{\text {waves }}$ are the vector of forces originated from currents, winds and waves respectively.

$$
\left(I_{z}-N_{\dot{r}}\right) \dot{r}=\left[\begin{array}{lll}
0 & 0 & 1
\end{array}\right]\left(\mathbf{F}_{\text {rudder }}+\mathbf{F}_{\text {curr }}+\mathbf{F}_{\text {wind }}+\mathbf{F}_{\text {waves }}\right)
$$


Table 1: Parameters used for tuning the PID in equation 4.2.

\begin{tabular}{|c|l|l|}
\hline Parameter & Value & Unit \\
\hline$\omega_{n}$ & 0.01 & $\mathrm{rad} / \mathrm{s}$ \\
\hline$\zeta$ & 0.7 & - \\
\hline$\alpha$ & 10 & - \\
\hline
\end{tabular}

The heading control diagram is shown in figure 18. A simple PID with closed-loop feedback is used. The PID was tuned accordingly to the equations obtained from 4.2, extracted from MAZZILLI; TANNURI (2010). These gains are obtained from solving the system in a way where the closed-loop system contains a pair of dominant conjugate poles with natural frequency $\omega_{n}$ and $\zeta$ damping, and a non-dominant real pole located at $-\alpha$. The values used for this work are shown in table 1 .

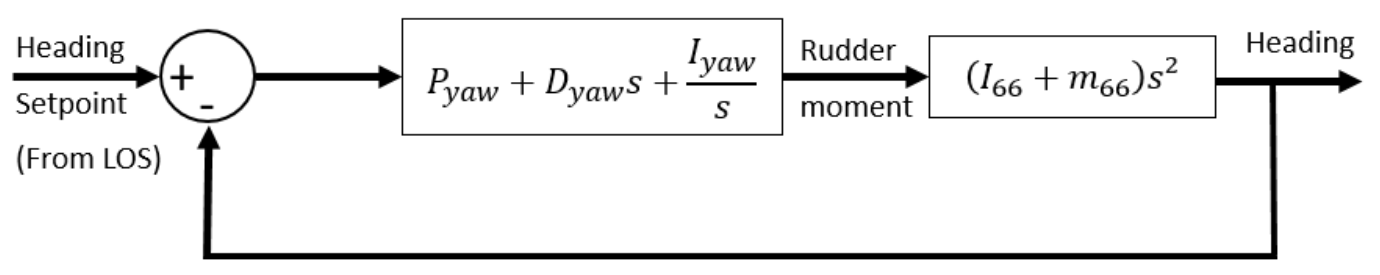

Figure 18: Heading control system.

$$
\left\{\begin{array}{l}
P_{\text {yaw }}=\left(I_{z}-N_{\dot{r}}\right) \cdot\left(1+2 \alpha \zeta^{2}\right) \omega_{n}^{2} \\
I_{\text {yaw }}=\left(I_{z}-N_{\dot{r}}\right) \cdot(2+\alpha) \zeta \omega_{n} \\
D_{\text {yaw }}=\left(I_{z}-N_{\dot{r}}\right) \cdot \alpha \zeta \omega_{n}^{2}
\end{array}\right.
$$

The PID also has an anti-windup strategy. The integral error absolute value stops to increase when the rudder is at its maximum angle, and it can only decrease while the rudder is saturated. Despite the use of the anti-windup, the preliminary tests indicated that the integral component reduces the system stability in a detrimental way. Since for our work a small amount of steady-state error is allowed as long as the vessel does not cross the channel margins, the integral gain was disabled for the simulations.

It is also worth noting that the controller should not compensate the first-order wave perturbations due to their large oscillatory intensity with a zero mean. In real situations, a filter (such as a notch filter) is included in the control loop to discard the first-order perturbations from the measured signal. In the Fast-Time simulations, for a matter of simplification, the first-order wave perturbations were artificially disabled whilst maintaining the second-order perturbations. 
In order to convert the turning moment demanded by the controller to an actual rudder angle $\delta$, the equation 4.3 is used, where $\hat{N}_{r}$ is a constant. This constant is dependent on the vessel and rudder characteristics, its longitudinal (advance) ( $u$ ) and lateral $(v)$ velocities and the propeller rotation $\left(\omega_{p}\right)$. The constant $\hat{N}_{r}$ is obtained through simulations, with the engine set to Dead Slow Ahead, no lateral speed and constant advance speed.

$$
F_{\text {rudder }}=\hat{N}_{r}\left(u, v, \omega_{p}\right) \delta
$$

Since most of the simulated vessels are underactuated, having only a rudder and a propeller available for controlling them along the trajectory, the line-of-sight objective is to keep the transverse error to a minimum by defining a desired heading that minimizes this error.

The line-of-sight scheme used for this is the same presented in chapter 3.1.3. The gains $K_{v}$ and $K_{i}$ are empirical values that determine how fast the vessel trajectory will converge to the desired path. For this work it is used $K_{v}=5.7 \times 10^{-4}$ and $K_{i}=10^{-12}$.

\subsubsection{Cluster Analysis}

The first step to cluster the data is to obtain a distance or dissimilarity matrix. In this case, the data consist of time-series obtained from the Fast-Time Simulations. There are a few methods to measure the distance between time-series, but the most commonly used is the Dynamic Time Warping (DTW) with constrains.

The DTW algorithm used in this work is a version present in the cdtw library for python. This version implements a diversity of distances and constraint windows. For this work, we used the Euclidean distance and a Paliwal window.

Since the main interest is to group the environmental conditions accordingly to their effect in the vessel, the vessel's drift angle was selected as the time-series to be grouped. In addition, other time-series could be selected, such as the demanded rudder (in order to also consider for the clustering the control response to the environmental conditions). A weighted average of the dissimilarities of each time-series must be used for the clustering algorithm if more than one time-series is adopted.

Despite the fast-time simulation integration time-step being between 0.1 and 0.5 second, the sample time of the time-series used in the DTW is 10 seconds in order to reduce computation time. The downsampling is important since the algorithm runs at $O\left(n^{2}\right)$ 
time cost, $n$ being the number of points in the time-series. Also, only the upper diagonal triangle of the dissimilarity matrix is calculated due to the matrix symmetry.

In order to cluster the $n$ data points, the Partitioning Around Medoids (PAM, also known as k-medoids) algorithm is used. This algorithm requires as input a defined number of clusters $k$ and it minimizes a cost function $f(m, o), m$ being the cluster medoids and $o$ the data points. The algorithm can be defined as the following:

- 1) Randomly assign $k$ points of the data as medoids.

- 2) Assign each data point to the closest medoid.

- 3) While the cost function decreases:

- a) For each cluster separately find the point that minimizes the cost function respective to its cluster.

- b) If the swap between the currents medoids and the points obtained in the previous step reduces the global cost function, swap them, otherwise stop.

The traditional cost function used for PAM is the sum of dissimilarities between each data point $o_{i}$ and its respective medoid $m_{i}$, as shown in equation 4.4:

$$
f_{1}(m, o)=\sum_{i=1}^{n} \text { dissimilarity }\left(o_{i}, m_{i}\right)
$$

Since the cost function 4.4 tends to make groups with similar number of elements, we have defined two other cost functions:

1. The sum of mean dissimilarities between the points and their respective medoids, where $k$ is the number of groups in the clustering and $n_{i}$ is the total number of elements in the $i^{\text {th }}$ group:

$$
f_{2}(m, o)=\sum_{i=1}^{k} \sum_{j=1}^{n_{i}} \frac{\text { dissimilarity }\left(o_{j}, m_{j}\right)}{n_{i}}
$$

2. The maximum of mean dissimilarities between the points and their respective medoids:

$$
f_{2}(m, o)=\max \left(\sum_{i=1}^{n_{1}} \frac{\operatorname{dissimilarity}\left(o_{i}, m_{i}\right)}{n_{1}}, \ldots, \sum_{i=1}^{n_{k}} \frac{\operatorname{dissimilarity}\left(o_{i}, m_{i}\right)}{n_{k}}\right)
$$


Since the number of groups $k$ is an essential input for the PAM algorithm, but the best number of groups in the data is unknown, we first run the algorithm using a selected range of values for $k$. Each value of $k$ is run 3 times with random initialization, and in order to limit the processing time, a limit of 10 iterations is defined. For each $k$ it is selected the run that minimizes the cost function, and the other two are discarded. After this process, the best number of groups is selected by the Silhouette method.

The Silhouette method is an objective measurement of cluster quality. The Silhouette coefficient can be defined as 4.7, where $S(k)$ is the Silhouette value, $g\left(k, o_{i}\right)$ is the average distance between the element $o_{i}$ and the elements of the closest neighbouring cluster, and $l\left(k, o_{i}\right)$ is the average distance between $o_{i}$ and members of the same cluster, as shown in figure 19.

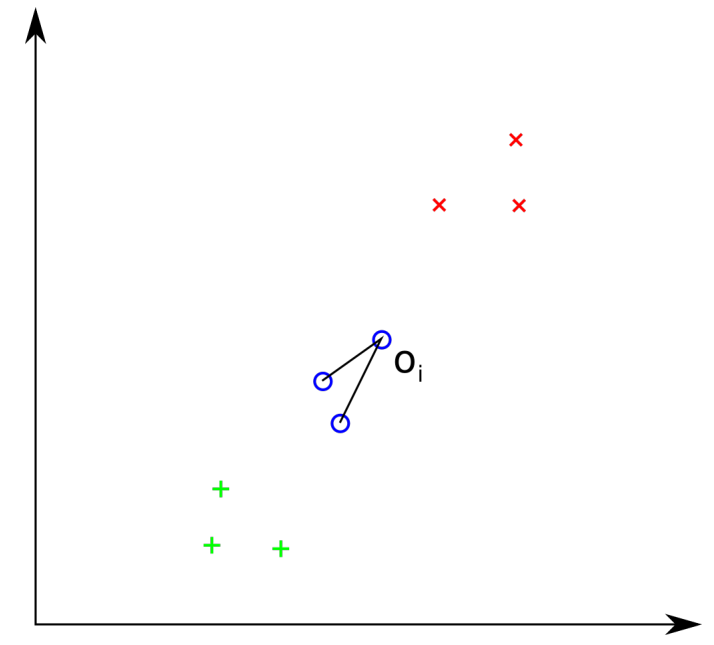

(a) $l\left(k, o_{i}\right)$ is the average distance between $o_{i}$ and elements of the same group.

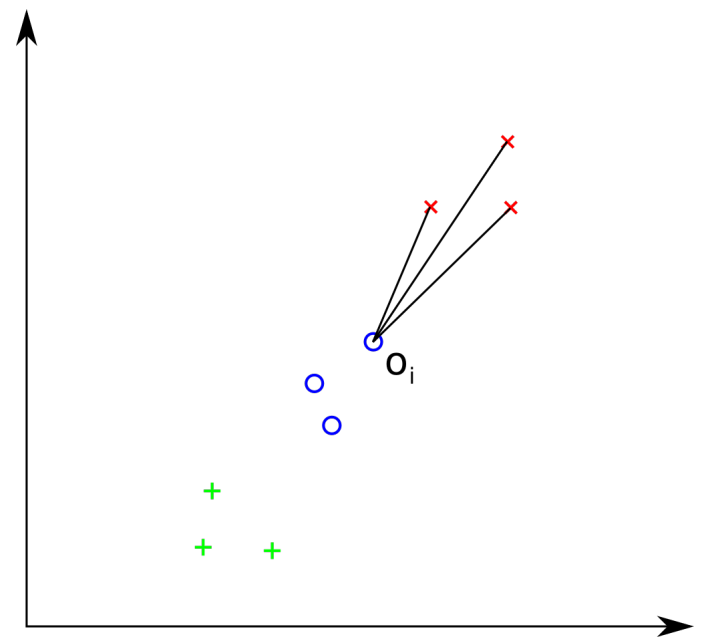

(b) $g\left(k, o_{i}\right)$ is the average distance between $o_{i}$ and the elements of the different group that is the closest to $o_{i}$.

Figure 19: Exemplification of the $g\left(k, o_{i}\right)$ and $l\left(k, o_{i}\right)$ values.

The silhouette value can be considered a ratio between the distance of members in the same group and the distance of its members and its neighboring group. To find the overall quality of the clustering, the Silhouette coefficient is averaged for all the elements of the data, and the number of groups $k$ that maximizes the Silhouette coefficient allows the best separation of data into groups. (KAUFMAN; ROUSSEEUW, 2005)

$$
S(k)=\frac{1}{n} \sum_{i=1}^{n} \frac{g\left(k, o_{i}\right)-l\left(k, o_{i}\right)}{\max \left(g\left(k, o_{i}\right), l\left(k, o_{i}\right)\right)}
$$

The silhouette coefficient is calculated individually for clusters using different cost 
functions, and the combination of number of groups $k$ and cost function that maximizes the silhouette coefficient is chosen for the analysis.

\subsubsection{Analysis}

Once the number of clusters is defined, visual tools are used to help evaluate the clustering. These visual tools were developed in MatLab.

One of this visual tools is an adaption of the script Wind_rose (MA , 2020). This script plots a wind rose, a radial histogram that displays from which direction the environmnental agents come from, and codify their intensities by color.

This tool plots one wind rose for each one of the environmental agents for the entire period, as shown in figure 20 and one for each group obtained in the previous step. It is also possible to categorize the cluster points accordingly to their average drifting and plot a wind rose for the points above certain percentile. The direction used for wind and wave are their incidence angles, and for the currents are their emission angle. 

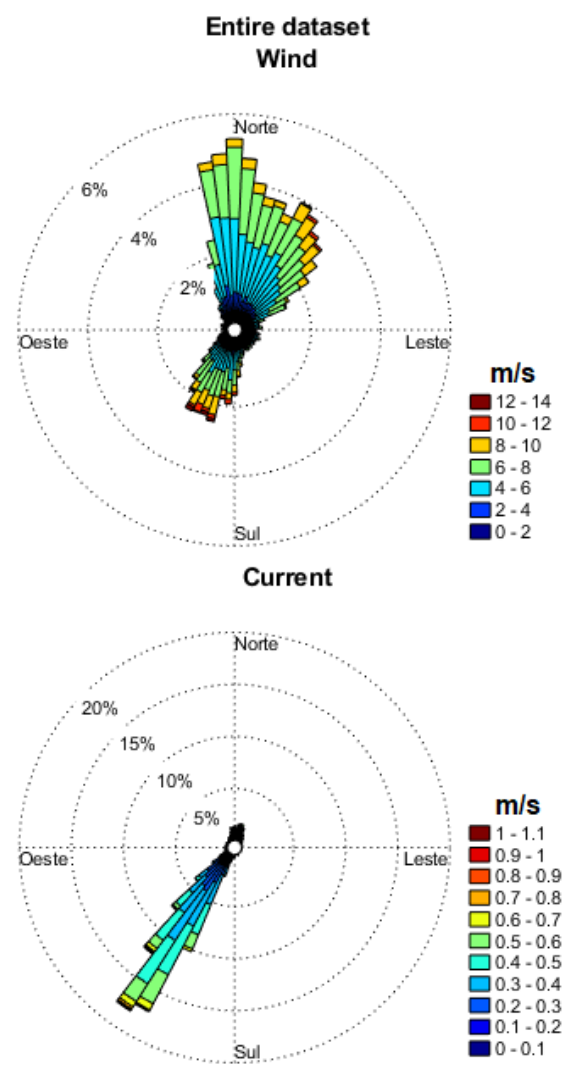

1st Wave

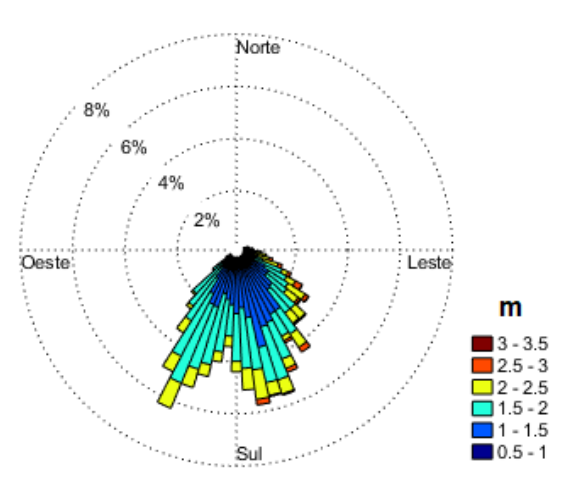

Figure 20: Example of radial histogram plot for the entire dataset of the Tubarão port. Wind and current speeds are in meters per second, and waves height in meters.

Another tool plots the time-series for each cluster, highlighting a user chosen percentile of the cases with higher average drifting as shown in figure 21. It is also highlighted the medoid curve for the cluster and the medoid for the cases in the user chosen upper percentile. The medoid of the upper percentile is obtained using the cost function 4.5. 


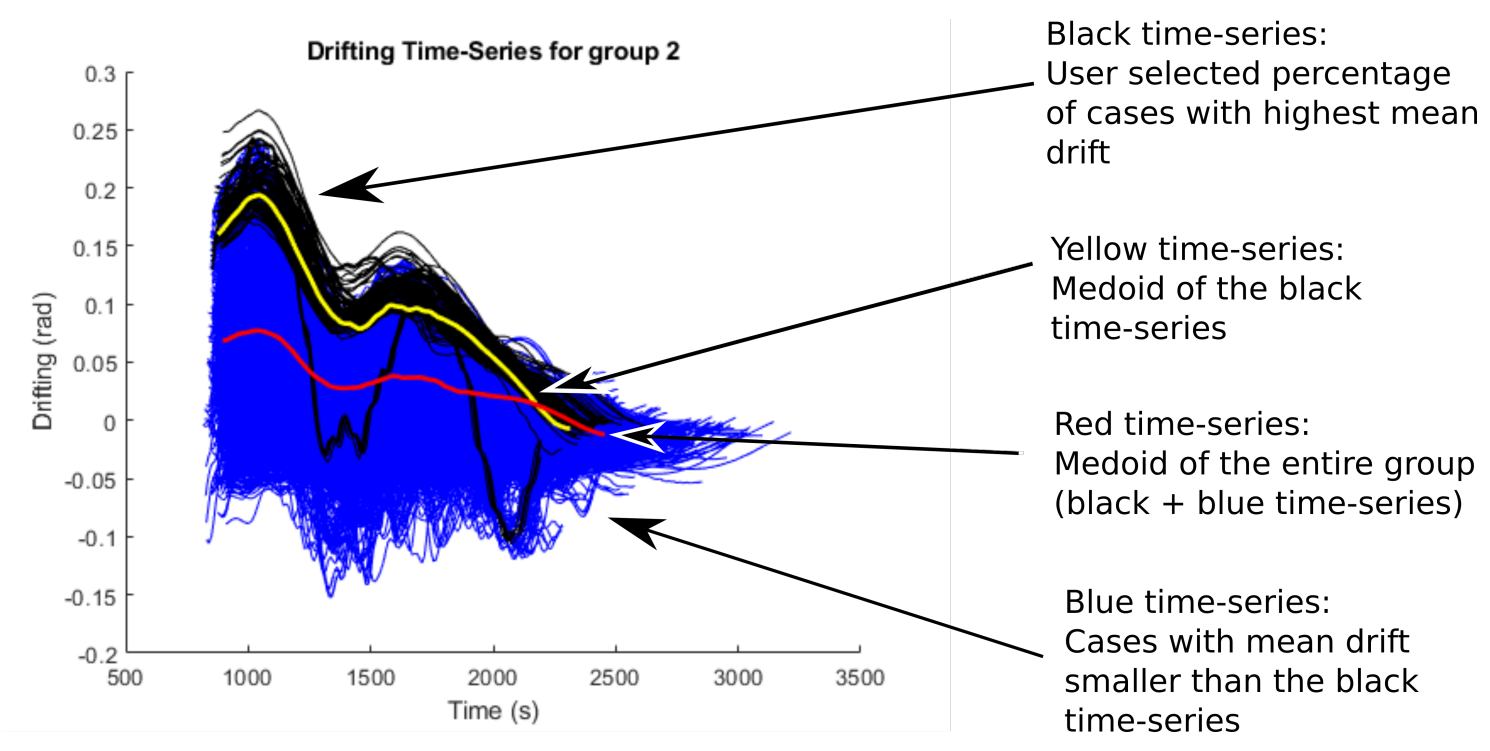

Figure 21: Example of time-series plot for a group.

It is also plotted the average environmental conditions for each cluster. In order to obtain the average environmental condition, considering its direction, the current and waves velocities for each cluster are divided into two orthogonal components, then they are averaged and combined to extract the mean condition. This method is used to find the environmental condition that represents the group, since the group medoid depends on the local minimum found by the PAM algorithm, and it can vary from run to run. 


\section{CASE STUDIES}

This chapter contains the analysis of four cases, one is a vessel entering the port of Tubarão using environmental data from mathematical models, including current velocity maps and wave significant height maps. The second one is a vessel entering the port of Suape. The third and fourth one are navigation operations in the Campos basin, one is made with the vessel fully loaded and the other with the vessel in ballast condition.

\subsection{Tubarão Port}

The current methodology was first applied for the Very Large Ore Carrier (VLOC) Vale Brasil entering the port of Tubarão, in Espírito Santo. For this specific port there is available a dataset containing the environmental conditions at the point B4 (indicated at the Figure 22) for each hour along a period of one year, $D_{t u b}$, between March of 2014 and March of 2015, totaling 8737 values of waves significant height, period and direction, and wind and currents average velocity and direction. The overall structure for the dataset $D_{t u b}$ is shown in table 2 and its directional histograms in figure 23. 

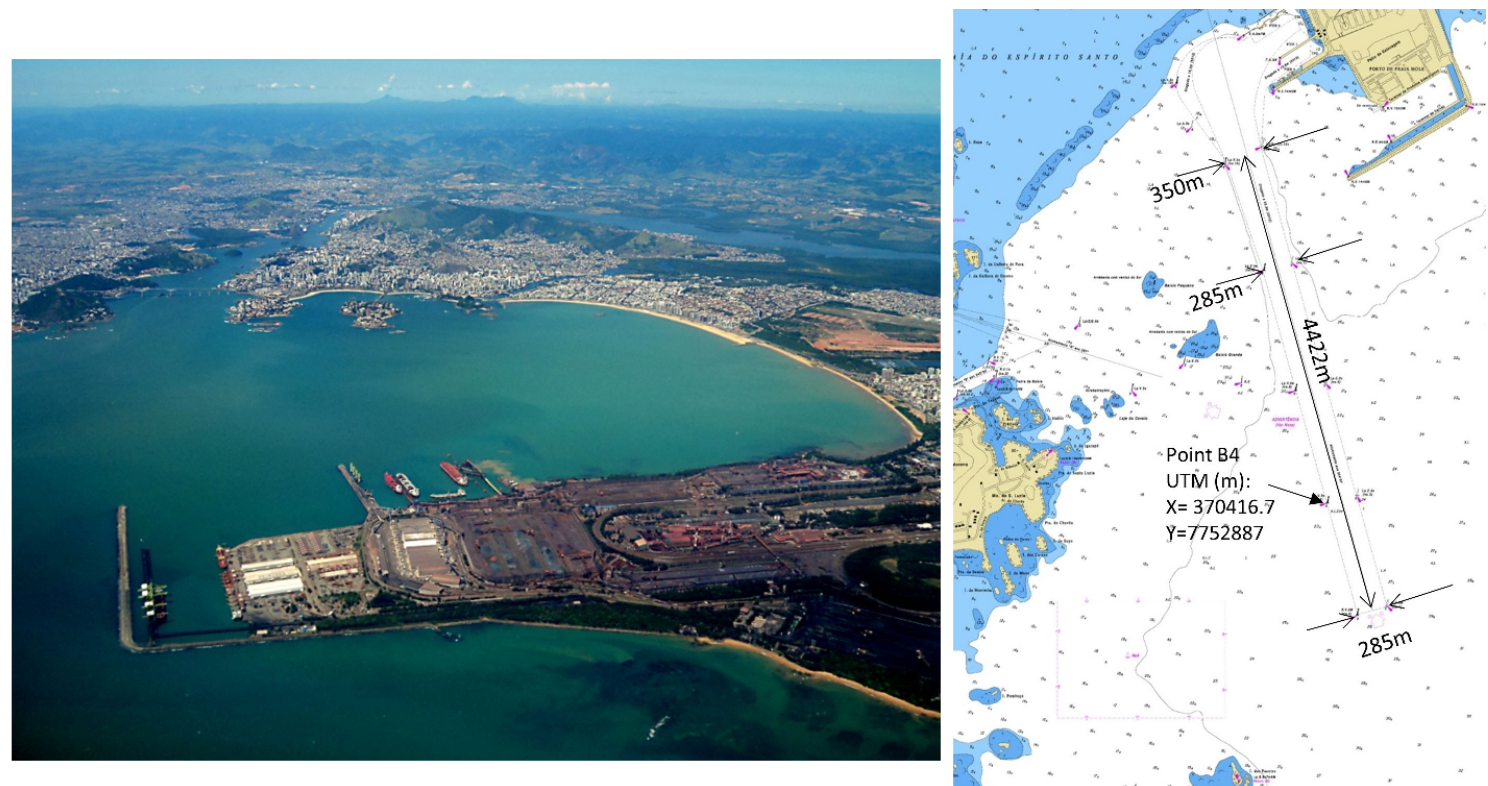

Figure 22: Left: Aerial view of the Tubarão port. Right: Tubarão port access channel. The B4 point indicates the point where the environmental conditions were obtained. Source: TPN .

Table 2: Example of the $D_{t u b}$ fields and structure. Hs denotes wave significant height, Tp wave peak period.

\begin{tabular}{|c|c|c|c|c|c|c|c|}
\hline \multirow{2}{*}{ Time } & \multicolumn{2}{|c|}{ Wind } & \multicolumn{2}{c|}{ Currents } & \multicolumn{3}{c|}{ Waves } \\
\cline { 2 - 7 } & $\begin{array}{c}\text { Velocity } \\
(\mathrm{m} / \mathrm{s})\end{array}$ & Direction & $\begin{array}{c}\text { Velocity } \\
(\mathrm{m} / \mathrm{s})\end{array}$ & Direction & $\begin{array}{c}\text { Hs } \\
(\mathrm{m})\end{array}$ & $\begin{array}{c}\text { Tp } \\
(\mathrm{s})\end{array}$ & Direction \\
\hline $21 / 06 / 20146: 00$ & 7.4 & $218^{\underline{\mathrm{O}}}$ & 0.95 & $155^{\underline{\mathrm{O}}}$ & 1.05 & 8.9 & $130^{\underline{\mathrm{O}}}$ \\
$21 / 06 / 20147: 00$ & 6.8 & $193^{\underline{\mathrm{O}}}$ & 0.80 & $144^{\underline{\mathrm{O}}}$ & 1.12 & 8.6 & $122^{\underline{\mathrm{O}}}$ \\
$21 / 06 / 20148: 00$ & 5.3 & $160^{\underline{\mathrm{O}}}$ & 0.79 & $162^{\underline{\mathrm{O}}}$ & 1.11 & 8.2 & $125^{\underline{\mathrm{O}}}$ \\
$\vdots$ & $\vdots$ & $\vdots$ & $\vdots$ & $\vdots$ & $\vdots$ & $\vdots$ & $\vdots$ \\
\hline
\end{tabular}
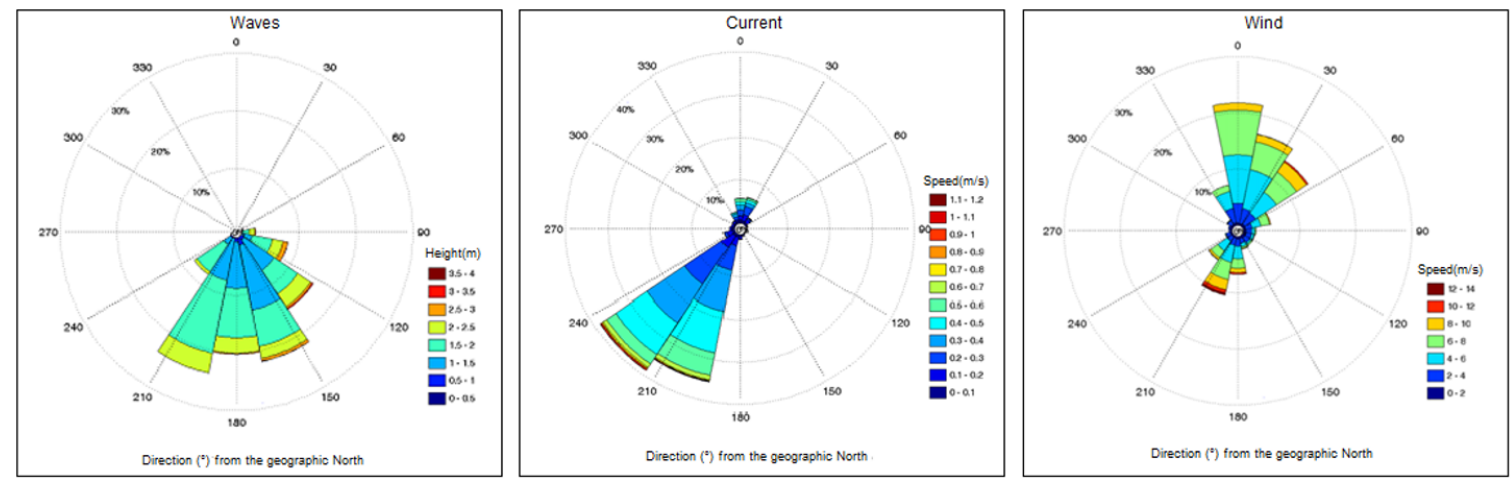

Figure 23: Directional histogram for wind, waves and currents in the studied site.

This dataset has been generated by TetraTech ${ }^{T M}$ (CLAUZET et al., 2016), whom collected, assured and described the data. Their model uses wind time-series obtained from 
the Climate Forecast System Reanalysis Version 2, which combines ocean-atmosphereland coupling models with measurements to provide a quasi-global forecasting system. The waves, period, significant height and direction were obtained from the WaveWatchIII forecast models. Tides were obtained from the Hybrid Coordinate Ocean Model and the TPXO global model. These parameters were used along others, such as the bathymethry, to define boundary conditions for hydrodynamic simulations using the Delft3D models for waves and currents. From this process a detailed map of current and waves for the region along the entire period was obtained. The Figure 24 shows the current map for the two principal directions (going to NE and SW). The figure 25 presents the wave maps for directions SE and W (coming from).
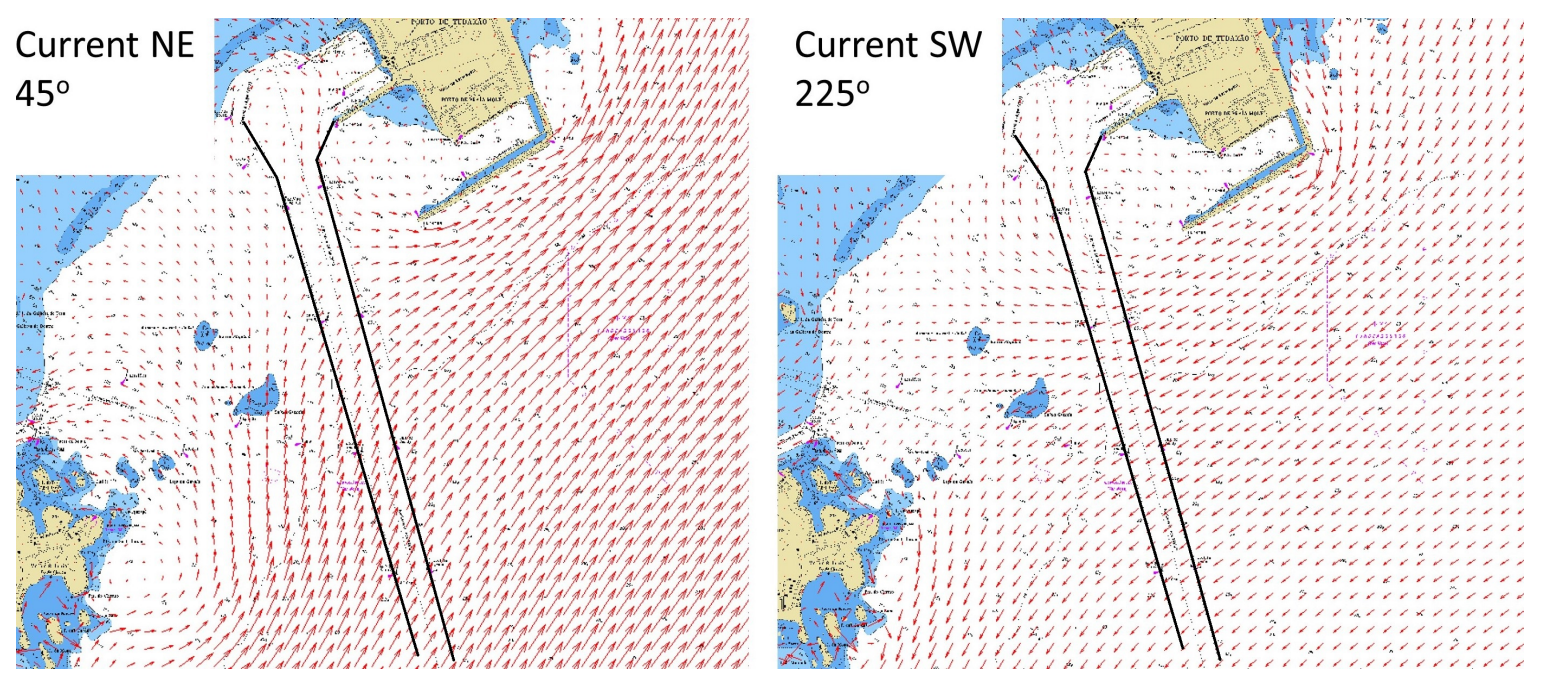

Figure 24: Currents velocity and direction maps for the Tubarão port. Source: TPN.
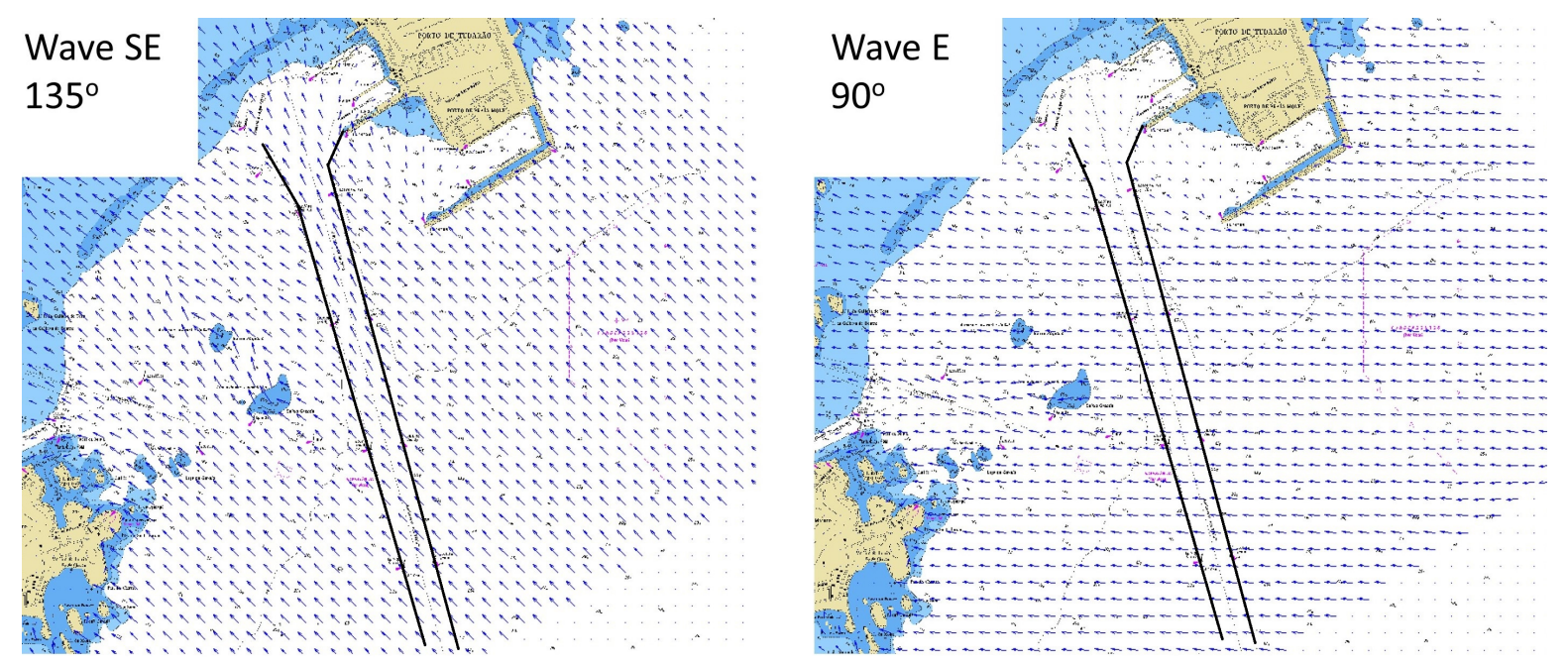

Figure 25: Wave significant height and direction maps for the Tubarão port. Source: TPN.

The vessel used for this maneuver was the Vale Brasil, from the Valemax class, whose 
characteristics are shown in table 3. This vessel is a bulk carrier used for ore exportation by the mining corporation Vale. This class of vessels is frequently loaded at the Tubarão port with iron ore, mainly for exportation to China.

Table 3: Valemax ship used for the simulations. Source: TPN.

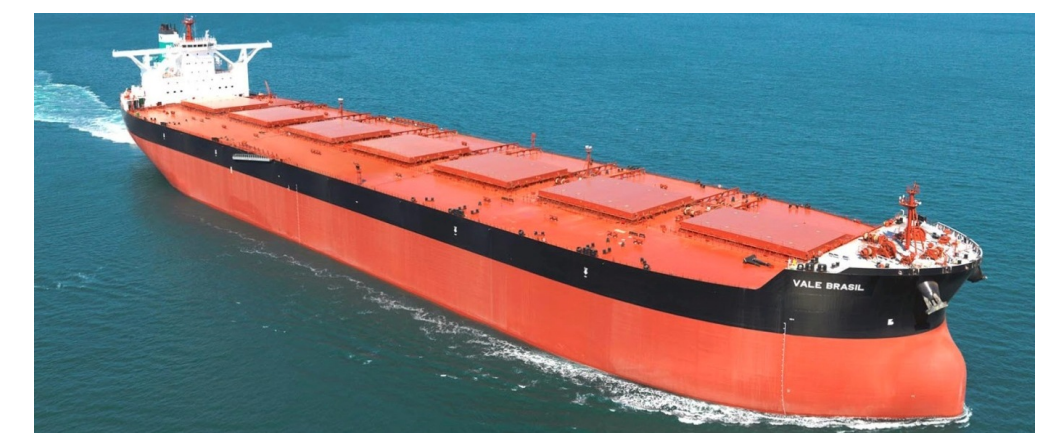

\begin{tabular}{|c|c|}
\hline Name & Vale Brasil \\
\hline Overall length & $362.0 \mathrm{~m}$ \\
\hline Beam & $65.0 \mathrm{~m}$ \\
\hline Draft (Loaded) & $23.0 \mathrm{~m}$ \\
\hline Adopted draft (Ballast) & $11.2 \mathrm{~m}$ \\
\hline Displacement (Loaded) & 379510 ton \\
\hline Displacement (Ballast) & 197057 ton \\
\hline
\end{tabular}

The port channel was modeled accordingly to the nautical chart, shown in figure 22 . Since there are current velocity and wave significant height maps available for this port, they were used for the simulations. Two current maps and four wave maps, shown in table 4, were used. In order to select which maps to use for the simulation, the waves and current directions at the reference point B4 were compared to the environmental conditions for the simulation and the map with closest direction was chosen.

Table 4: Available current and Wave maps directions for Tubarão port.

\begin{tabular}{|c|c|}
\hline Currents & Waves \\
\hline $225^{\circ}$ & $45^{\circ}$ \\
\hline $45^{\circ}$ & $90^{\circ}$ \\
\hline & $135^{\circ}$ \\
\hline & $180^{\circ}$ \\
\hline
\end{tabular}


After obtaining the automatic pilot parameters shown in table 5, ship maneuvering fast-time simulations were carried for each one of the environmental conditions. From the 8737 conditions, the vessel reached the end of channel without crossing the channel margins in 8695 cases. The cluster analysis was applied only to these cases.

Table 5: Parameters used for the automatic pilot in the Tubarão simulations.

\begin{tabular}{|c|l|l|}
\hline Parameter & Value & Unit \\
\hline$\hat{N}_{r}\left(u, v, \omega_{p}\right)$ & 385560 & tf.m \\
\hline$P_{\text {yaw }}$ & 2668811 & - \\
\hline$I_{\text {yaw }}$ & 1729785 & - \\
\hline$D_{\text {yaw }}$ & 207574164 & - \\
\hline
\end{tabular}

The cluster analysis was made for both cost functions in equations 4.4, 4.5 and 4.6, and then the silhouette coefficients were obtained, as shown in figure 26. By selecting the case that maximizes the silhouette coefficient, it was chosen the cost function 4.5 and a number of groups $k=2$ resulting in a silhouette coefficient of 0.609 . The groups environmental conditions are shown in figures 27 and 28 and the drift angle time-series are shown in figures 29 and 30. The total processing time for this method ran on a computer with an i7-7700 cpu @ 3.6Ghz is given in table 6 .

Table 6: Processing time for each step of the methodology for this scenario ran on a computer with an i7-7700 3.6Ghz processor.

\begin{tabular}{|c|l|}
\hline Process & Processing time \\
\hline Fast-time simulations & 8 hours \\
\hline Dynamic Time Warping & 3 hours \\
\hline Cluster Analysis & 8 hours \\
\hline
\end{tabular}

The two clusters present different characteristics, and that is typical of that area. Group 1 represents the most common condition (6628 conditions), with winds and currents coming from NE direction. Group 2 represents the entrance of cold fronts, with the inversion of the wind direction $(\mathrm{S})$ and associated with an inversion in the current direction. 


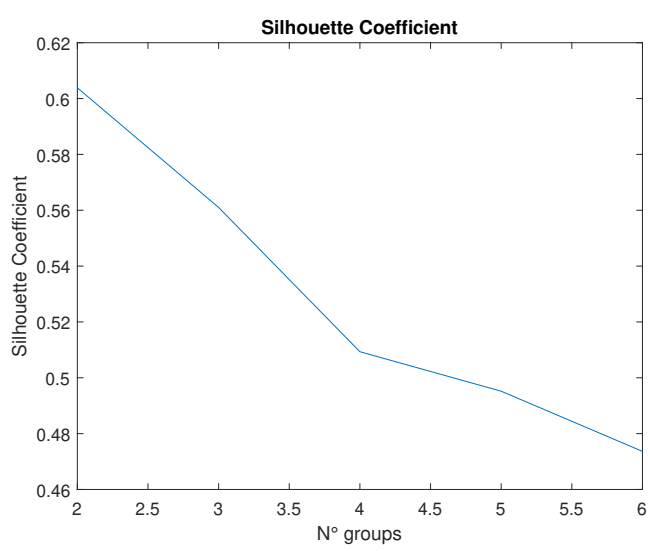

(a) Silhouette coefficients for cost function 4.4.

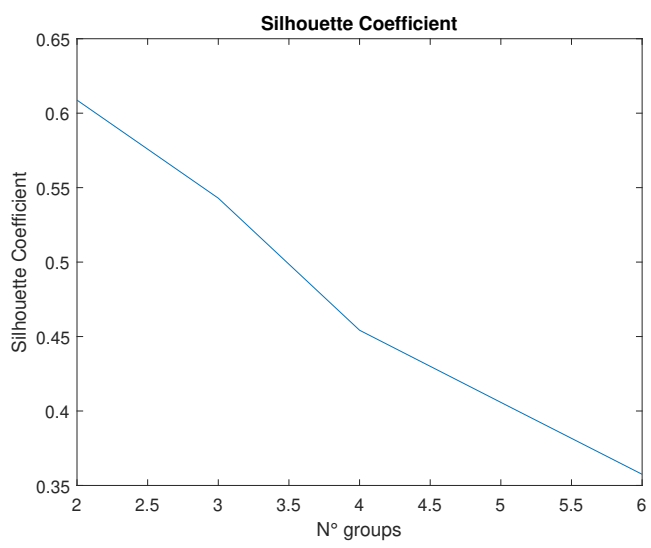

(b) Silhouette coefficients for cost function 4.5.

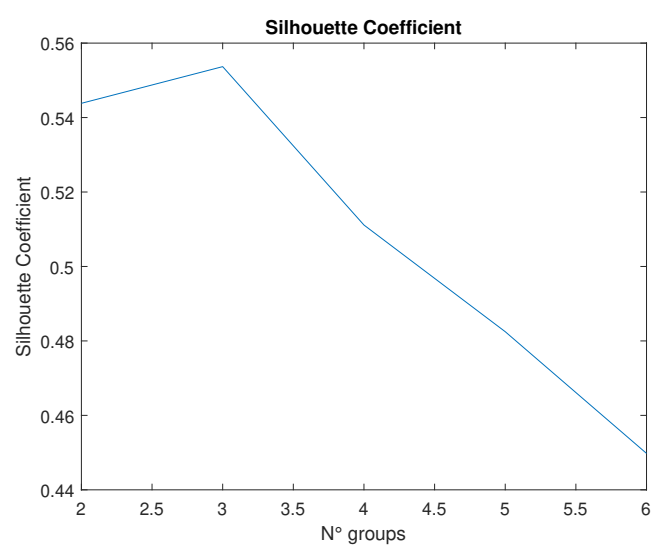

(c) Silhouette coefficients for cost function 4.6.

Figure 26: Silhouette coefficients for Tubarão simulations.

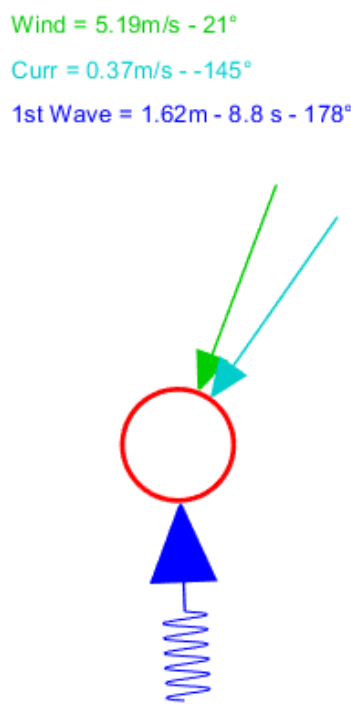

$\mathrm{N}^{\circ}$ conditions: 6628
Wind $=5.58 \mathrm{~m} / \mathrm{s}--168^{\circ}$

Curr $=0.21 \mathrm{~m} / \mathrm{s}-5^{\circ}$

1st Wave $=1.66 \mathrm{~m}-9.5 \mathrm{~s}-142^{\circ}$

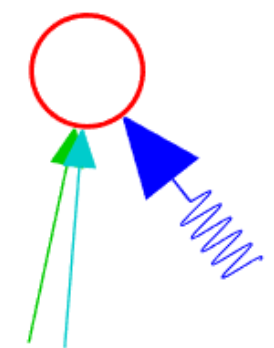

$\mathrm{N}^{\circ}$ conditions: 2067

Figure 27: Mean environmental conditions for $k=2$ and cost function 4.5 for the Tubarão port. 

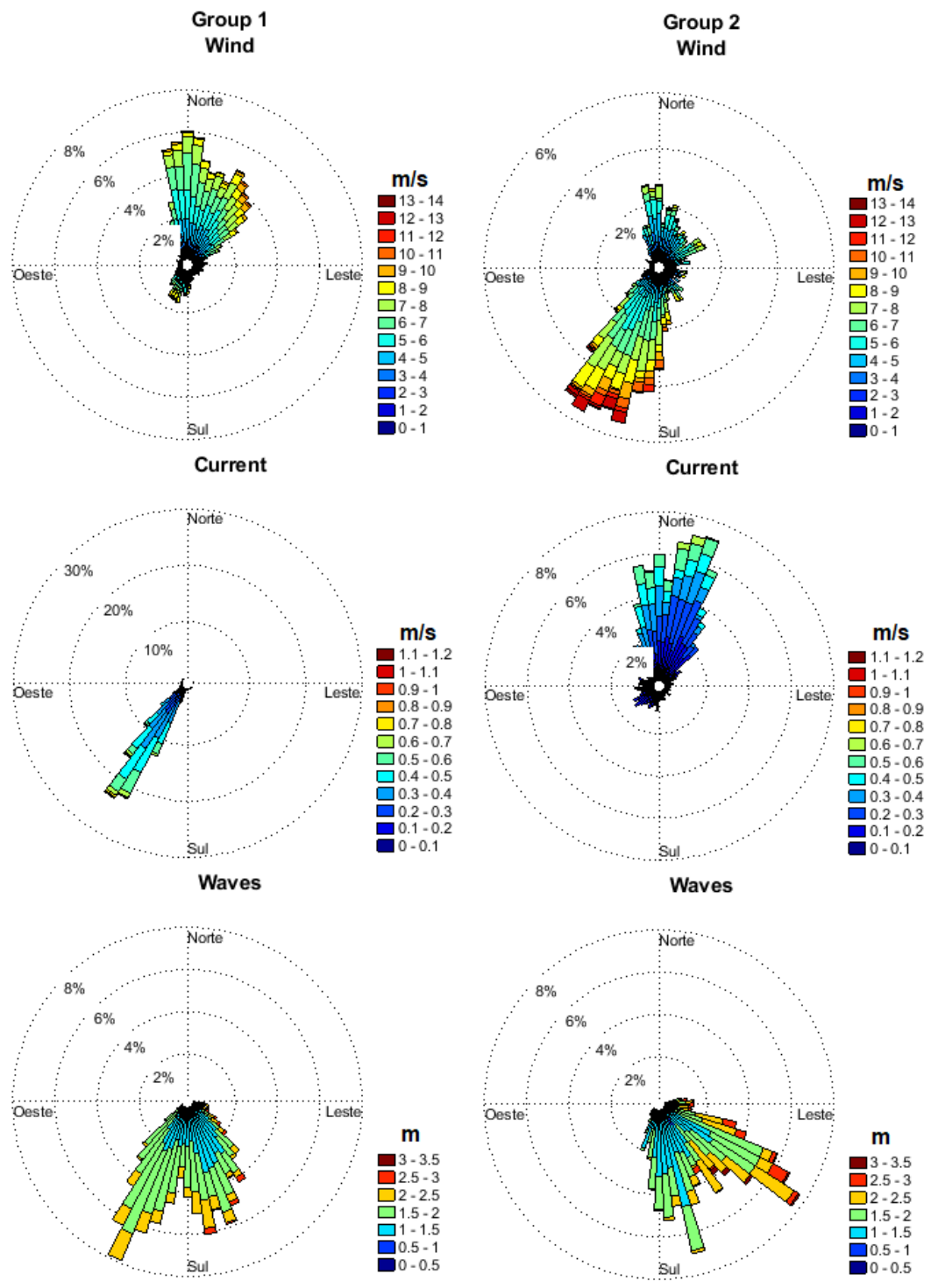

Figure 28: Radial histograms for environmental conditions for $k=2$ and cost function 4.5 for the Tubarão port. 


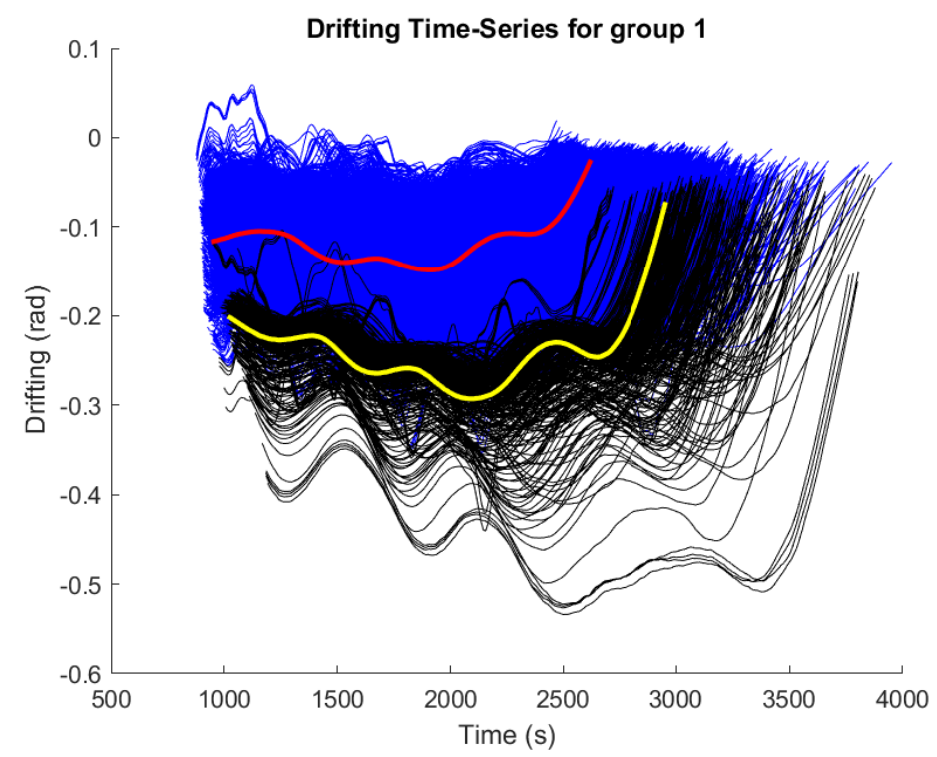

Figure 29: Drift angle time-series for the first group for $k=2$ for the Tubarão port. The black curves represents the $5 \%$ simulations with largest average drift angle having the yellow curve as its medoid. Red curve is the group medoid.

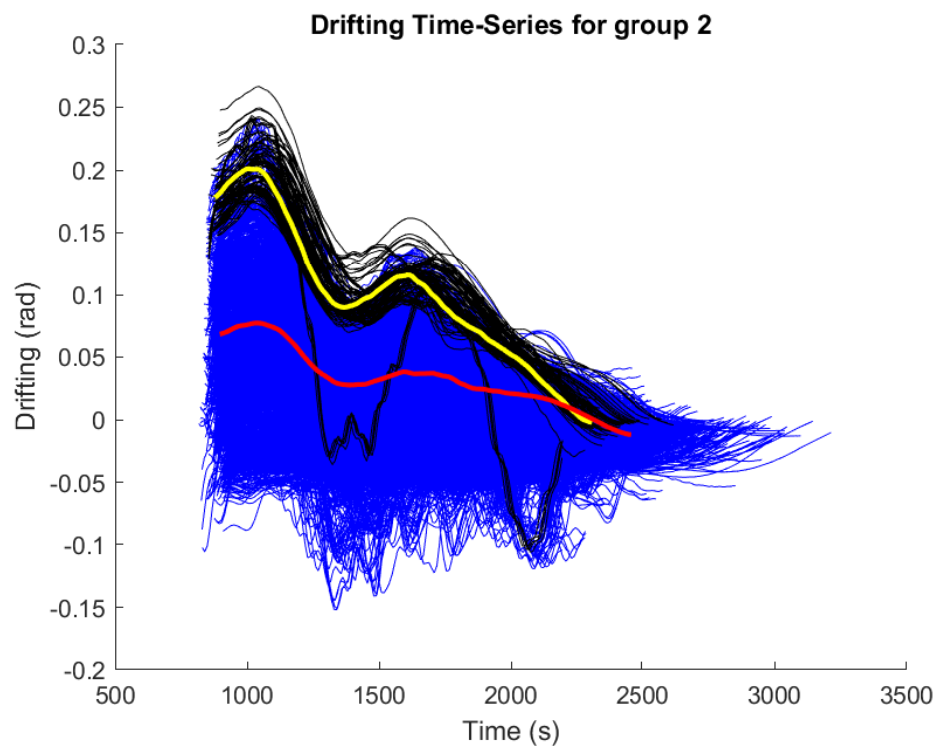

Figure 30: Drift angle time-series for the second group for $k=2$ for the Tubarão port. The black curves represents the $5 \%$ simulations with largest average drift angle having the yellow curve as its medoid.

By analysing the charts, it is possible to notice how the algorithm have roughly separated the environmental conditions by the current and wind directions. It is also possible to notice in figures 29 and 30 how the overall absolute drifting decreases towards the end of the maneuver. This behavior can be attributed to the decrease of current speed towards the end of channel, decreasing the vessel's drift angle. It is possible to notice how 
the two groups have time-series that are qualitatively different in their shape, that could explain why the silhouette method is maximized for two groups.

Sometimes it can be desirable to obtain a representative environmental condition that represents more extreme cases of a typical scenario. Since the cluster analysis in this case did separate the environmental conditions in two qualitatively different groups, it is possible to use the user defined percentile to obtain a environmental condition that represents a percentile of cases with larger drift angle, for example as shown in figure 31 .

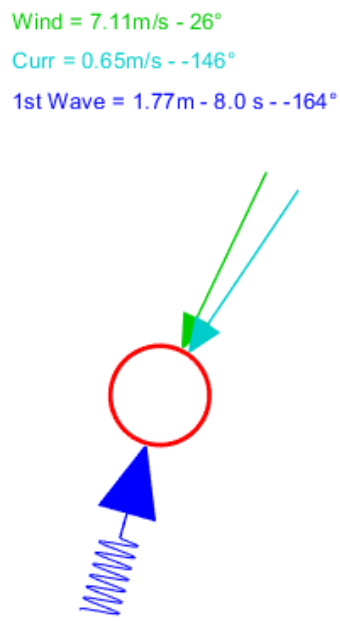

$\mathrm{N}^{\circ}$ conditions: 6628
Wind $=5.73 \mathrm{~m} / \mathrm{s}--160^{\circ}$

Curr $=0.54 \mathrm{~m} / \mathrm{s}-7^{\circ}$

1st Wave $=1.55 \mathrm{~m}-8.3 \mathrm{~s}-140^{\circ}$

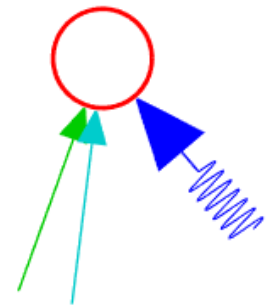

$\mathrm{N}^{\circ}$ conditions: 2067

Figure 31: Example of average environmental conditions for the cases with the $5 \%$ highest average drift angle for the Tubarão port.

The trajectories of the vessel under the conditions defined by the clusters are presented in 32. It shows a portside drift for the cluster Group 1 (simulations $1 \mathrm{a}$ and 1b) since the wind and current come from NE (starboard-bow incidence angle). The drift increases for simulation $1 \mathrm{~b}$, executed with the $5 \%$ stronger conditions of the Group 1. The simulations $2 \mathrm{a}$ and $2 \mathrm{~b}$ presented an opposite drift angle (to starboard side) since the wind and current come from SW (portside stern incidence angle). These simulations demonstrate the qualitative modification of the maneuver under conditions from different cluster groups (drift to starboard or portside). They also show that the user can test more difficult maneuvers in the same scenario by selecting the percentile of stronger conditions inside the cluster. It is also noticeable the reduction of drifting towards the end of the channel (since the current is reduced as shown in Figure 24). 


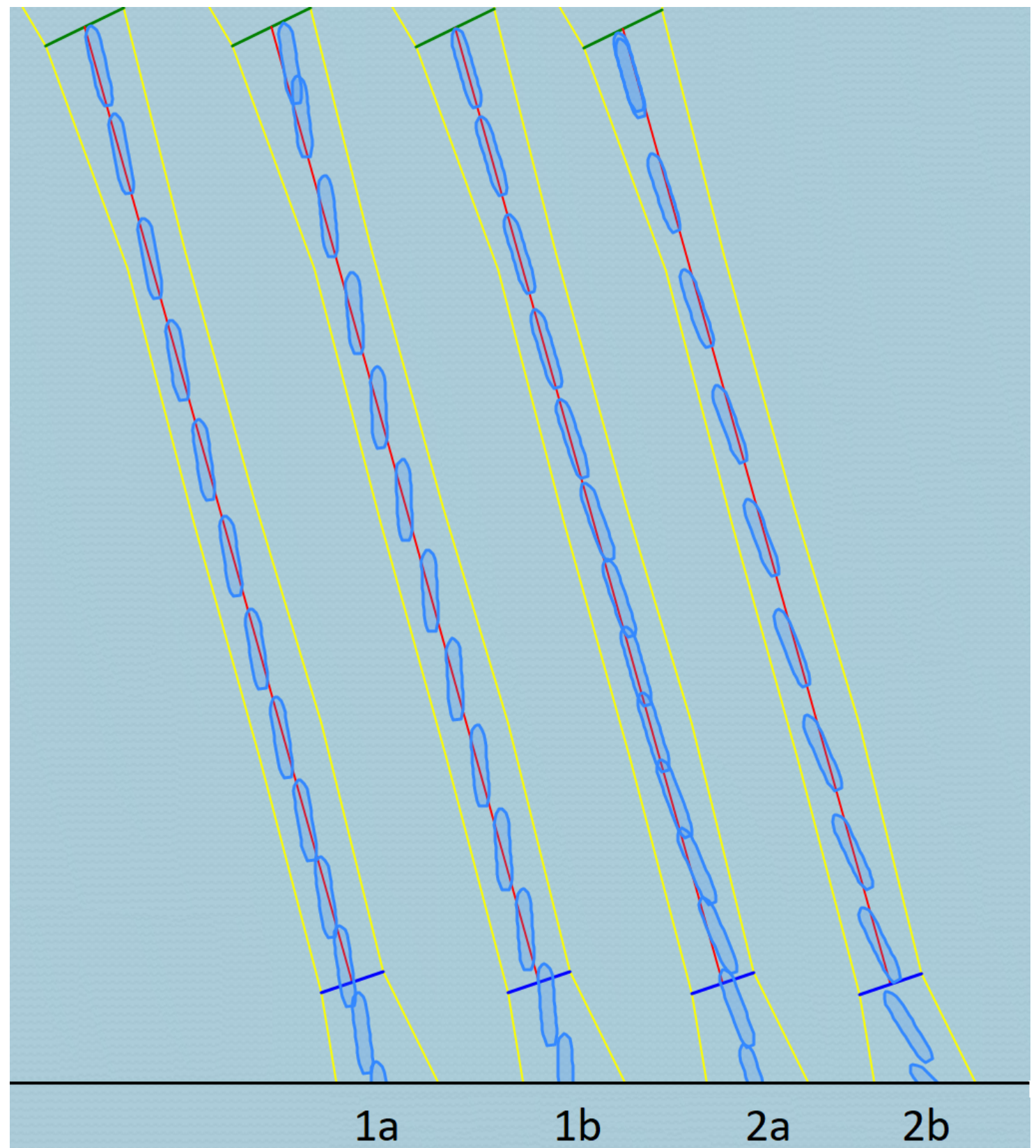

Figure 32: Time-lapse of selected maneuvers in Tubarão, with 3 minute sampling. The number denotes the group number, the letter "a" denotes the medoid for the entire group, and the letter "b" denotes the medoid for the $5 \%$ condition with highest drift.. Channel in yellow, start of channel in blue and end of channel in green.

\subsection{Suape Port}

The Suape Port, located in the Brazilian state of Pernambuco, is one of the largest ports in Brazil and in 2018 it saw a movimentation of about 23 million of tonnes, mainly liquid cargo such as petroleum by-products. (SANTANA, 2018)

This port allows the berthing of vessels up to 170.000 DTW (Deadweight tonnage) 
and 14.5 draft. A new access channel $5 \mathrm{~km}$ long, $300 \mathrm{~m}$ wide, and $15.5 \mathrm{~m}$ deep oriented at about $256^{\circ}$ is under analysis by the port authority.

For this area there are available models for current, waves and wind behavior along the year. These conditions were obtained by numerical simulations made by Delft3d-Wave and Delft3d-Flow having data from the NOAA WaveWatchIII and Climate Forecast system as inputs. That dataset provides an hourly estimate of the channel environmental conditions between January $1^{\text {st }} 2016$ and December $31^{\text {th }}$ 2016, totaling 8782 individual environmental conditions. This model contains estimates for wind mean velocity and direction, surface currents mean velocity and directions, and two surface wave components significant height, mean period, and mean direction. (WATAI et al., 2017)

The vessel selected for this analysis is the "Angra dos Reis" an Aframax class vessel. The vessel specifications are shown in table 7. For this specific operation it is considered that the vessel is fully loaded and it will enter the port. The engine speed order starts as Half Ahead, it is reduced to Slow Ahead after the first third of the channel and it is reduced to Dead Slow Ahead in the last third of channel. This was made to mimic the real scenario, where the pilot reduces the ship speed as he approaches the breakwater.

Table 7: Characteristics of the vessel used for Suape's simulations. Source: TPN.

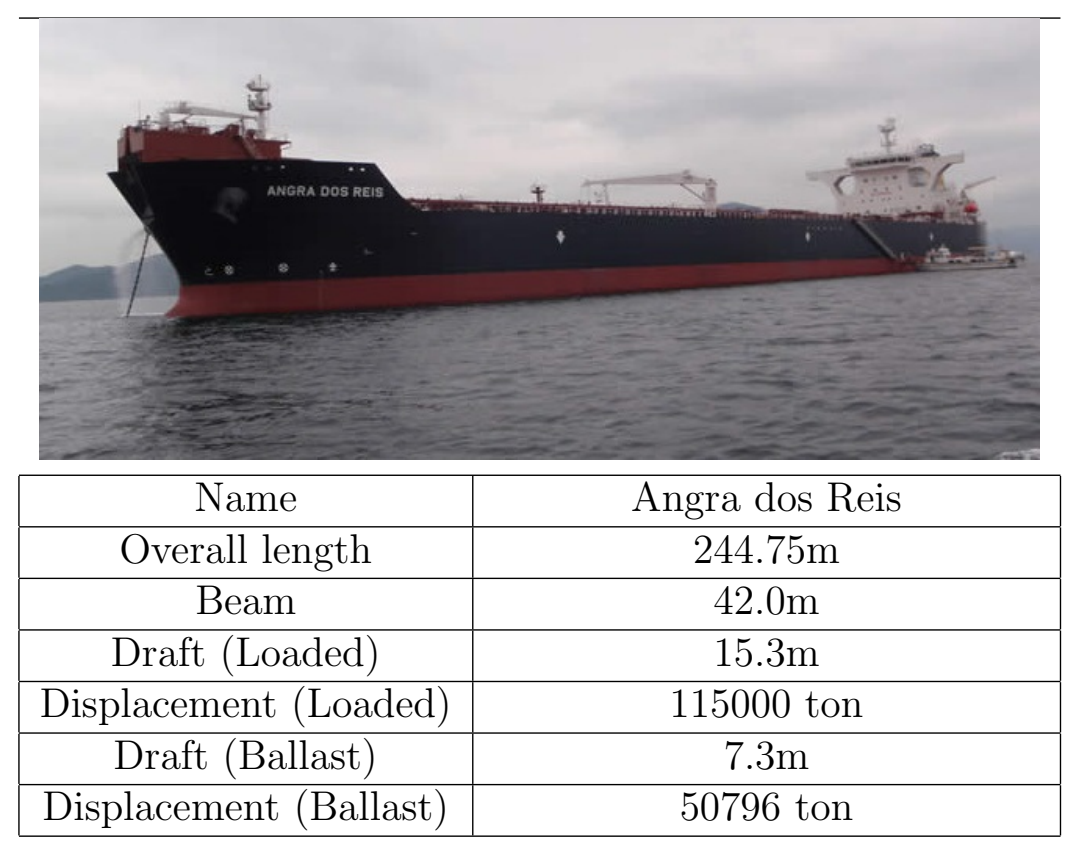

The port channel was included in the nautical chart available for the port, as shown in figure 33. For the sake of simplification, it was considered that the intensities and directions of the environmental conditions were constant along the entire channel. 


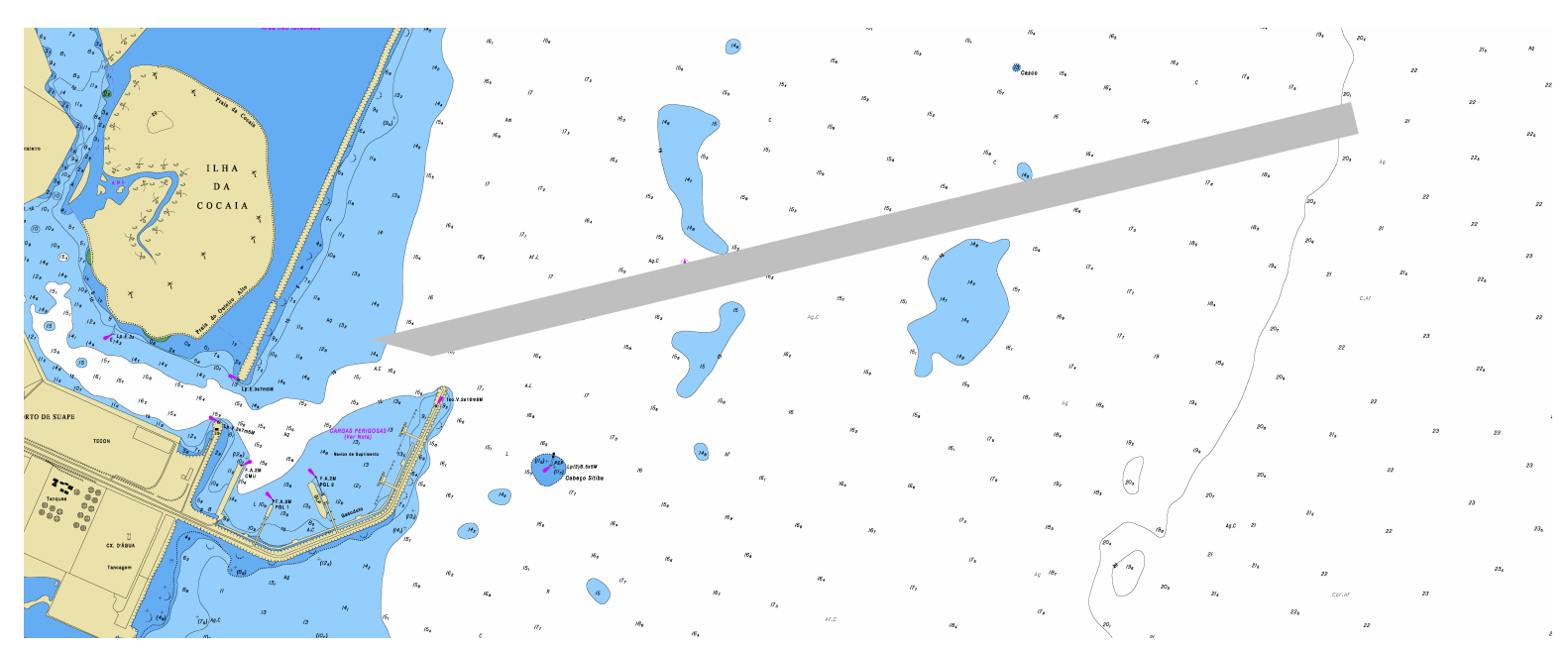

Figure 33: Suape port access channel. Source: TPN.

After obtaining the automatic pilot parameters shown in table 8, the simulations were carried for all the environmental conditions and the clustering methodology was applied. From the 8782 simulations the vessel has reached the end of the channel without crossing its margins in 8469 cases, and only those cases were considered for the clustering.

Table 8: Parameters used for the automatic pilot for the simulations with the vessel Aframax fully loaded.

\begin{tabular}{|c|l|l|}
\hline Parameter & Value & Unit \\
\hline$\hat{N}_{r}\left(u, v, \omega_{p}\right)$ & 48460 & tf.m \\
\hline$P_{\text {yaw }}$ & 840823 & - \\
\hline$I_{\text {yaw }}$ & 544978 & - \\
\hline$D_{\text {yaw }}$ & 65397360 & - \\
\hline
\end{tabular}

Once the simulations were completed, the dissimilarity matrix for the drifting curves was obtained and the cluster analysis was applied using the cost functions 4.4, 4.5 and 4.6. The silhouette coefficients were obtained as shown in figure 34 and the best cluster was selected, having $k=2$, cost function 4.6 and a silhouette coefficient of 0.694 . The environmental conditions for each cluster are shown in figures 35 and 36. The environmental mean conditions for the cases with the $5 \%$ largest mean absolute drifting angle are shown in figure 37.

Also, since the ocean waves are traditionally divided into Swell and Local Sea waves, a classification heuristic is used in order to classify the two wave components of the dataset for visualization purposes. This heuristic is based in the observation that the Local Sea 
waves are generated by the winds near the region and have shorter periods when compared to the Swell. This classification divides the waves accordingly to table 9. In the case where two components have the same classification, only the component with largest significant height is considered. (HUANG et al., 2019)

Table 9: Criteria for classification of waves components into Swell or Local Sea waves. Source: HUANG et al. (2019).

\begin{tabular}{|l|c|}
\hline Type of Wave & Criteria \\
\hline Swell & Mean period over $12 \mathrm{~s}$ \\
& or \\
& $\begin{array}{c}\text { mean period over } 8 \mathrm{~s} \text { and misalignment } \\
\text { in relation to the wind over } 45^{\circ}\end{array}$ \\
\hline Local Sea & Mean period below $8 \mathrm{~s}$ \\
& $\begin{array}{c}\text { or } \\
\text { mean period below } 12 \mathrm{~s} \text { and misalignment } \\
\text { in relation to the wind lower than } 45^{\circ}\end{array}$ \\
\hline
\end{tabular}




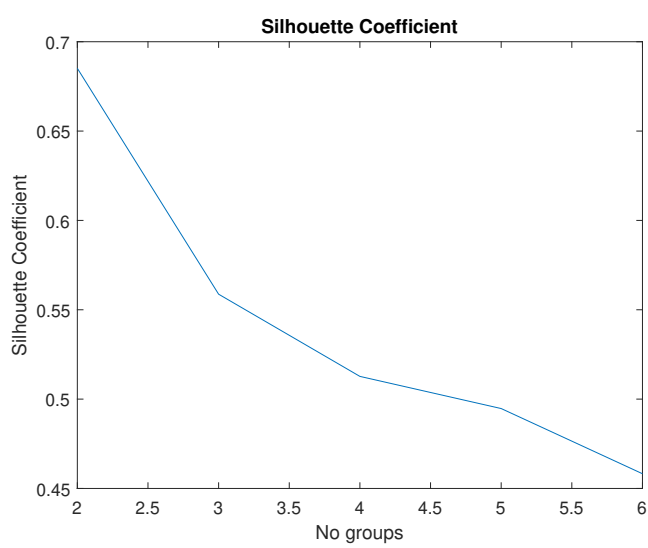

(a) Silhouette coefficients for cost function 4.4.

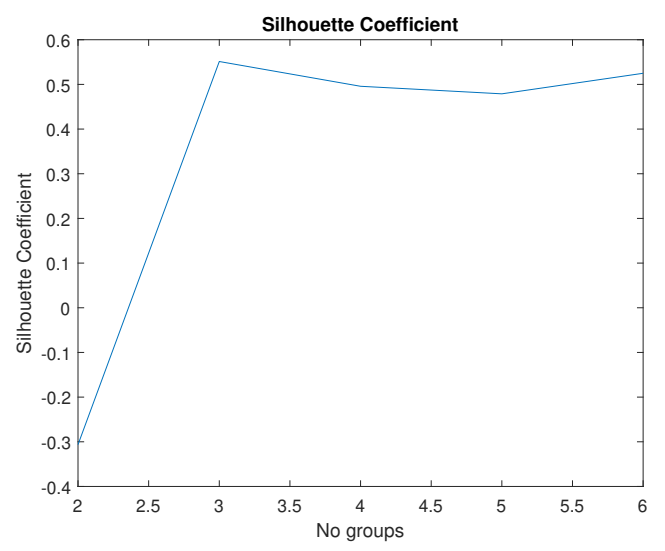

(b) Silhouette coefficients for cost function 4.5.

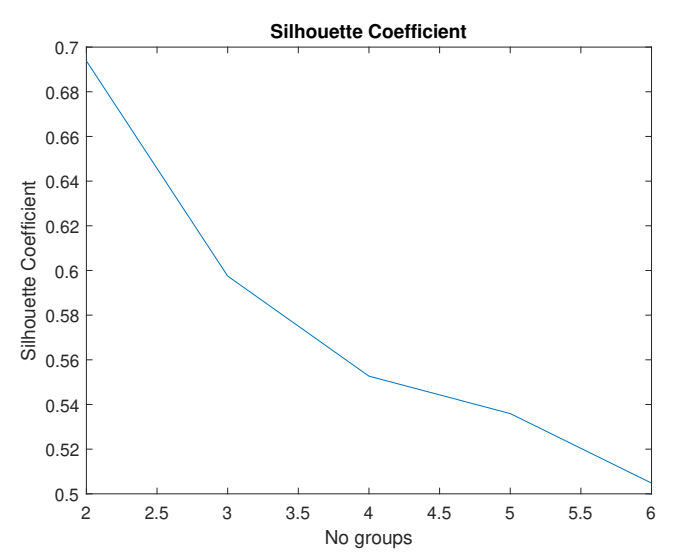

(c) Silhouette coefficients for cost function 4.6.

Figure 34: Silhouette coefficients for Suape port.

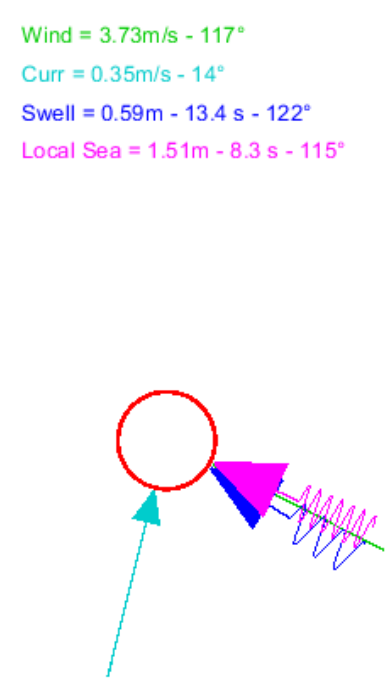

$N^{\circ}$ conditions: 6608

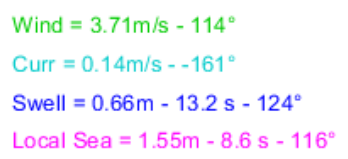

Wind $=3.71 \mathrm{~m} / \mathrm{s}-114^{\circ}$

Curr $=0.14 \mathrm{~m} / \mathrm{s}--161^{\circ}$

Swell $=0.66 \mathrm{~m}-13.2 \mathrm{~s}-124^{\circ}$

Local Sea $=1.55 m-8.6 s-116^{\circ}$

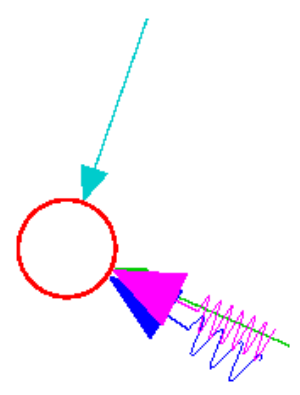

$\mathrm{N}^{\circ}$ conditions: 1861

Figure 35: Mean environmental conditions for $k=2$ and cost function 4.6 for the Suape port. 

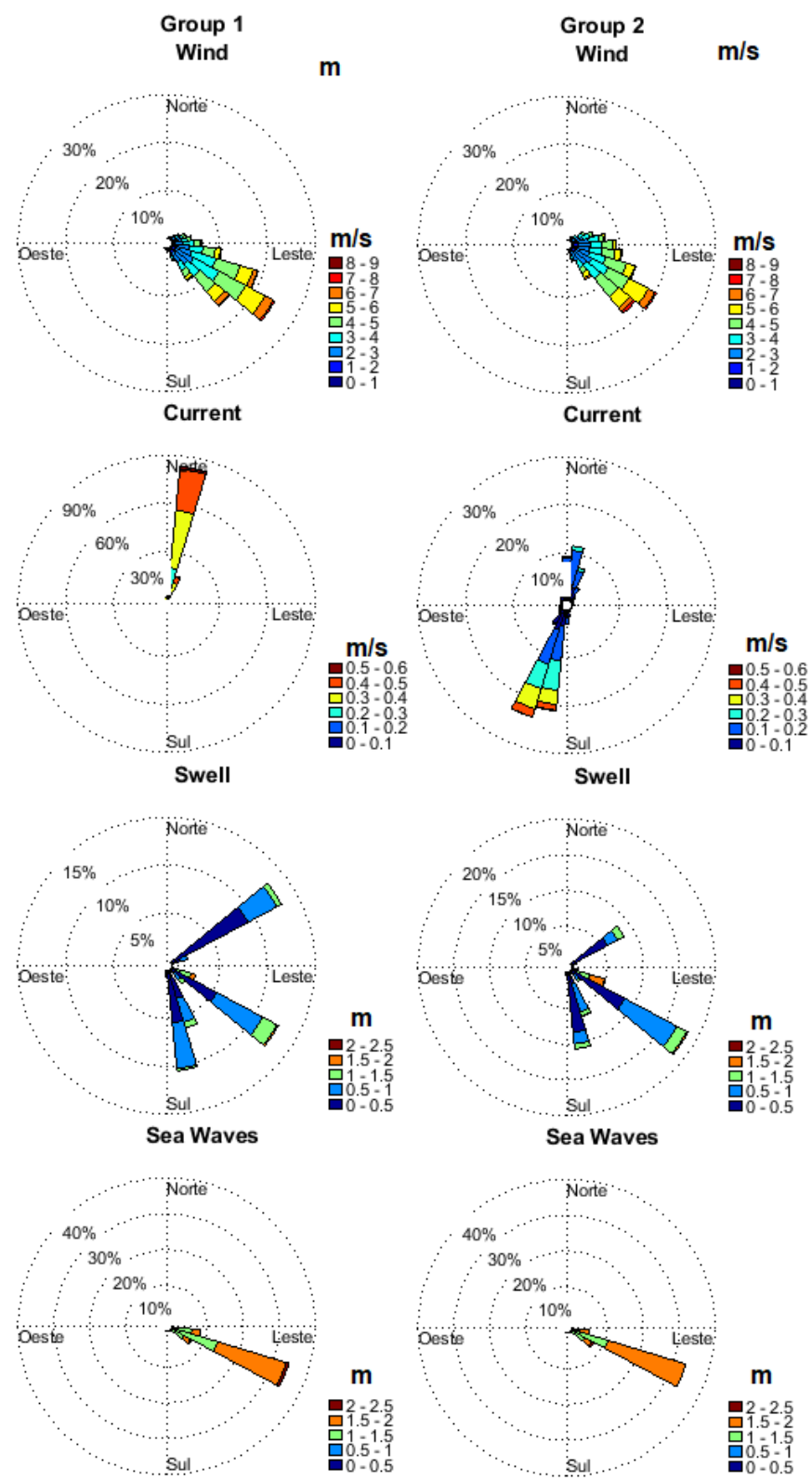

Figure 36: Radial histograms for environmental conditions for $k=2$ and cost function 4.6 for the Suape port. 


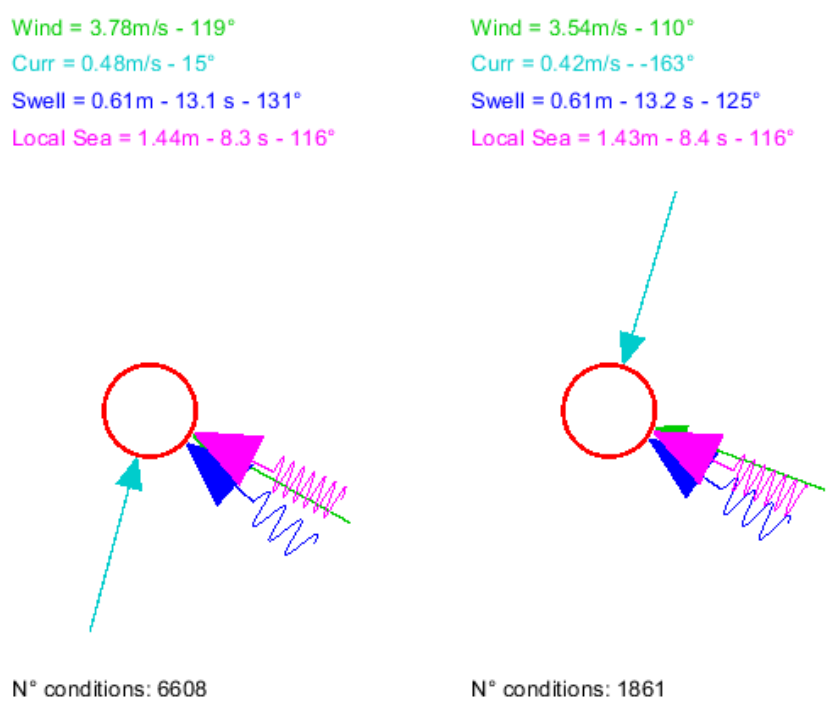

Figure 37: Mean environmental conditions for $k=2$ and cost function 4.6 for the cases with $5 \%$ highest mean drifting for the Suape port simulations.

The drifting time-series for each cluster is shown in figures 38 and 39. It is possible to notice that for both clusters the drifting increases towards the end of the channel, this is can be attributed to the decrease in the vessel's speed towards the end of the maneuver due to the decrease of the propeller speed. It is also possible to notice how the two groups have time-series that are qualitatively different in their shape, that could explain why the silhouette method is maximized for two groups.

It is also possible to notice that the best clustering divides the environmental conditions in two groups having a very similar directions and and intensities, except for the current. This can be due to the relative uniformity of the environmental conditions that have been used as inputs. 


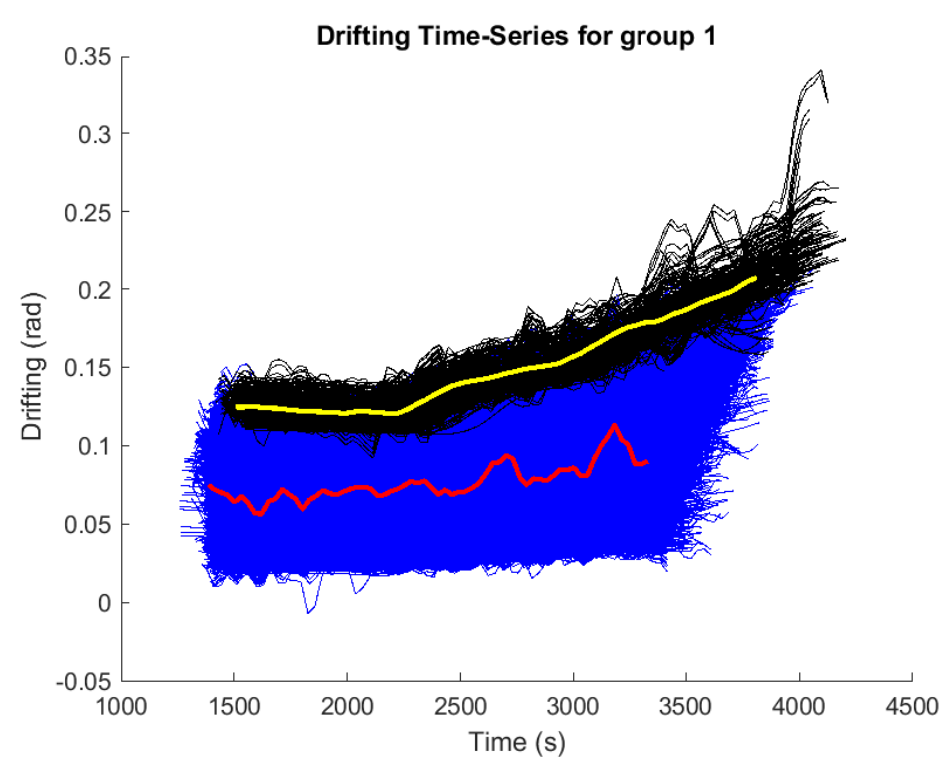

Figure 38: Drifting time-series for the first group for $k=2$ for the Suape port. The black curves represents the $5 \%$ simulations with largest mean drift having the yellow curve as its medoid. Red curve is the group medoid.

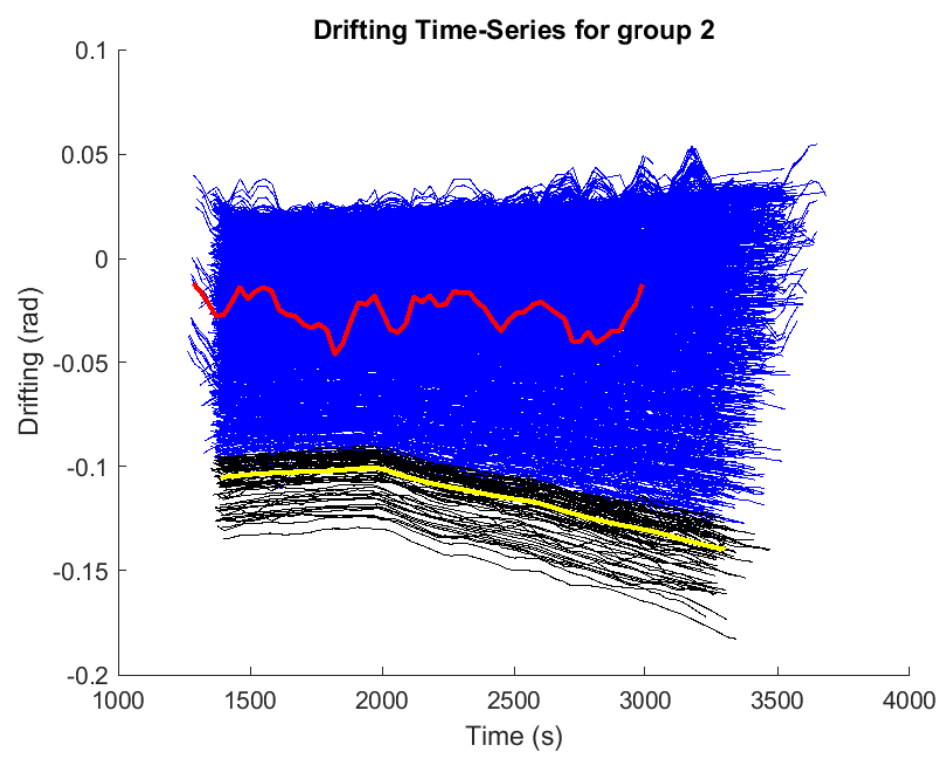

Figure 39: Drifting time-series for the second group for $k=2$ for the Suape port. The black curves represents the $5 \%$ simulations with largest mean drift having the yellow curve as its medoid.

The trajectories of the vessel under the conditions defined by the clusters are presented in 40. It shows a starboard side drift for the cluster Group 1 (simulations 1a and 1b) since the wind, waves and current come from the SE-SW quadrant (port bow and port stern incidence angle). The drift increases for simulation 1b, executed with the $5 \%$ stronger conditions of the Group 1. The simulations $2 \mathrm{a}$ and $2 \mathrm{~b}$ presented an opposite drift angle 
(to port side) since the current comes from North (starboard stern incidence angle). The drifting in $2 \mathrm{a}$ and $2 \mathrm{~b}$ are slightly lower since the waves and winds still come from SW (portside stern incidence angle).

In a similar way to the Tubarão port simulations, these simulations demonstrate the qualitative modification of the maneuver under conditions from different cluster groups (drift to starboard or portside). They also show that the user can test more difficult maneuvers in the same scenario by selecting the percentile of stronger conditions inside the cluster. It is also noticeable the increase of drifting towards the end of the channel, due to the decrease of the propeller rotational speed.

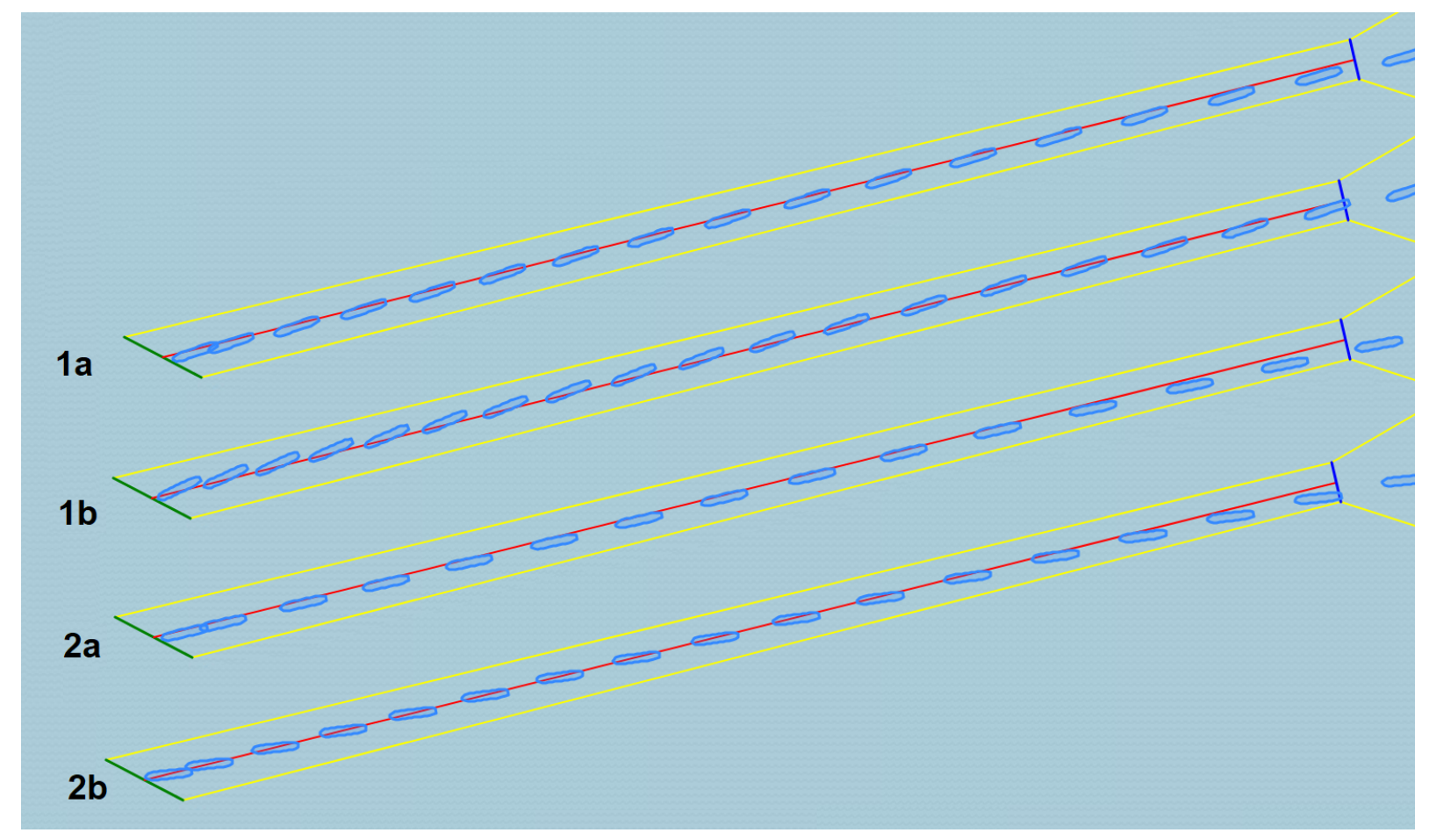

Figure 40: Time-lapse of selected maneuvers in the Suape port, with 2 minute sampling. The number denotes the group number, the letter "a" denotes the medoid for the entire group, and the letter "b" denotes the medoid for the $5 \%$ condition with highest drift. Channel in yellow, start of channel in blue and end of channel in green.

\subsection{Campos Basin}

Another case study is the Campos Basin, situated in the Rio de Janeiro state. The Campos basin is an important site for offshore oil extraction, counting for a large part of Brazilian oil production.

For that basin, there is an available set of environmental conditions directly measured in the region, consisting of 17537 measurements of average wind, current and two waves 
components taken between January $1^{\text {st }} 2004$ and January $1^{\text {st }} 2010$, with a time interval of 3 hours. For the simulations the period between January $1^{\text {st }} 2004$ and December $31^{\text {st }}$ 2006 was used, totaling 5848 cases.

This dataset was obtained by a the application of the models listed in table 10. In order to calibrate the models, measurements of currents, winds and waves were made by sensors installed on the oil platforms in the region.

Table 10: REMO, Portuguese acronym for Oceanographic Modeling and Observation Network; ECMWF: European Centre for Medium-Range Weather Forecasts; and BOMOSHU: Brazil Offshore Metocean Storm Hindcast Update. Source: TANNURI et al. (2020)

\begin{tabular}{|c|c|c|c|}
\hline Parameter & Numerical model & Spatial resolution & Reference \\
\hline Current & REMO & $9 \mathrm{~km}$ & LEWIS (1989) \\
\hline Wind & ECMWF & $7 \mathrm{~km}$ & \\
\hline Wave & BOMOSHU & $7 \mathrm{~km}$ & \\
\hline
\end{tabular}

The simulated maneuver consists of the vessel "Angra dos Reis" from the Aframax class, whose characteristics are shown in table 7 , navigating on open seas in a straigth path with heading $90^{\circ}$, it was defined also a maximum deviation of 100 meters from the desired path for the maneuver to be considered valid. For each environmental condition this maneuver was simulated twice, one with the vessel in ballast condition and the other with it fully loaded in order to compare how the ballast interacts with the maneuver.

After obtaining the automatic pilot parameters for the vessel in ballast condition, shown in table 11, the simulations were carried for all the environmental conditions and the clustering methodology was applied. From the 5848 simulations the vessel has reached the end of the trajectory while maintaning the allowable cross-track error in 5767 cases, and only those cases were considered for the first clustering. The silhouette coefficients for cost functions 4.4, 4.5 and 4.6 are shown in figure 41. The chosen cost function was 4.6 and a number of groups $k=2$ with a silhouette coefficient of 0.599 . 
Table 11: Parameters used for the automatic pilot for the simulations with the vessel Aframax in ballast condition.

\begin{tabular}{|c|l|l|}
\hline Parameter & Value & Unit \\
\hline$\hat{N}_{r}\left(u, v, \omega_{p}\right)$ & 39640 & tf.m \\
\hline$P_{\text {yaw }}$ & 328585 & - \\
\hline$I_{\text {yaw }}$ & 212972 & - \\
\hline$D_{\text {yaw }}$ & 25556618 & - \\
\hline
\end{tabular}

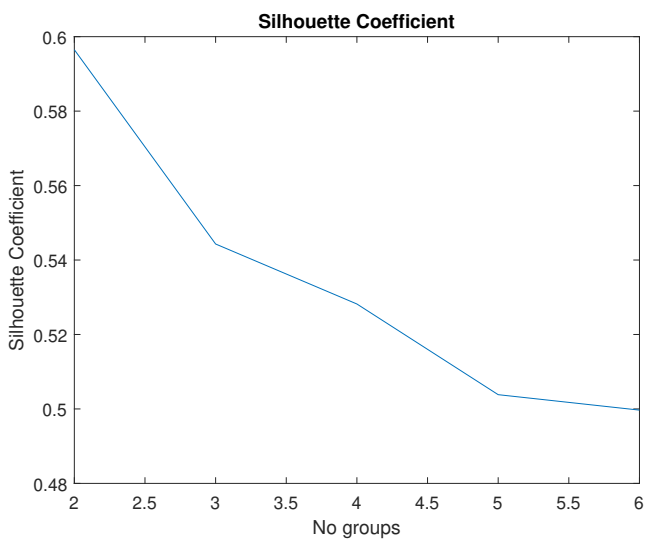

(a) Silhouette coefficients for cost function 4.4.

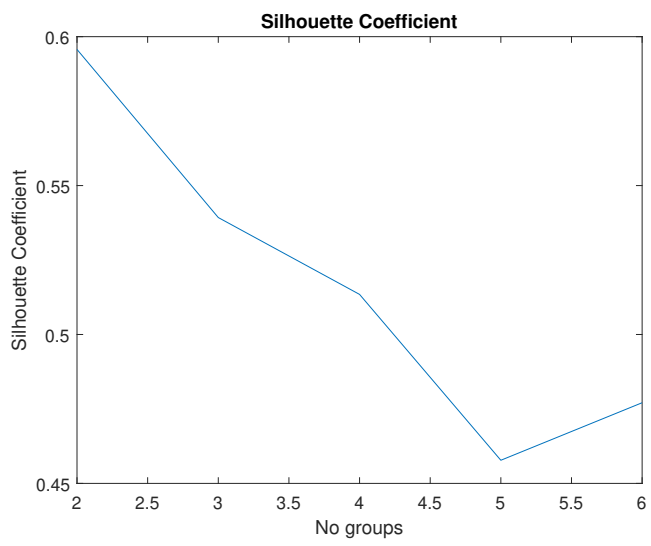

(b) Silhouette coefficients for cost function 4.5.

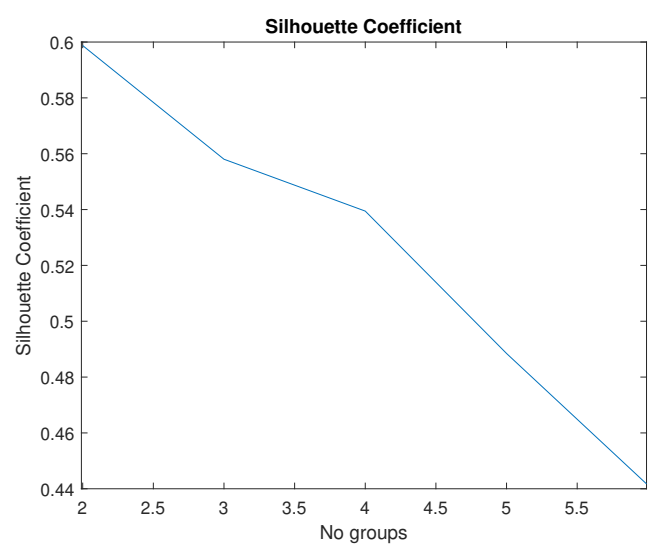

(c) Silhouette coefficients for cost function 4.6.

Figure 41: Silhouette coefficients for Campos basin simulations with vessel in ballast condition.

The same maneuver was made with the vessel fully loaded, with the automatic pilot parameters shown in table 8, and from the 5848 cases, it reached the end of the track within constraints in 5749 cases, the silhouette coefficient curves are shown in figure 42 . The chosen cost function was 4.4 and a number of groups $k=2$ with a silhouette coefficient of 0.554 . 


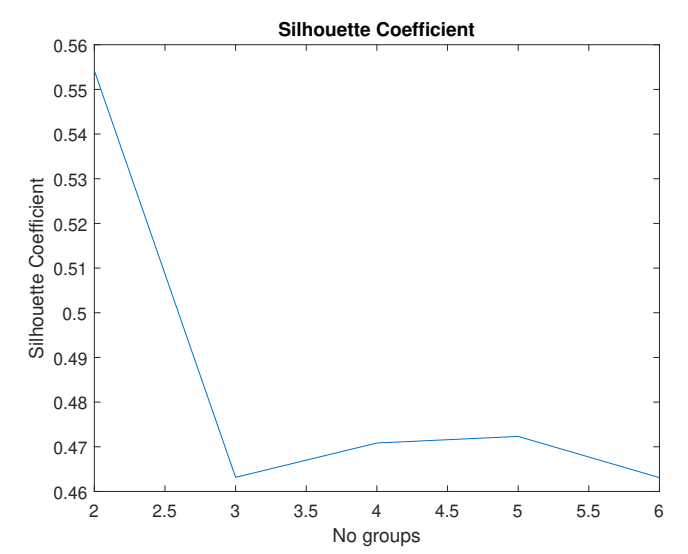

(a) Silhouette coefficients for cost function 4.4.

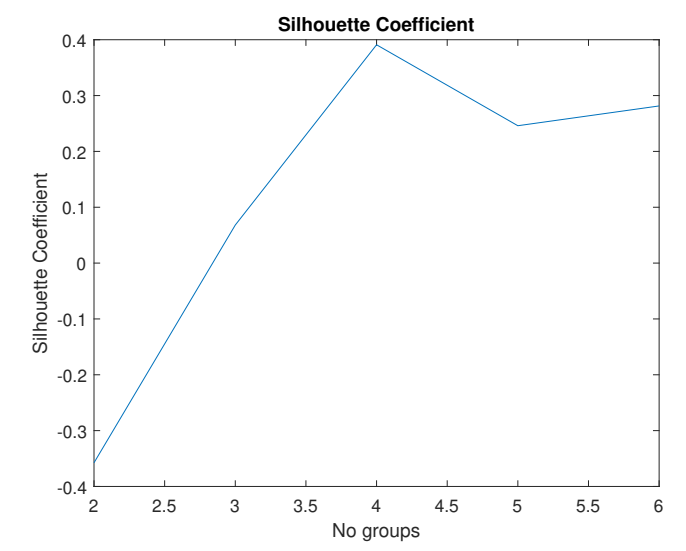

(b) Silhouette coefficients for cost function 4.5.

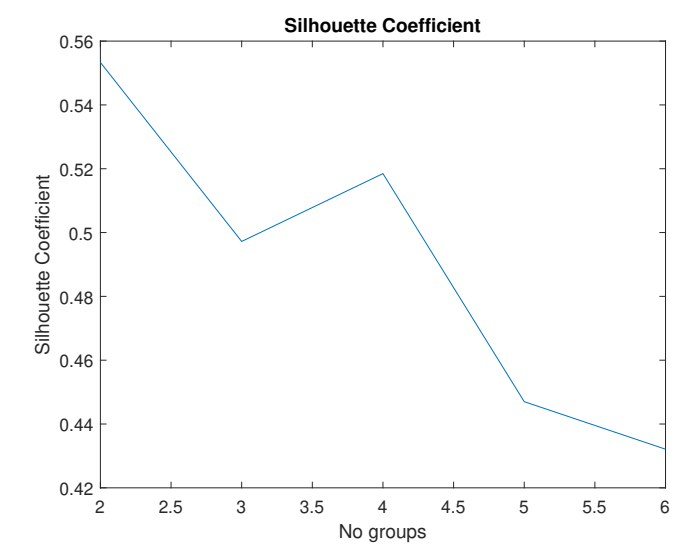

(c) Silhouette coefficients for cost function 4.6.

Figure 42: Silhouette coefficients for Campos basin simulations with vessel in fully loaded condition.

From comparison between the cases where the vessel is fully loaded and the cases where it is in ballast condition, it is possible to notice that the cluster gave better grouping for the maneuvers made in ballast condition. A comparison between the average environmental conditions, as shown in figure 43, reveals that the groups have combinations of winds, waves and currents direction split in a similar way. The mean conditions for the cases with the $5 \%$ highest mean drifting is shown in figure 44 . 


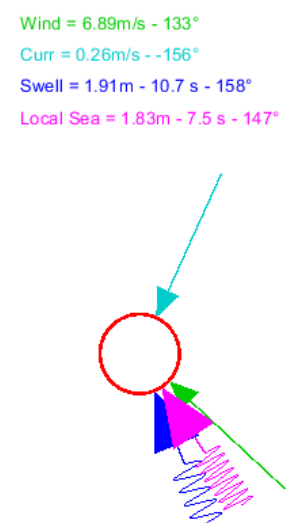

$N^{\circ}$ conditions: 2641

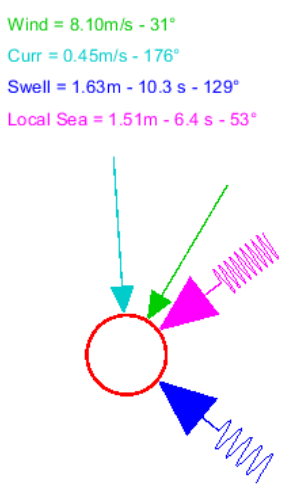

$N^{\circ}$ conditions: 3126

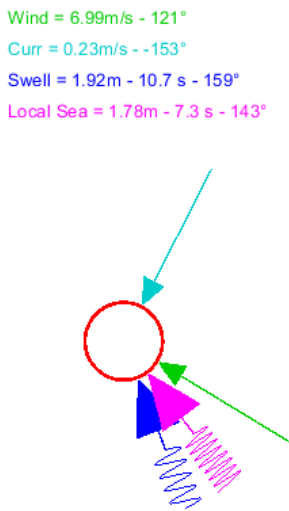

$N^{\circ}$ conditions: 2464

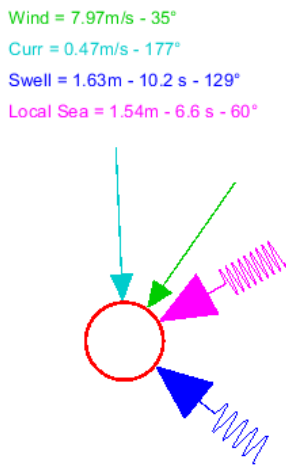

$\mathrm{N}^{\circ}$ conditions: 3285

(a) Mean environmental conditions for groups when the vessel is in ballast condition

(b) Mean environmental conditions for groups when the vessel is fully loaded.

Figure 43: Mean environmental conditions for groups in the Campos basin.

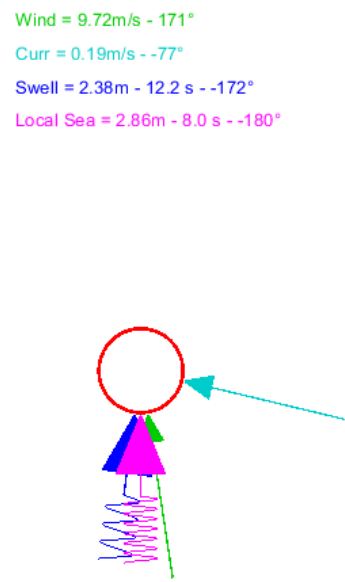

$N^{\circ}$ conditions: 2641

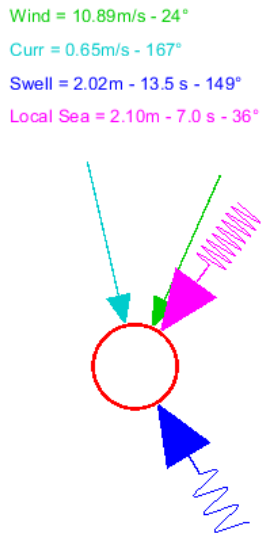

$\mathrm{N}^{\circ}$ conditions: 3126

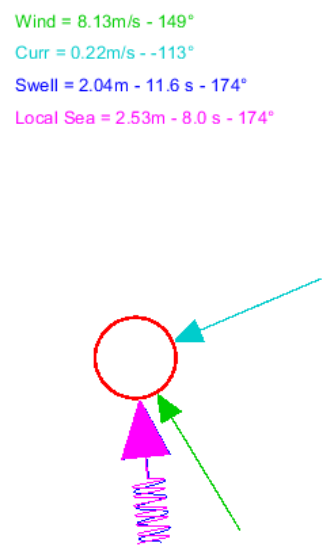

$N^{\circ}$ conditions: 2464

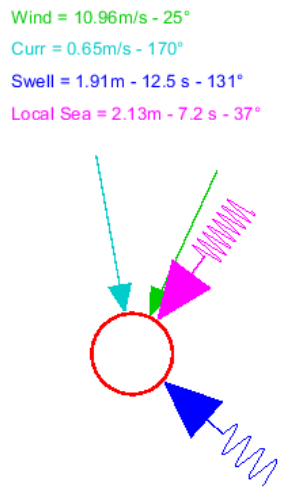

$N^{\circ}$ conditions: 3285

(a) Mean environmental conditions for the cases

(b) Mean environmental conditions for the cases with $5 \%$ highest mean drifting when the vessel is fully loaded. is in ballast condition

Figure 44: Mean environmental conditions for cases with $5 \%$ highest mean drifting for the groups in the Campos basin.

When comparing all the environmental conditions, as shown in figure 45, it is possible to notice how the wind directions are more spread for group 2 in fully loaded condition than it is in group 1 for ballast condition. This effect can possibly be attributed to the fact that the vessel fully loaded has lower surface area exposed to the wind, meaning that the wind effects in the maneuver are less important. It is also possible to notice that the currents and waves have been split in a similar way, with only minor alterations. 
The drifting time-series, shown in figures 46 and 47, also allow the comparison between some aspects of those simulations. The average drifting is lower for the vessel fully loaded. It is also possible that the user defined percentile of $5 \%$ of the largest mean drifting timeseries selects cases with both positive and negative driftings for group 1 in the simulations with the vessel fully loaded.

The division between starboard and portside drifting that occurs in the previous cases analysed also occurs for these simulations in the Campos Basin as shown in figure 48. The simulation with the vessel in ballast condition shows a near zero drift for the cluster medoid 1a due to the incidence of currents from NE (portside bow incidence) and wind and waves incidence from SE (starboard bow incidence). For the medoid for the cases with $5 \%$ highest drifting $(1 \mathrm{~b})$ there is a starboard drift due to the incidence of wind and waves from South (starboard incidence). The simulations $2 \mathrm{a}$ and $2 \mathrm{~b}$ presented an opposite drift angle (to port side) since all the environmental agents, except for the Swell, come from NE (port bow incidence angle). A very similar situation occurs when the vessel is fully loaded. It is also noticeable that the resulting drifting angle is kept at a roughly constant level in contrast to the Tubarão and Suape cases. 

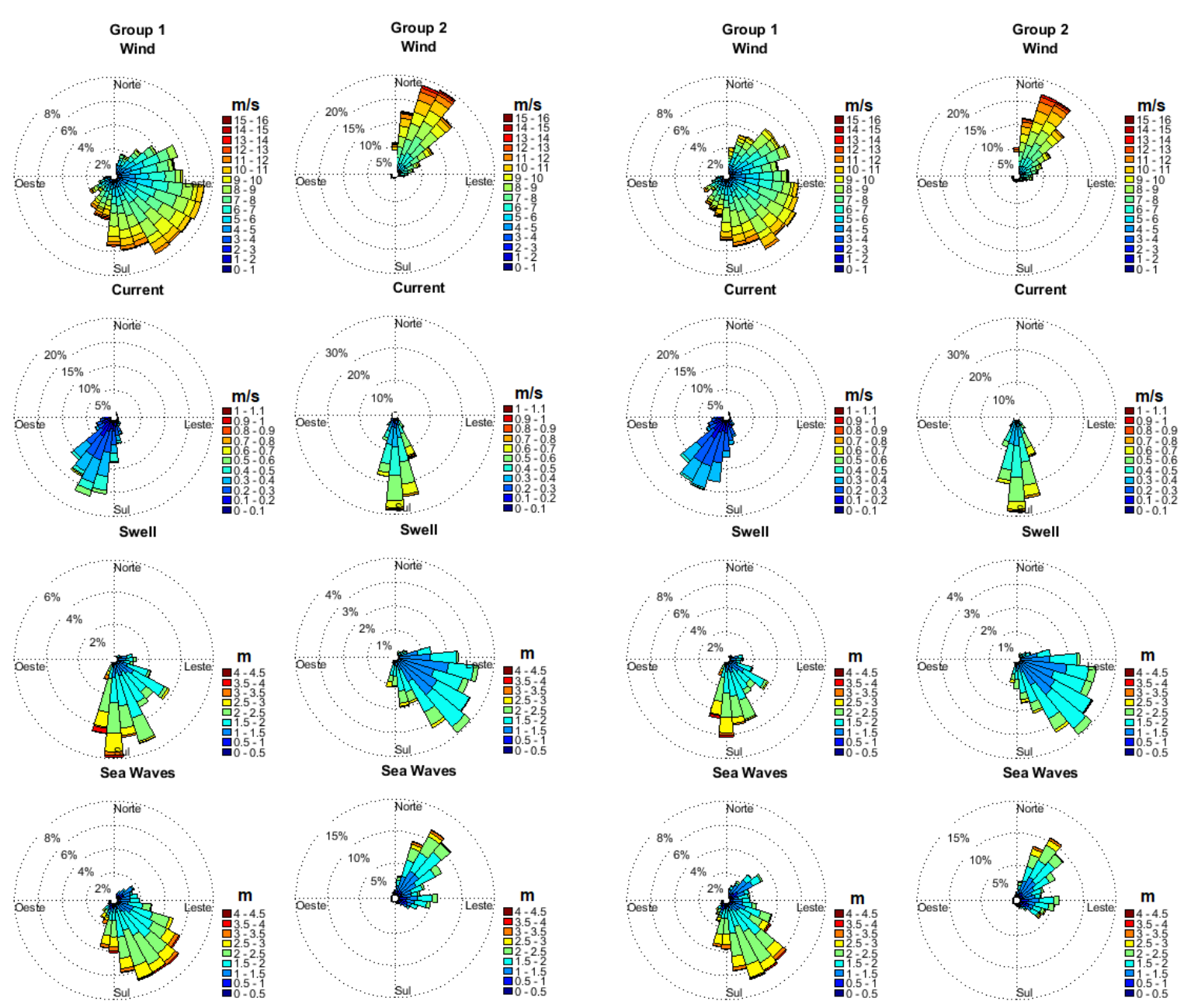

(a) Environmental conditions for groups when the vessel is in ballast condition.

(b) Environmental conditions for groups when the vessel is fully loaded.

Figure 45: Environmental conditions for groups in the Campos basin.

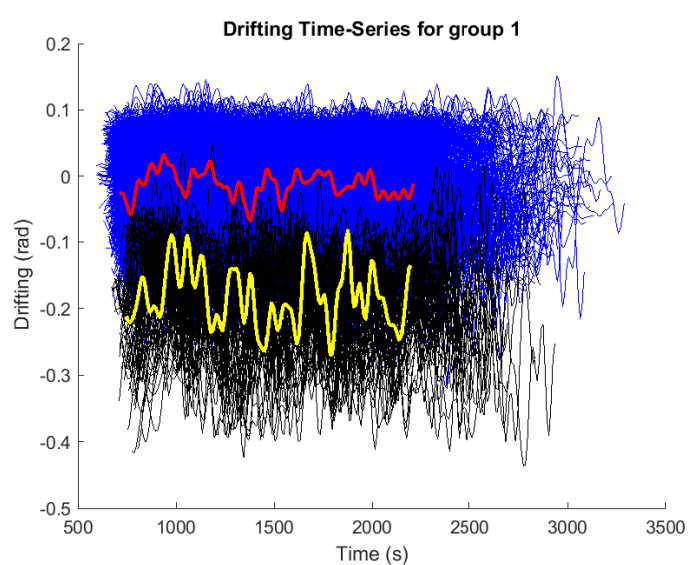

(a) Drifting time-series for the first group for $k=2$ for the vessel in ballast condition.

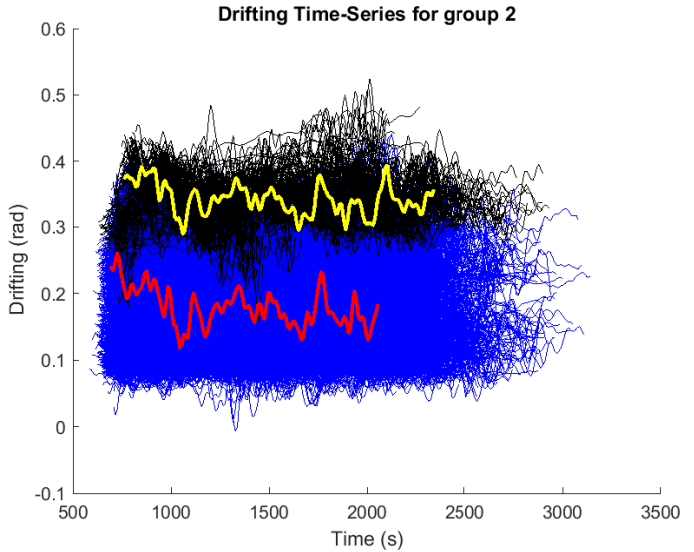

(b) Drifting time-series for the second group for $k=2$ for the vessel in ballast condition.

Figure 46: Drifting time-series for the simulation in ballast condition in the Campos basin. 


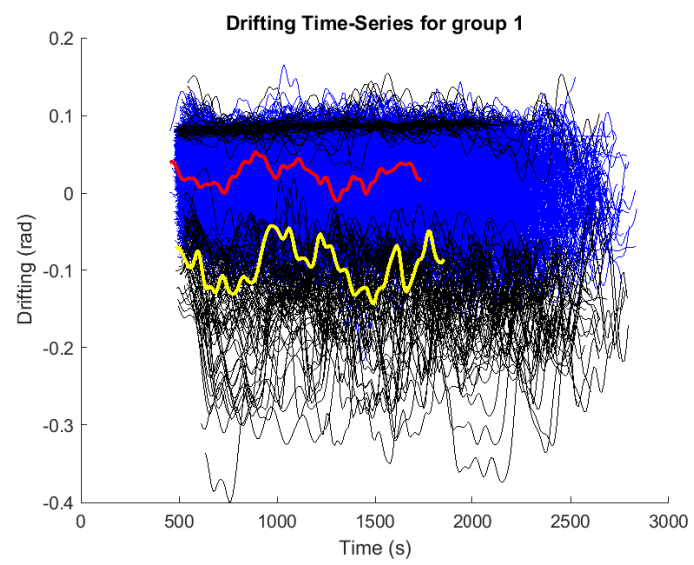

(a) Drifting time-series for the first group for $k=2$ for the vessel fully loaded.

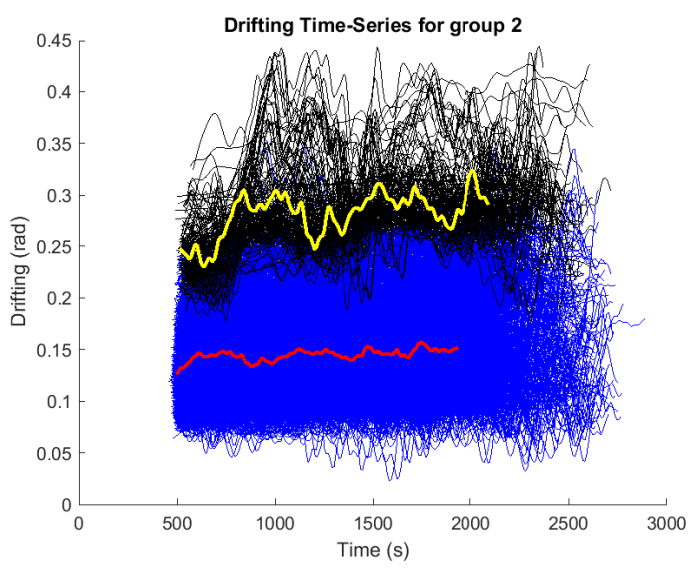

(b) Drifting time-series for the second group for $k=2$ for the vessel fully loaded.

Figure 47: Drifting time-series for the simulation with the vessel fully loaded in the Campos basin. 


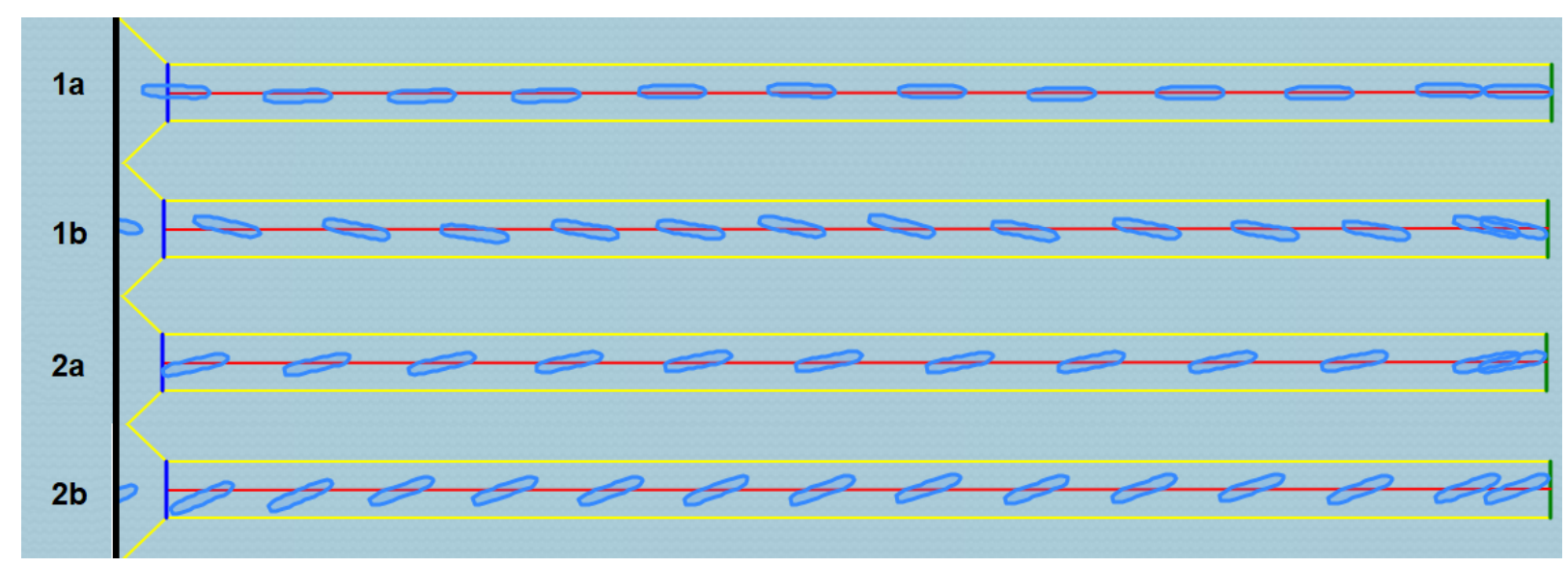

(a) Simulation time-lapse with the vessel in ballast condition

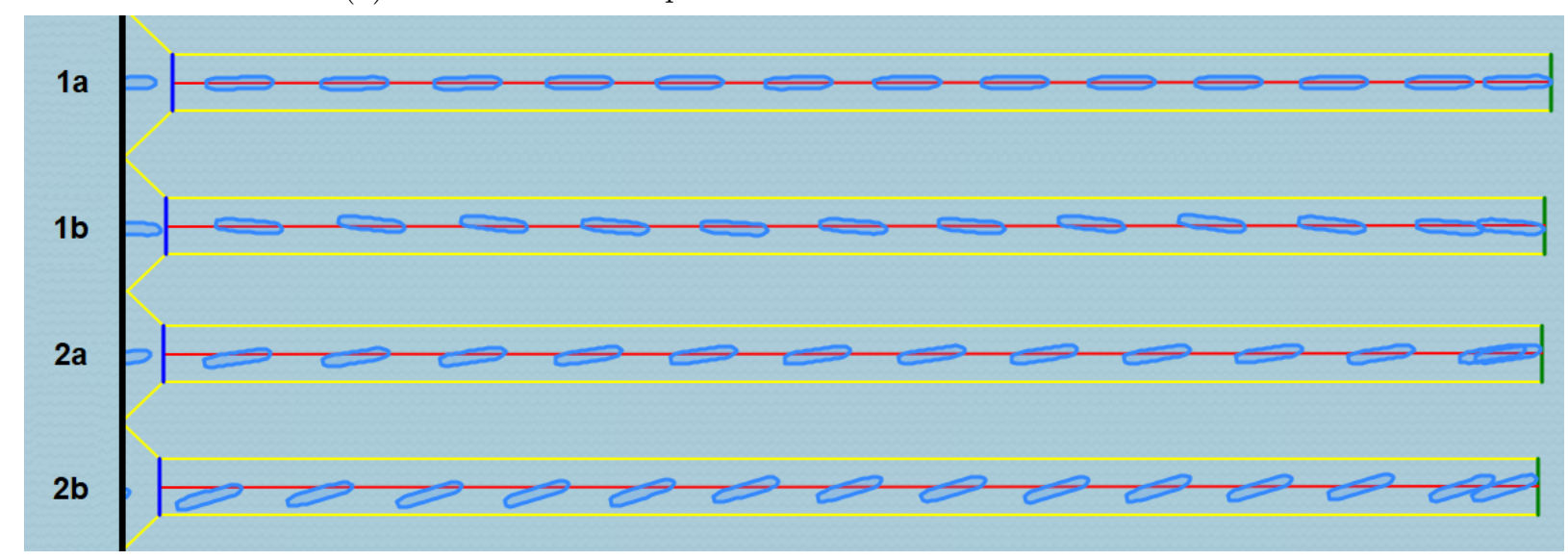

(b) Simulation time-lapse with the vessel fully loaded.

Figure 48: Time-lapse of selected maneuvers in the Campos basin, with 2 minute sampling. The number denotes the group number, the letter "a" denotes the medoid for the entire group, and the letter "b" denotes the medoid for the $5 \%$ condition with highest drift. Maximum allowable cross-track error, only the simulation between the blue and green lines is considered for the clustering. 


\section{EXPERIMENTAL SIMULATIONS}

In order to evaluate the methodology developed in chapter 4 a set of 52 simulations were made in the Full Mission simulator at TPN-USP. In these simulations, the same maneuvers analysed in chapter 5 were made by the second officer Rodrigo Negrizoli da Silva (Officer 1) and deck cadet Gustavo França de Monteiro Mendonça (Officer 2).

For each scenario a set of 8-18 simulations was made, where the officers were instructed to keep the vessel as far as possible from the channel margins, as well as keep a reasonable vessel speed while navigating in the channels. After each simulation a questionnaire was filled by the officer, where the maneuver's difficulty and vessel's drifting felt by the officer were asked. The officers received only information about the approximate direction and intensities of environmental agents in order to help they plan the maneuver. At the end of each set of simulations it was asked how would the officer cluster the simulated cases by similarity. The table 12 was given to the officers as a guideline to classify the perceived maneuver difficulty. In-between and fractional values were also allowed.

Table 12: Qualitative and quantitative difficulty grades used by the officers.

\begin{tabular}{|c|c|}
\hline Qualitative difficulty & Quantitative difficulty \\
\hline Very easy & 0 \\
\hline Easy & 3 \\
\hline Moderate & 5 \\
\hline Hard & 7 \\
\hline Very Hard & 10 \\
\hline
\end{tabular}

It was also evaluated how close to the margin the vessel got during the maneuver. The minimum safe distance is considered to be half of the vessel's beam. This distance is used to quantitatively classify the difficult of the maneuver. If the officer got the vessel closer to the margin than the minimum safety distance but gave a difficulty score lower 
than 7 (Hard), the maneuver difficulty is increased by two points.

The set of environmental conditions used for each scenario uses the environmental conditions extracted from the entire group (coded as letter a), as well as for the cases with highest $5 \%$ (coded as letter $\mathrm{b}$ ) and $1 \%$ (coded as letter $\mathrm{c}$ ) mean drifting angles. The number of the case indicates from which group the case was extracted, the presence of a apostrophe indicates that the case was randomly draw from the respective subdivision, otherwise the case used was the respective medoid.

The results obtained are analysed by the comparisons between the average difficulty grades and drifting. A correlation table is also made with the main variables used for the simulation in order to evaluate if there is any linear relation between these variables and the perceived difficulty. It is noteworthy the fact that the correlation analysis can only find linear relations between the simulations variables.

\subsection{Tubarão Port}

For this port it was simulated the medoid's environmental conditions of the two groups, as well the environmental conditions for the medoids of the $5 \%$ and $1 \%$ cases with highest absolute mean drifting angles. It was also randomly selected two non-medoid conditions for each group. The environmental conditions simulated are shown in table 13. 
Table 13: Environmental conditions used for the Tubarão simulations with officers. The directions follow the convention used for this work (wind and waves incidence angle and currents emission angle).

\begin{tabular}{|c|c|c|c|c|c|c|c|}
\hline \multirow{2}{*}{ Simulation } & \multicolumn{2}{|c|}{ Wind } & \multicolumn{2}{c|}{ Currents } & \multicolumn{3}{c|}{ Waves } \\
\cline { 2 - 8 } & $\begin{array}{c}\text { Velocity } \\
(\mathrm{m} / \mathrm{s})\end{array}$ & Direction & $\begin{array}{c}\text { Velocity } \\
(\mathrm{m} / \mathrm{s})\end{array}$ & Direction & $\begin{array}{c}\mathrm{Hs} \\
(\mathrm{m})\end{array}$ & $\begin{array}{c}\mathrm{Tp} \\
(\mathrm{s})\end{array}$ & Direction \\
\hline $1 \mathrm{a}$ & 3.1 & $239^{\circ}$ & 0.43 & $217^{\circ}$ & 1.94 & 9.9 & $171^{\circ}$ \\
\hline $1 \mathrm{~b}$ & 5.6 & $37^{\circ}$ & 0.69 & $209^{\circ}$ & 1.44 & 8.3 & $199^{\circ}$ \\
\hline $1 \mathrm{c}$ & 6.2 & $47^{\circ}$ & 0.88 & $212^{\circ}$ & 2.06 & 11.0 & $181^{\circ}$ \\
\hline $2 \mathrm{a}$ & 3.2 & $31^{\circ}$ & 0.23 & $3^{\circ}$ & 0.95 & 9.2 & $150^{\circ}$ \\
\hline $2 \mathrm{~b}$ & 7.3 & $180^{\circ}$ & 0.55 & $8^{\circ}$ & 1.56 & 6.3 & $113^{\circ}$ \\
\hline $2 \mathrm{c}$ & 5.1 & $199^{\circ}$ & 0.60 & $20^{\circ}$ & 1.55 & 7.0 & $144^{\circ}$ \\
\hline $1 \mathrm{a}{ }^{\prime}$ & 8.9 & $195^{\circ}$ & 0.20 & $217^{\circ}$ & 2.49 & 13.2 & $109^{\circ}$ \\
\hline $1 \mathrm{~b}$ & 8.1 & $202^{\circ}$ & 0.45 & $214^{\circ}$ & 1.95 & 7.5 & $109^{\circ}$ \\
\hline $2 \mathrm{a}$ & 4.0 & $358^{\circ}$ & 0.11 & $235^{\circ}$ & 0.82 & 7.6 & $178^{\circ}$ \\
\hline $2 \mathrm{~b}$ & 3.8 & $18^{\circ}$ & 0.56 & $6^{\circ}$ & 1.47 & 8.4 & $162^{\circ}$ \\
\hline
\end{tabular}

The results obtained from the questionnaire are shown in table 14. It is possible to notice a partial consistency with the original hypothesis used to develop the methodology, since cases with stronger drifting are considered on average harder. 
Table 14: Questionnaire answers for the Tubarão port simulations. The +2 denotes that the difficulty given by the officer was increased by two points due to the maneuver being carried without a safe distance from the margins.

\begin{tabular}{|c|c|c|c|}
\hline \multicolumn{4}{|c|}{ Maneuvers controlled by Officer 1} \\
\hline Simulation & Difficulty & Drifting (Sway) & Notes \\
\hline $1 \mathrm{a}$ & 3 & Moderate, port & - \\
\hline $1 b$ & 7 & Strong, port & $\begin{array}{l}\text { Many speed corrections were needed } \\
\text { to control the ship's drifting. }\end{array}$ \\
\hline $1 \mathrm{c}$ & 7 & Very strong, port & $\begin{array}{l}\text { Many speed corrections were needed } \\
\text { to control the ship's drifting. }\end{array}$ \\
\hline $2 \mathrm{a}$ & 3 & Weak, starboard & - \\
\hline $2 \mathrm{~b}$ & 5 & Moderate, starboard & $\begin{array}{l}\text { Strong current action on the port } \\
\text { quarter makes the maneuver harder. }\end{array}$ \\
\hline $2 \mathrm{c}$ & $5+2$ & Moderate, starboard & $\begin{array}{l}\text { Strong current action on the port } \\
\text { quarter makes the maneuver harder. }\end{array}$ \\
\hline $1 \mathrm{a}^{\prime}$ & $3+2$ & Moderate, port & - \\
\hline $1 b$ & 3 & Weak, port & - \\
\hline $2 a^{\prime}$ & 0 & Very weak, port & - \\
\hline $2 b^{\prime}$ & 3 & Weak, starboard & - \\
\hline
\end{tabular}

When the Officer 1 was asked how would him separate the simulated cases, he divided them into two groups, according with the perceveid drifting direction (starboard or port) as shown in table 15. The clustering provided by the officer for this batch of simulations agrees with the one made by the algorithm, except that the boundary between the two groups made by the algorithm is not situated at zero drifting.

Table 15: Officer classification of the simulated cases for the Tubarão port into bins.

\begin{tabular}{|c|c|c|}
\hline \multicolumn{3}{|c|}{ Clustering made by Officer 1} \\
\hline Simulation group & Criteria given by the officer & Cases \\
\hline 1 & Port drifting & $1 \mathrm{a}, 1 \mathrm{~b}, 1 \mathrm{c}, 1 \mathrm{a}$, , 1b', 2a' \\
\hline 2 & Starboard drifting & $2 \mathrm{a}, 2 \mathrm{~b}, 2 \mathrm{c}, 2 \mathrm{~b}$ \\
\hline
\end{tabular}

Two examples of the simulations $1 \mathrm{a}$ and $2 \mathrm{c}$ are shown in figure 49. These two simula- 
tions were selected because they represent the two extremes of simulations. In simulation 1a, it was kept a safe distance during the whole simulation, never smaller than 70 meters, while in simulation $2 \mathrm{c}$ for the most part the vessel navigated too close to the channel margins, reaching a critical minimum distance of 5 meters.

Keeping a close distances to the channel margins while navigating is considered a factor that makes the maneuver unviable because there is no room left for an emergency maneuver since any change in the vessel's heading can cause its bow or stern to cross the dredged section of the channel and run aground.

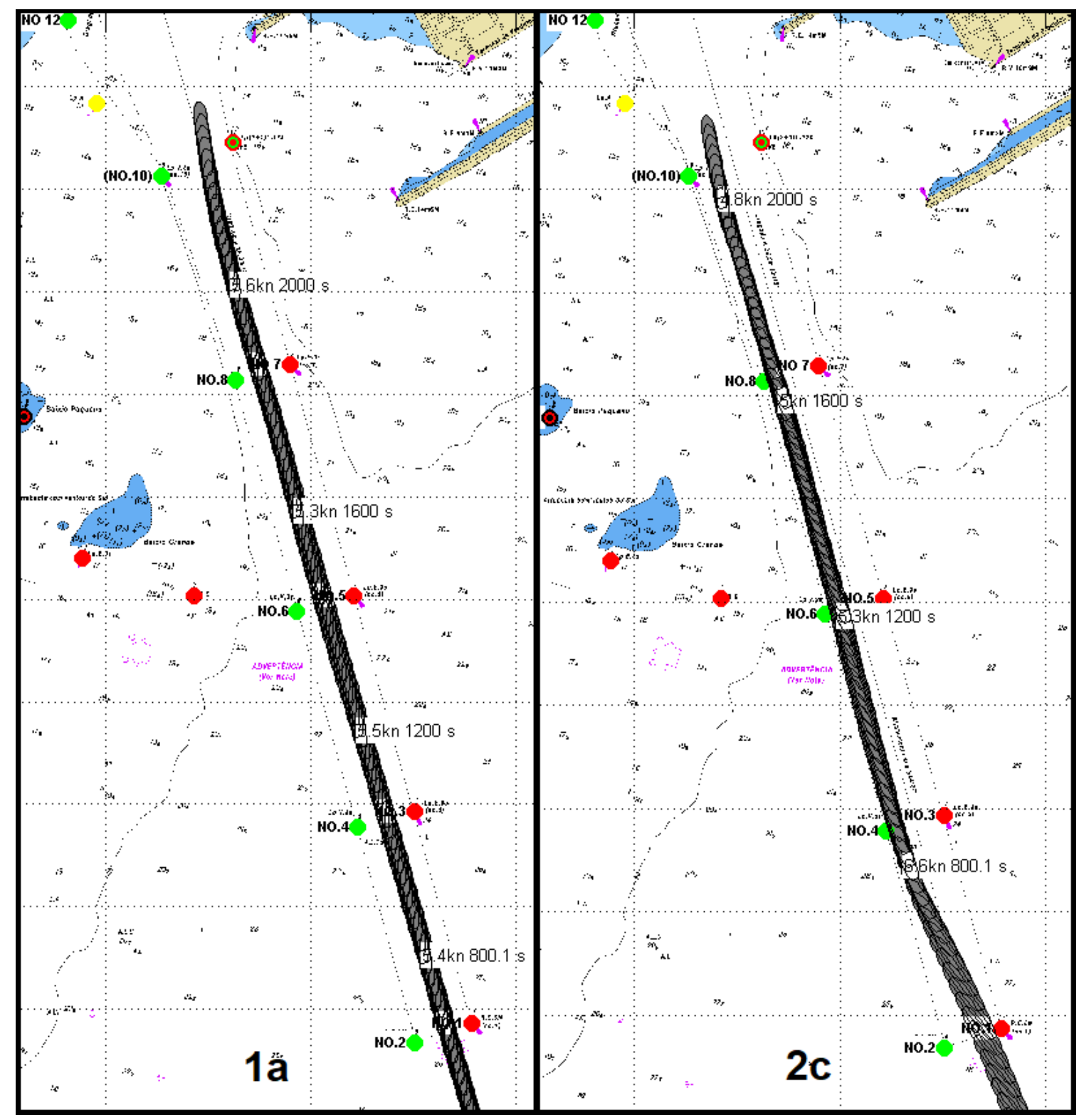

Figure 49: Time-lapse of selected Tubarão maneuvers made by the Officer 1 . On the left is the simulation with moderate conditions $1 \mathrm{a}$, on the right is the simulation with extreme conditions, 2c. 
In order to evaluate what are the factors that influence the maneuver difficulty (and if the drifting angle is a good difficulty predictor), the correlation table 16 was made measuring the correlations between the perceived difficulty of the maneuver and the maneuver parameters. The order the simulations were made is added as a parameter in order to analyse if there is a learning curve in the course of simulations. The statistical significance column shows the p-value for the correlations, where usually in order for the correlation to be statistically significant the p-value must be smaller than 0.05 .

Table 16: Correlations and statistical significance between the perceived maneuver difficulty and the simulations parameters for the Tubarão port.

\begin{tabular}{|c|l|l|}
\hline Simulation Parameter & Correlation with Difficulty & Statistical Significance \\
\hline Order of simulation & -0.484 & 0.156 \\
\hline Average drifting angle & 0.716 & 0.020 \\
\hline Average roll perturbation & 0.749 & 0.013 \\
\hline Average yaw perturbation & 0.410 & 0.239 \\
\hline RoT average perturbation & 0.273 & 0.445 \\
\hline Current transverse speed & 0.680 & 0.030 \\
\hline Wind transverse speed & 0.850 & 0.002 \\
\hline Wave incidence angle & -0.043 & 0.906 \\
\hline
\end{tabular}

It was found a moderate negative correlation between the order of simulation and difficulty, what suggests some sort of learning happening during the simulation. It was also found that higher average drifting, roll perturbations, stronger currents and wind speeds increase the maneuver difficulty. In order to aid the visualization of the correlation between the drifting angle and the difficulty, the image 54 was assembled, where the increase in the mean difficulty follows an increase in the mean drifting angle. 


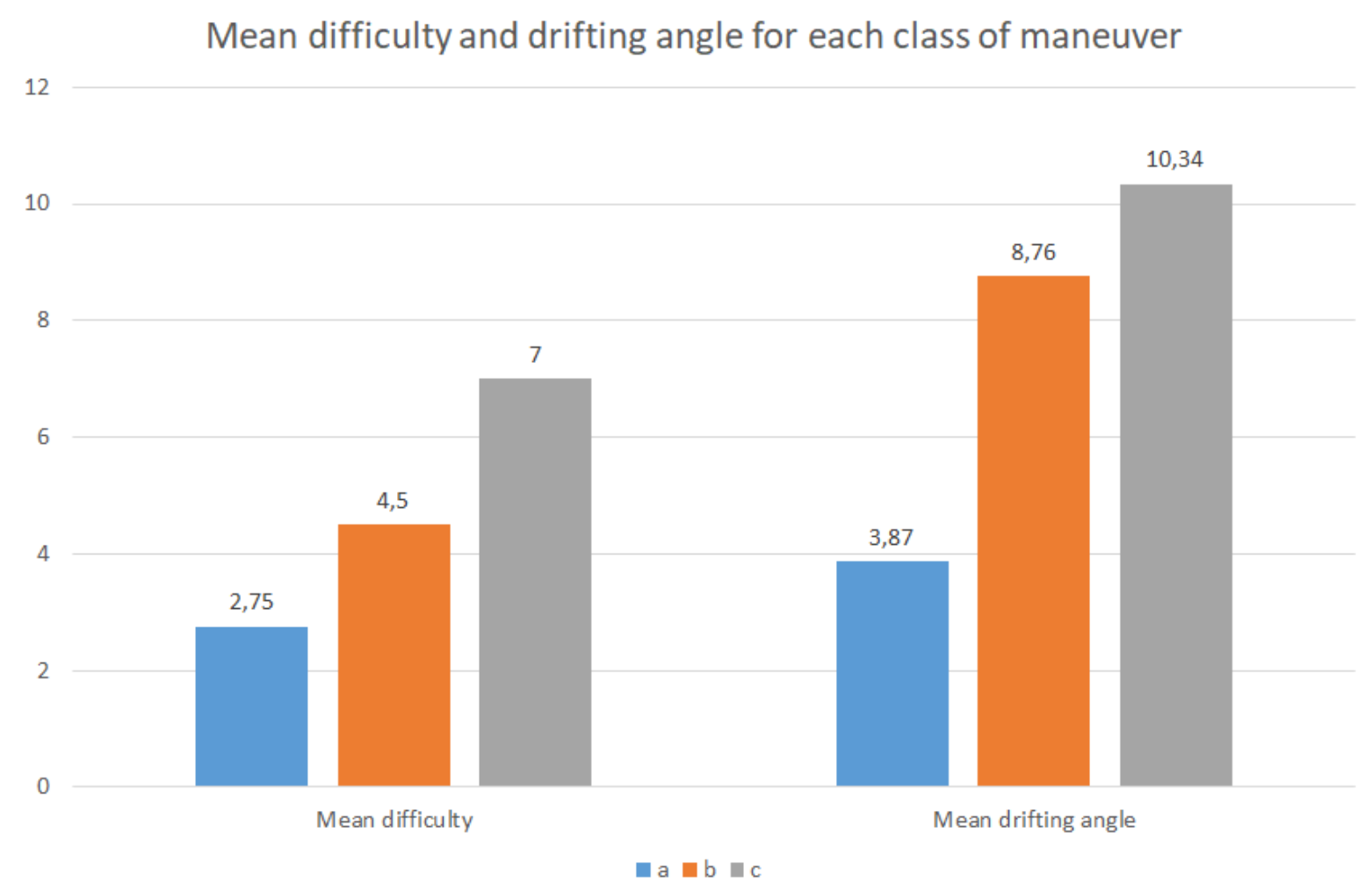

Figure 50: Mean difficulty and drifting angle for simulations in Tubarão.

\subsection{Suape Port}

For this port, the simulated environmental conditions were the medoid's environmental conditions of the two groups, as well the environmental conditions for the medoids of the $5 \%$ and $1 \%$ cases with highest absolute mean drifting angles. It was also randomly selected two non-medoid conditions for each group. The environmental conditions simulated are shown in table 17 . The vessel started those simulations at $8 \mathrm{kn}$ and reach the end of the channel having at most $5 \mathrm{kn}$. 
Table 17: Environmental conditions used for the Suape simulations with officers. The arrow $(\nearrow)$ denotes the direction of the environmental agent.

\begin{tabular}{|c|c|c|c|c|c|c|c|c|c|c|}
\hline \multirow[t]{2}{*}{ Simulation } & \multicolumn{2}{|c|}{ Wind } & \multicolumn{2}{|c|}{ Currents } & \multicolumn{3}{|c|}{$1^{\text {st }}$ Wave } & \multicolumn{3}{|c|}{$2^{\text {nd }}$ Wave } \\
\hline & $\begin{array}{c}\text { Velocity } \\
(\mathrm{m} / \mathrm{s})\end{array}$ & $\nearrow$ & $\begin{array}{c}\text { Velocity } \\
(\mathrm{m} / \mathrm{s})\end{array}$ & $\nearrow$ & $\begin{array}{l}\mathrm{Hs} \\
(\mathrm{m})\end{array}$ & $\begin{array}{l}\mathrm{Tp} \\
(\mathrm{s})\end{array}$ & $\nearrow$ & $\begin{array}{l}\mathrm{Hs} \\
(\mathrm{m})\end{array}$ & $\begin{array}{l}\mathrm{Tp} \\
(\mathrm{s})\end{array}$ & $\nearrow$ \\
\hline $1 \mathrm{a}$ & 3.4 & 130 & 0.25 & 10 & 1.64 & 9.2 & 115 & 0 & 0 & 0 \\
\hline $1 b$ & 5.3 & 119 & 0.45 & 16 & 0.41 & 12.4 & 165 & 1.43 & 7.2 & 125 \\
\hline $1 \mathrm{c}$ & 5.4 & 142 & 0.49 & 16 & 0.51 & 10.4 & 165 & 1.36 & 8.6 & 115 \\
\hline $2 \mathrm{a}$ & 3.8 & 140 & 0.19 & 199 & 2.18 & 10.4 & 125 & 0 & 0 & 0 \\
\hline $2 b$ & 6.0 & 130 & 0.33 & 199 & 2.25 & 10.4 & 125 & 0 & 0 & 0 \\
\hline $2 c$ & 3.5 & 55 & 0.49 & 196 & 1.30 & 15.8 & 65 & 0.49 & 11.7 & 165 \\
\hline $1 a^{\prime}$ & 3.9 & 8 & 0.43 & 10 & 0.61 & 14.8 & 55 & 1.03 & 7.2 & 115 \\
\hline $1 b^{\prime}$ & 3.4 & 40 & 0.46 & 13 & 0.33 & 15.7 & 55 & 1.22 & 8.1 & 115 \\
\hline $2 a^{\prime}$ & 2.1 & 92 & 0.12 & 2 & 0.47 & 11.0 & 125 & 1.28 & 7.7 & 115 \\
\hline $2 b^{\prime}$ & 3.0 & 49 & 0.38 & 193 & 0.42 & 14.0 & 165 & 1.66 & 8.1 & 105 \\
\hline
\end{tabular}

It was found that the waves made the maneuver $2 \mathrm{~b}$ speciously harder accordingly to Officer 1, despite the presence of an almost identical wave in the case 2a, what can indicate that a the combination of a strong wave with high drifting increases the perceived difficulty more than only strong drifting.

The figure 51, shows a comparison between a case with low drifting and one with higher drifting. 
Table 18: Questionnaire answers for the Suape port simulations made by officers.

\begin{tabular}{|c|c|c|c|}
\hline \multicolumn{4}{|c|}{ Maneuvers Controlled by Officer 1} \\
\hline Simulation & Difficulty & Drifting (Sway) & Notes \\
\hline $1 \mathrm{a}$ & 3 & Weak, starboard & - \\
\hline $1 \mathrm{~b}$ & 5 & Moderate, starboard & - \\
\hline $1 \mathrm{c}$ & 5 & Moderate, starboard & - \\
\hline $2 \mathrm{a}$ & 5 & Moderate, port & - \\
\hline $2 \mathrm{~b}$ & 7 & Strong, port & $\begin{array}{l}\text { Strong waves makes course keeping } \\
\text { hard, currents action on the stern } \\
\text { makes speed reduction harder. }\end{array}$ \\
\hline $2 \mathrm{c}$ & $3+2$ & Moderate, port & $\begin{array}{l}\text { Waves period and direction makes } \\
\text { the maneuver easier. }\end{array}$ \\
\hline $1 a^{\prime}$ & 3 & Weak, starboard & - \\
\hline $1 b^{\prime}$ & 0 & Weak, starboard & - \\
\hline $2 \mathrm{a}^{\prime}$ & 0 & Weak, starboard & - \\
\hline $2 b^{\prime}$ & 3 & Weak, port & - \\
\hline \multicolumn{4}{|c|}{ Maneuvers Controlled by Officer 2} \\
\hline $1 \mathrm{a}$ & 4 & Starboard & $\begin{array}{c}\text { Easy maneuver } \\
\text { Negligible perturbation from } \\
\text { environmental conditions. }\end{array}$ \\
\hline $1 b$ & 4 & Starboard & $\begin{array}{c}\text { Easy maneuver, but at the end } \\
\text { of the channel the stern drifted to } \\
\text { starboard, demanding an increase in } \\
\text { the rudder angle and } \\
\text { a dead slow ahead machine }\end{array}$ \\
\hline $2 \mathrm{a}$ & 4 & Port & $\begin{array}{c}\text { Easy maneuver } \\
\text { no alterations }\end{array}$ \\
\hline $2 \mathrm{~b}$ & 4.5 & Port & $\begin{array}{l}\text { Easy maneuver, with slight } \\
\text { influence from currents and wind }\end{array}$ \\
\hline $1 a^{\prime}$ & 5 & Starboard & $\begin{array}{c}\text { Easy maneuver, with slight } \\
\text { influence from currents }\end{array}$ \\
\hline $1 b^{\prime}$ & 5 & Starboard & $\begin{array}{c}\text { Easy maneuver, with slight } \\
\text { influence from currents }\end{array}$ \\
\hline
\end{tabular}


When Officer 1 was asked how would him cluster the simulations, the criteria shown in table 19 was given. The maneuvers were divided into two groups using the same criteria used for the Tubarão port, the drifting angle.

Table 19: Officer 1 classification of the simulated cases for the Suape port.

\begin{tabular}{|c|c|c|}
\hline \multicolumn{3}{|c|}{ Clustering made by Officer 1} \\
\hline Simulation group & Criteria given by the officer & Cases \\
\hline 1 & Starboard drifting & $1 \mathrm{a}, 1 \mathrm{~b}, 1 \mathrm{c}, 1 \mathrm{a}$, , 1b', 2a' \\
\hline 2 & Port drifting & $2 \mathrm{a}, 2 \mathrm{~b}, 2 \mathrm{c}, 2 \mathrm{~b}$ \\
\hline
\end{tabular}

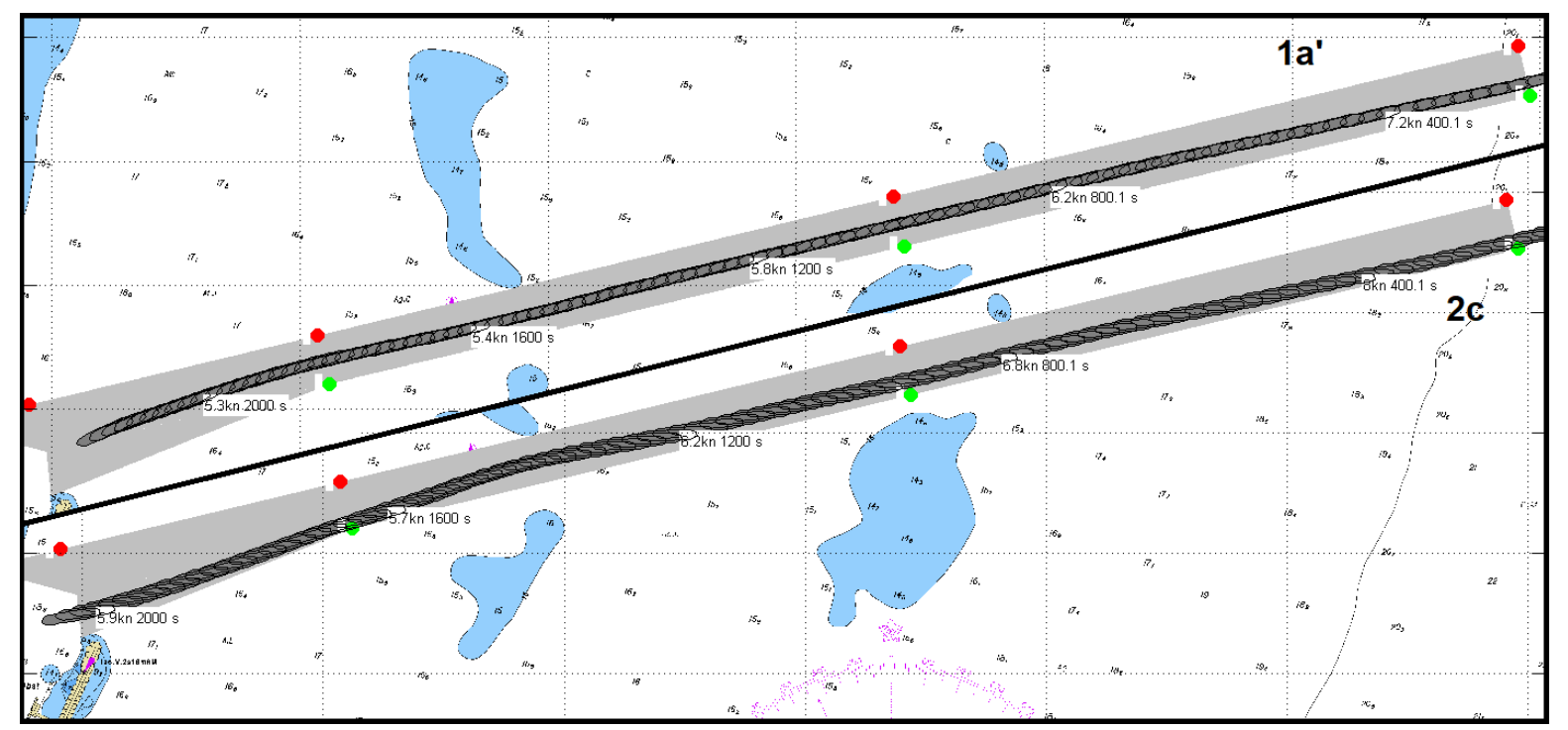

Figure 51: Time-lapse of selected Suape maneuvers made by Officer 1. On the top is the simulation with moderate conditions 1a', on the bottom is the simulation with extreme conditions, 2c.

By calculating the correlations, shown in table 20, it was found a discrepancy between the two officers. While there is a negative correlation between the difficulty and the order of simulation for the Officer 1 (that can indicate a learning curve during the simulations), the correlation is strongly positive for the Officer 2. The drifting angle apparently has no impact on the difficulty felt by the Officer 1, and despite the moderate correlation found for the Officer 2, it still isn't possible to confirm it due to the low statistical significance. A comparison between the average drifting angle, difficulty and all the cases simulated is shown in figure 52, and it shows a small increase in mean difficulty as the mean drifting increases. 
Table 20: Correlations and statistical significance between the perceived maneuver difficulty and the simulations parameters for the Suape port.

\begin{tabular}{|c|c|c|}
\hline Simulation Parameter & Correlation w/ Difficulty(Statistical Significance) \\
\hline & Officer $\mathbf{1}$ & Officer $\mathbf{2}$ \\
\hline Order of simulation & $-0.6862(0.028)$ & $0.924(0.008)$ \\
\hline Drifting & $0.061(0.688)$ & $0.528(0.282)$ \\
\hline Average roll perturbation & $0.523(0.121)$ & $-0.138(0.795)$ \\
\hline Average yaw perturbation & $0.508(0.134)$ & $-0.579(0.228)$ \\
\hline RoT average perturbation & $0.515(0.128)$ & $-0.070(0.895)$ \\
\hline Current transverse speed & $0.145(0.690)$ & $0.688(0.131)$ \\
\hline Wind transverse speed & $0.736(0.015)$ & $-0.368(0.473)$ \\
\hline Wave incidence angle & $0.523(0.121)$ & $-0.829(0.042)$ \\
\hline
\end{tabular}

\section{Mean difficulty and drifting angle for each class of maneuver}

12

10

8

6

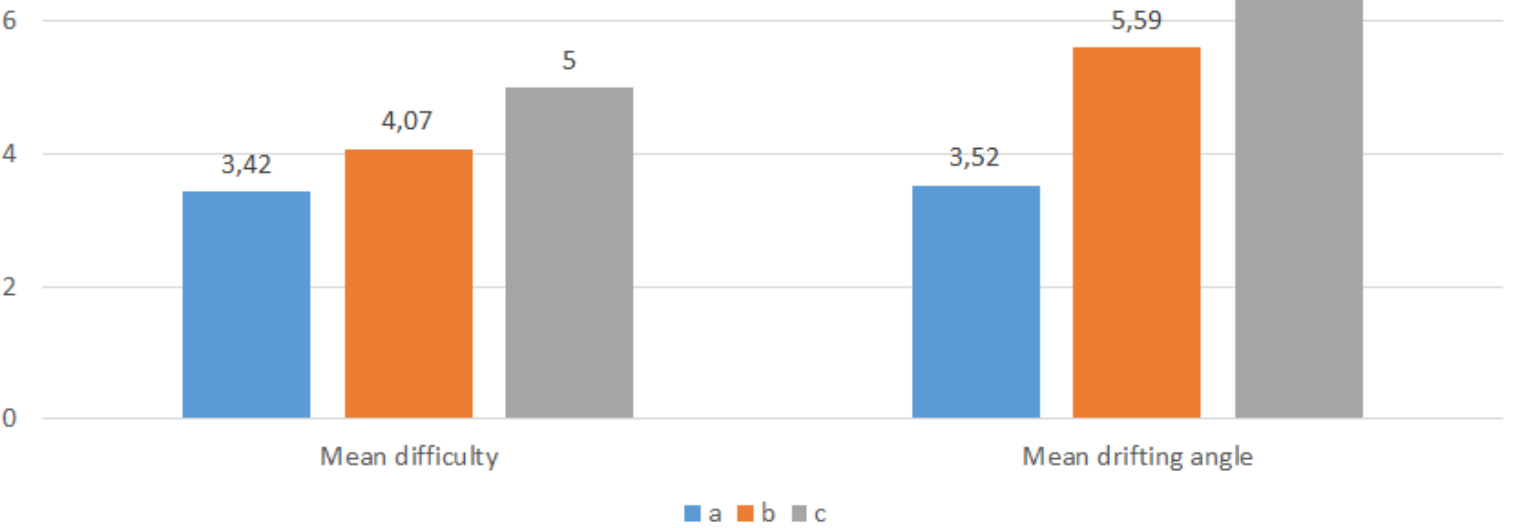

Figure 52: Mean difficulty and drifting angle for simulations in Suape. 


\subsection{Campos Basin: Fully Loaded Vessel}

Since the notes about the previous simulations indicates that the wave influences the maneuver's difficulty, a different approach was made for the Campos basin: a set of new medoids was obtained, using a constraint that they must have similar wave heights. The selected medoids have between 2.0 and 2.6 meters significant wave heights. These new medoids were obtained for the same groups obtained in chapter 5 , as well as for the $5 \%$ and $1 \%$ cases with highest absolute mean drifting angles in each group. The environmental conditions used are shown in table 21.

Table 21: Environmental conditions used for the Campos simulations with officers. The arrow $(\nearrow)$ denotes the direction of the environmental agent.

\begin{tabular}{|c|c|c|c|c|c|c|c|c|c|c|}
\hline \multirow[t]{2}{*}{ Simulation } & \multicolumn{2}{|c|}{ Wind } & \multicolumn{2}{|c|}{ Currents } & \multicolumn{3}{|c|}{$1^{\text {st }}$ Wave } & \multicolumn{3}{|c|}{$2^{\text {nd }}$ Wave } \\
\hline & $\begin{array}{c}\text { Velocity } \\
(\mathrm{m} / \mathrm{s})\end{array}$ & $\nearrow$ & $\begin{array}{c}\text { Velocity } \\
(\mathrm{m} / \mathrm{s})\end{array}$ & $\nearrow$ & $\begin{array}{l}\mathrm{Hs} \\
(\mathrm{m})\end{array}$ & $\begin{array}{l}\mathrm{Tp} \\
(\mathrm{s})\end{array}$ & $\nearrow$ & $\begin{array}{l}\mathrm{Hs} \\
(\mathrm{m})\end{array}$ & $\begin{array}{l}\mathrm{Tp} \\
(\mathrm{s})\end{array}$ & $\nearrow$ \\
\hline $1 \mathrm{a}$ & 10.1 & 230 & 0.26 & 201 & 2.34 & 8.1 & 197 & 0 & 0 & 0 \\
\hline $1 b$ & 6.8 & 187 & 0.21 & 355 & 2.42 & 14.1 & 194 & 0 & 0 & 0 \\
\hline $1 \mathrm{c}$ & 5.8 & 145 & 0.26 & 340 & 2.52 & 11.2 & 182 & 0 & 0 & 0 \\
\hline $2 \mathrm{a}$ & 10.3 & 12 & 0.52 & 183 & 2.04 & 6.3 & 22 & 1.36 & 10.7 & 176 \\
\hline $2 b$ & 12.6 & 6 & 0.70 & 166 & 2.46 & 7.0 & 16 & 0.51 & 15.6 & 145 \\
\hline $2 \mathrm{c}$ & 11.4 & 27 & 0.75 & 167 & 2.42 & 7.2 & 31 & 0.49 & 14.0 & 192 \\
\hline $1 a^{\prime}$ & 5.3 & 121 & 0.13 & 216 & 2.24 & 12.7 & 133 & 0 & 0 & 0 \\
\hline $1 b^{\prime}$ & 8.5 & 102 & 0.33 & 204 & 2.30 & 6.2 & 108 & 0 & 0 & 0 \\
\hline $2 a^{\prime}$ & 7.1 & 52 & 0.60 & 166 & 2.20 & 10.8 & 111 & 1.28 & 5.2 & 50 \\
\hline $2 b^{\prime}$ & 7.7 & 47 & 0.60 & 164 & 2.11 & 10.8 & 112 & 1.50 & 5.6 & 48 \\
\hline
\end{tabular}

As in the other scenarios simulated, a questionnaire is filled by the officers after ever simulation, the questionnaire answers are shown in table 22. It is possible to notice a trend similar to the one found for the Tubarão simulations, where the overall perceived difficulty increases for simulations where the environmental conditions produces a larger drifting. 
Table 22: Questionnaire answers for the Campos Basin simulations made by the officers with the vessel fully loaded.

\begin{tabular}{|c|c|c|c|}
\hline \multicolumn{4}{|c|}{ Maneuvers controlled by Officer 1} \\
\hline Simulation & Difficulty & Drifting (Sway) & Notes \\
\hline $1 \mathrm{a}$ & 5 & Weak, starboard & - \\
\hline $1 b$ & $3+2$ & Weak, port & - \\
\hline $1 \mathrm{c}$ & $5+2$ & Moderate, port & - \\
\hline $2 \mathrm{a}$ & $5+2$ & Moderate, starboard & - \\
\hline $2 \mathrm{~b}$ & 7 & Moderate, starboard & - \\
\hline $2 \mathrm{c}$ & 10 & Strong, starboard & - \\
\hline $1 a^{\prime}$ & 3 & Weak, starboard & - \\
\hline $1 b^{\prime}$ & 3 & Weak, starboard & - \\
\hline $2 a^{\prime}$ & 3 & Moderate, starboard & - \\
\hline $2 b^{\prime}$ & 5 & Moderate, starboard & - \\
\hline \multicolumn{4}{|c|}{ Maneuvers controlled by Officer 2} \\
\hline $1 \mathrm{a}$ & 5 & Starboard & Winds and currents tolerable. \\
\hline $1 b$ & 7 & Starboard & $\begin{array}{c}\text { Winds and currents interfered } \\
\text { with the vessel's manoeuvrability. } \\
\text { Maneuver failed. }\end{array}$ \\
\hline $1 b$ & 5 & Starboard & $\begin{array}{l}\text { Winds and currents tolerable. } \\
\text { Second attempt. }\end{array}$ \\
\hline $1 \mathrm{c}$ & 5 & Starboard & Winds and currents tolerable. \\
\hline $2 \mathrm{a}$ & 7 & Port & $\begin{array}{l}\text { Winds destabilized the vessel, } \\
\text { some kicks-ahead were used resulting } \\
\text { in a slight increase in the vessel's speed. }\end{array}$ \\
\hline $2 b$ & 9 & Port & $\begin{array}{l}\text { Strong winds destabilized the vessel, } \\
\text { some kicks-ahead were used but } \\
\text { there was no significant increase in } \\
\text { vessel's speed. }\end{array}$ \\
\hline $2 \mathrm{c}$ & 9.5 & Port & $\begin{array}{l}\text { Lost the control of the vessel } \\
\text { due to strong currents. } \\
\text { Maneuver failed. }\end{array}$ \\
\hline $2 \mathrm{c}$ & 9 & Port & $\begin{array}{l}\text { Strong winds destabilized the vessel, } \\
\text { some kicks-ahead were used but } \\
\text { there was no significant increase in } \\
\text { vessel's speed. Second attempt. }\end{array}$ \\
\hline
\end{tabular}


The Officer 1 clustered the simulations accordingly to table 23. The cases were divided accordingly with the perceived effect of the waves, as shown in table 23 . This might be due to the high significant height of waves in the selected cases for the simulations associated with their incidence angle. Cases with a stronger perceived wave effect have waves which the average direction is closer to the vessel's beams. An example of simulations time-lapse is shown in figure 53 .

Table 23: Officer 1 classification of the simulated cases for the Campos basin, vessel fully loaded.

\begin{tabular}{|c|c|c|}
\hline \multicolumn{3}{|c|}{ Clustering made by Officer 1} \\
\hline Simulation group & Criteria given by the officer & Cases \\
\hline 1 & Stronger wave effects & $1 \mathrm{a}, 1 \mathrm{~b}, 1 \mathrm{c}, 2 \mathrm{a}, 2 \mathrm{~b}, 2 \mathrm{c}$ \\
\hline 2 & Weaker wave effects & $1 \mathrm{a}^{\prime}, 1 \mathrm{~b}, 2 \mathrm{a}, 2 \mathrm{~b}$ \\
\hline
\end{tabular}

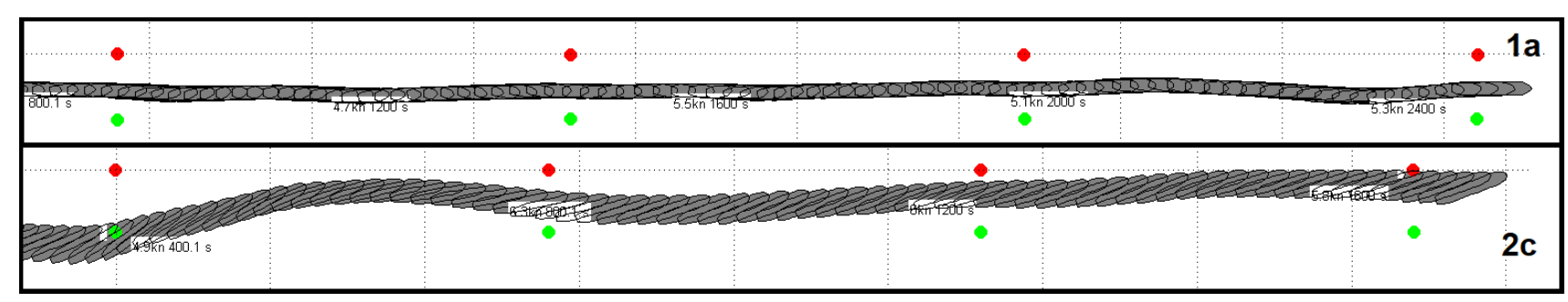

Figure 53: Time-lapse of selected Campos basin maneuvers made by Officer 1 with the vessel fully loaded. On the top is the simulation with moderate conditions 1a, on the bottom is the simulation with extreme conditions, $2 \mathrm{c}$.

In the same manner as in the previous cases analysed, the correlation table 24 was made. It was found a moderate correlation between drifting angle and difficulty for the Officer 1 and a strong correlation for Officer 2. Contrary to the previous simulations, the order of simulation and the wave induced perturbations didn't affect the difficulty in a significant way. The average difficulty and drifting angle are given by simulation category in figure 24 . 
Table 24: Correlations and statistical significance between the perceived maneuver difficulty and the simulations parameters for the Campos basin with the vessel fully loaded.

\begin{tabular}{|c|l|l|}
\hline Simulation Parameter & \multicolumn{2}{|l|}{ Correlation w/ Difficulty (Statistical Significance) } \\
\hline & Officer $\mathbf{1}$ & Officer $\mathbf{2}$ \\
\hline Order of simulation & $-0.347(0.326)$ & $0.753(0.031)$ \\
\hline Drifting & $0.612(0.060)$ & $0.921(0.001)$ \\
\hline Average roll perturbation & $-0.280(0.434)$ & $0.296(0.476)$ \\
\hline Average yaw perturbation & $0.186(0.606)$ & $0.513(0.194)$ \\
\hline RoT average perturbation & $0.075(0.837)$ & $0.295(0.479)$ \\
\hline Current transverse speed & $0.527(0.118)$ & $0.923(0.001)$ \\
\hline Wind transverse speed & $0.701(0.024)$ & $0.724(0.042)$ \\
\hline Wave incidence angle & $0.437(0.206)$ & $-0.755(0.030)$ \\
\hline
\end{tabular}

\section{Mean difficulty and drifting angle for each class of maneuver}

16

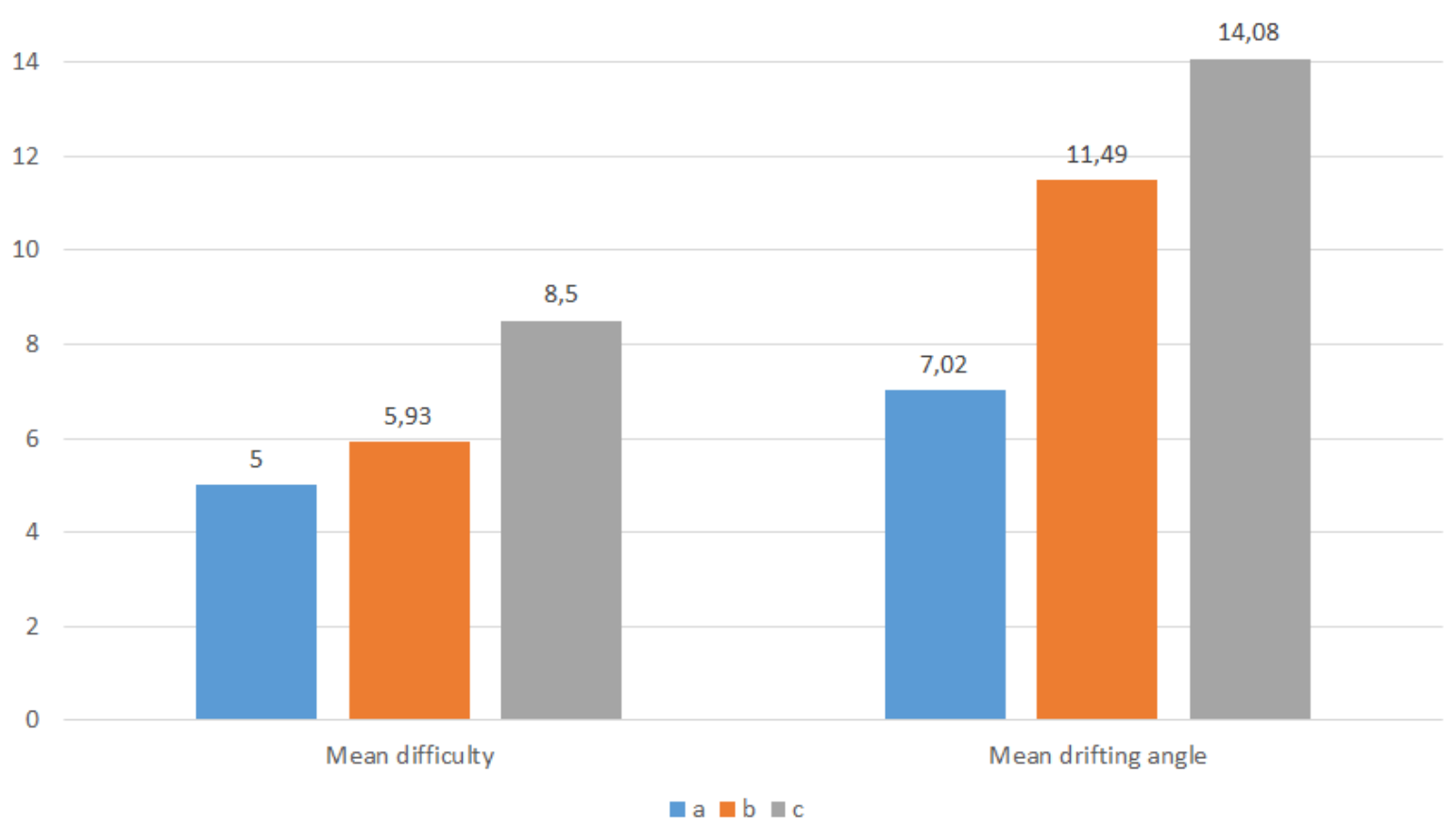

Figure 54: Mean difficulty and drifting angle for simulations in the Campos basin, with the vessel fully loaded. 


\subsection{Campos Basin: Ballast Vessel}

For the simulations in ballast condition it was used the medoid's environmental conditions of the two groups, as well the environmental conditions for the medoids of the $5 \%$ and $1 \%$ cases with highest absolute mean drifting angles. It was also selected one random case for each group (1a' and 2a').

Table 25: Environmental conditions used for the Campos simulations with officers. The arrow $(\nearrow)$ denotes the direction of the environmental agent.

\begin{tabular}{|c|c|c|c|c|c|c|c|c|c|c|}
\hline \multirow[t]{2}{*}{ Simulation } & \multicolumn{2}{|c|}{ Wind } & \multicolumn{2}{|c|}{ Currents } & \multicolumn{3}{|c|}{$1^{s t}$ Wave } & \multicolumn{3}{|c|}{$2^{n d}$ Wave } \\
\hline & $\begin{array}{c}\text { Velocity } \\
(\mathrm{m} / \mathrm{s})\end{array}$ & $\nearrow$ & $\begin{array}{c}\text { Velocity } \\
(\mathrm{m} / \mathrm{s})\end{array}$ & $\nearrow$ & $\begin{array}{l}\mathrm{Hs} \\
(\mathrm{m})\end{array}$ & $\begin{array}{l}\mathrm{Tp} \\
(\mathrm{s})\end{array}$ & $\nearrow$ & $\begin{array}{l}\mathrm{Hs} \\
(\mathrm{m})\end{array}$ & $\begin{array}{l}\mathrm{Tp} \\
(\mathrm{s})\end{array}$ & $\nearrow$ \\
\hline $1 \mathrm{a}$ & 10.1 & 230 & 0.26 & 201 & 2.3 & 8.1 & 197 & 0 & 0 & 0 \\
\hline $1 b$ & 11.9 & 162 & 0.15 & 228 & 3.6 & 9.1 & 162 & 0 & 0 & 0 \\
\hline $1 \mathrm{c}$ & 12.0 & 198 & 0.22 & 349 & 3.3 & 8.8 & 195 & 0 & 0 & 0 \\
\hline $2 \mathrm{a}$ & 10.5 & 13 & 0.23 & 193 & 1.9 & 6.0 & 19 & 1.1 & 11.3 & 158 \\
\hline $2 \mathrm{~b}$ & 12.3 & 25 & 0.59 & 170 & 2.1 & 6.2 & 25 & 0.3 & 6.7 & 154 \\
\hline $2 \mathrm{c}$ & 9.9 & 25 & 1.00 & 157 & 2.1 & 6.5 & 32 & 1.4 & 11.0 & 138 \\
\hline $1 a^{\prime}$ & 5.7 & 349 & 0.15 & 354 & 1.5 & 8.7 & 88 & 0.7 & 3.9 & 3 \\
\hline $1 b^{\prime}$ & 9.6 & 347 & 0.09 & 13 & 1.8 & 11.8 & 111 & 1.5 & 5.2 & 5 \\
\hline
\end{tabular}

As in the other scenarios simulated, a questionnaire is filled by the officers after ever simulation, the questionnaire answers are shown in table 22. It is possible to notice an overall reduction in the perceived difficulty, when compared to the scenario where the same vessel was fully loaded. One possible explication for this reduction in the perceived difficulty is the fact that when the vessel is in ballast condition it reacts quicker to the officer's commands, due to its lower inertia when compared to the vessel fully loaded. 
Table 26: Questionnaire answers for the Campos Basin simulations made by the Officer 1 with the vessel in ballast condition.

\begin{tabular}{|c|c|c|c|}
\hline Simulation & Difficulty & Drifting (Sway) & Notes \\
\hline $1 \mathrm{a}$ & $3+2$ & Weak, unknown & $\begin{array}{l}\text { It seems the drifting kept changing } \\
\text { during the navigation. }\end{array}$ \\
\hline $1 b$ & $5+2$ & Strong, port & - \\
\hline $1 \mathrm{c}$ & $4+2$ & Strong, port & - \\
\hline $2 \mathrm{a}$ & 3 & Moderate, starboard & - \\
\hline $2 \mathrm{~b}$ & 3 & Strong, starboard & - \\
\hline $2 \mathrm{c}$ & $3+2$ & Very strong, starboard & $\begin{array}{l}\text { Heading at } 065^{\circ} \text { stabilized the vessel's } \\
\text { movement, by keeping the rudder at } \\
\text { the middle it was possible to maneuver } \\
\text { by only changing the machine order. }\end{array}$ \\
\hline $1 a^{\prime}$ & $0+2$ & Very weak, starboard & - \\
\hline $1 b$ & 3 & Moderate, starboard & $\begin{array}{l}\text { Slow ahead was used for navigation, } \\
\text { vessel lost controlability in dead-slow } \\
\text { ahead. }\end{array}$ \\
\hline
\end{tabular}

The simulations were clustered by the Officer 1 accordingly with the perceived drifting angle (starboard or port) with the simulation 1a being unique in a way that it appeared as if the drifting changed direction during the simulation, as shown in table 27. Two examples of simulations are shown in figure 55 .

Table 27: Pilots classification of the simulated cases for the Campos basin simulations with the vessel in ballast condition.

\begin{tabular}{|c|c|c|}
\hline \multicolumn{3}{|c|}{ Clustering made by Officer 1 } \\
\hline Simulation group & Criteria given by the officer & Cases \\
\hline 1 & Port drifting & $1 \mathrm{~b}, 1 \mathrm{c}, 1 \mathrm{a}^{\prime}, 1 \mathrm{~b}^{\prime}, 2 \mathrm{a}^{\prime}$ \\
\hline 2 & Starboard drifting & $2 \mathrm{a}, 2 \mathrm{~b}, 2 \mathrm{c}, 1 \mathrm{a}^{\prime}, 1 \mathrm{~b}^{\prime}$ \\
\hline 3 & Drifting direction changes during the simulation & $1 \mathrm{a}$ \\
\hline
\end{tabular}




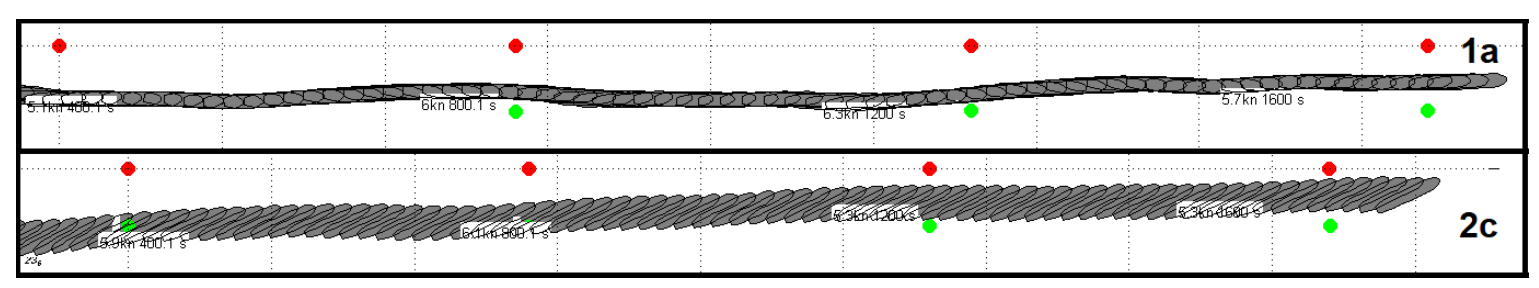

Figure 55: Time-lapse of selected Campos basin maneuvers with the vessel in ballast condition. On the top is the simulation with moderate conditions $1 \mathrm{a}$, on the bottom is the simulation with extreme conditions, $2 \mathrm{c}$.

The correlations shown in table 28 shows no correlation between drifting and difficulty, a moderate negative correlation between the order of simulation and moderate correlations with the environmental conditions. The figure 56 shows the average of perceived difficulty and drifting angle for the cases simulated. It is possible to notice that the average difficulty increases slightly with the increase in drifting angle.

Table 28: Correlations and statistical significance between the perceived maneuver difficulty and the simulations parameters for the Campos basin with the vessel in ballast condition.

\begin{tabular}{|c|l|l|}
\hline Simulation Parameter & Correlation with Difficulty & Statistical Significance \\
\hline Order of simulation & -0.559 & 0.118 \\
\hline Drifting & 0.079 & 0.840 \\
\hline Average roll perturbation & 0.512 & 0.159 \\
\hline Average yaw perturbation & 0.758 & 0.018 \\
\hline RoT average perturbation & 0.653 & 0.057 \\
\hline Current transverse speed & 0.031 & 0.937 \\
\hline Wind transverse speed & 0.554 & 0.121 \\
\hline Wave incidence angle & 0.818 & 0.007 \\
\hline
\end{tabular}


Mean difficulty and drifting angle for each class of maneuver

25

and 22,11

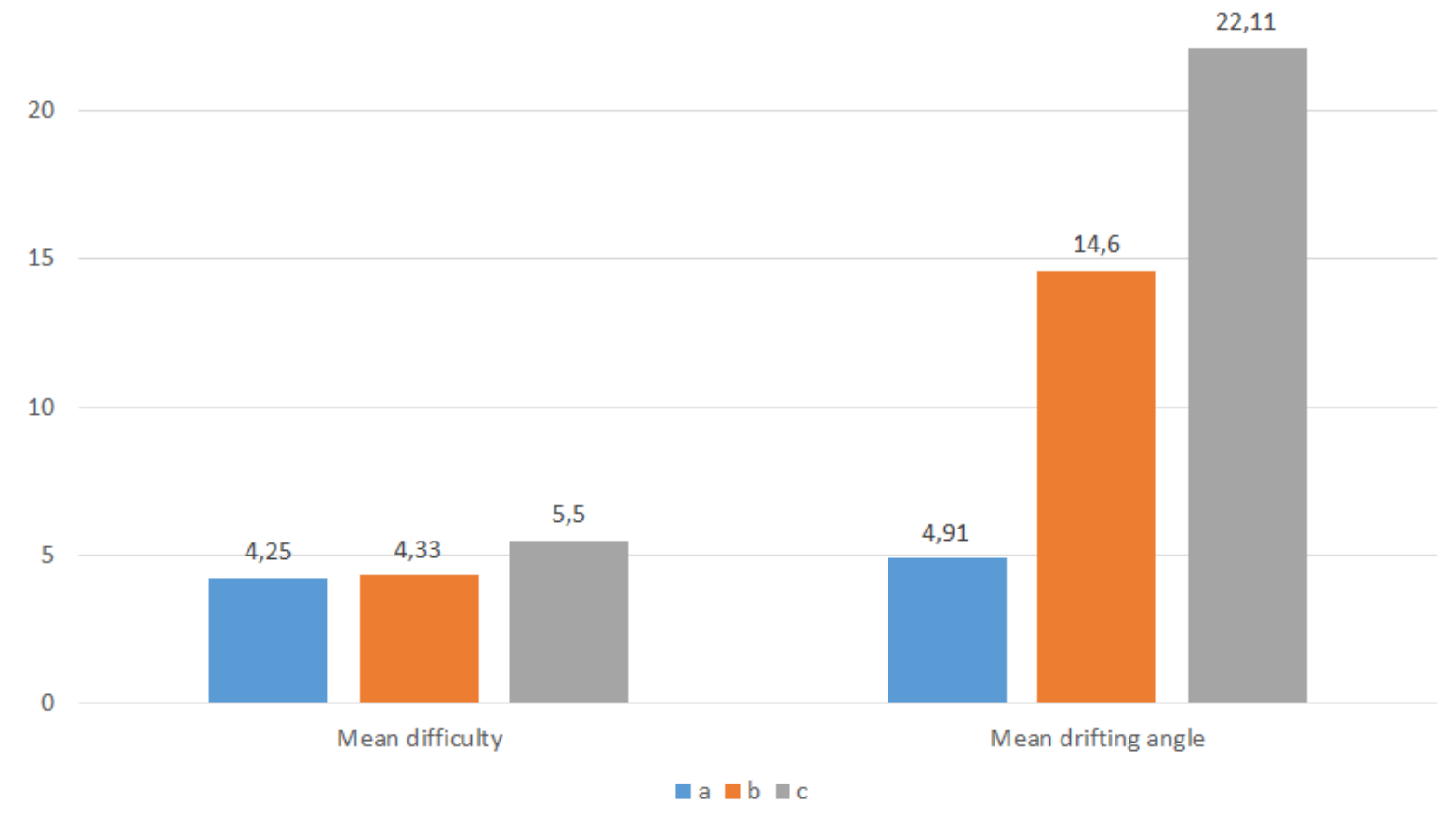

Figure 56: Mean difficulty and drifting angle for simulations in the Campos basin, with the vessel in ballast condition. 


\section{CONCLUSION AND NEXT STEPS}

At the current stage, it was developed a methodology for clustering the environmental conditions in a site accordingly to the characteristics of a maneuver made by an automatic pilot in a large batch of different environmental conditions. This work is a step towards the automation and standardization of the process of selecting which environmental conditions are most valuable for Real-Time maneuvering simulations, allowing a preview of the maneuvers being made in all the available scenarios.

The main difference between the methodology in this work and the current methodologies used is that this one focuses on overall effects felt by the vessel under the combination of all the environmental agents, instead of focusing in the environmental agents per se. This methodology can be expanded to accommodate any number of quantifiable parameters considered relevant for the differentiation and classification of the simulations into different bins, where each bin can be represented by only one environmental condition since the maneuvers in the same bin are similar.

The initial testing with real officers showed that our initial assumptions made for the first version of this method are at least partially true. The drifting angle can be used to both separate the data into groups qualitatively different and define difficulty levels for the maneuver in some cases, but there are other factors that should be incorporated in the analysis, such as the oscillatory effect of waves.

It was also noteworthy that despite the use of an automatic pilot, the validation of this methodology and the obtention of relevant parameters for the simulations relies on human officers, which adds a greater level of subjectivity. Ideally the validation should have been made with a larger number of pilots or officers in order to reduce individual biases, but due to time and officer availability constraints only a limited number of fast-time simulations can be made with real officers. In the long term, new validation maneuvers can be made for this research, and the methodology can be adapted and refined as new information in obtained. 


\section{REFERENCES}

ARAÚJO, C. E. S.; FRANCO, D.; MELO, E.; PIMENTA, F. Wave regime characteristics of the Southern Brazilian coast. VI International Conference on Coastal and Port Engineering in Developing Countries, v. 4, p. 1-15, 92003.

BELLMAN, R. Adaptive control processes. New Jersey: Princeton University Press, 1961. v. 8. 255 p. Disponível em: 〈http://dx.doi.org/10.1002/nav.3800080314〉.

BISHOP, C. M. Pattern Recognition And Machine Learning. [S.l.]: Springer, 2006.

CAMUS, P.; MENDEZ, F. J.; MEDINA, R.; COFIÑO, A. S. Analysis of clustering and selection algorithms for the study of multivariate wave climate. 2011. 453-462 p.

CARAWAY, N. M.; MCCREIGHT, J. L.; RAJAGOPALAN, B. Multisite stochastic weather generation using cluster analysis and k-nearest neighbor time series resampling. Journal of Hydrology, v. 508, p. 197 - 213, 2014. ISSN 0022-1694. Disponível em: 〈http://www.sciencedirect.com/science/article/pii/S0022169413007981〉.

ClAUZET, G.; LUCA, C. D.; ANSANELli, L. C.; GOUVEA, M.; OliveIRA, J. G. Modelagem Hidrodinâmica e de Propagação de Ondas na Plataforma Continental do Estado do Espírito Santo, Brasil. 2016.

DONG, L.; WANG, L.; KHAHRO, S. F.; GAO, S.; LIAO, X. Wind power day-ahead prediction with cluster analysis of NWP. 2016.

ESTER, M.; KRIEGEL, H.-P.; SANDER, J.; XU, X. A Density-Based Algorithm for Discovering Clusters in Large Spatial Databases with Noise. In: Second Int. Conf. on Knowledge Discovery and Data Mining. Portland: [s.n.], 1996. p. 6. ISBN 9780444527011.

EUÁN, C.; SUN, Y. Directional Spectra-Based Clustering for Visualizing Patterns of Ocean Waves and Winds. Journal of Computational and Graphical Statistics, Taylor \& Francis, v. 28, n. 3, p. 659-670, 2019. Disponível em: 〈https://doi.org/10.1080/10618600. $2019.1575745\rangle$.

FILHO, A.; ZIMBRES, M.; TANNURI, E. Development and Validation of a Customizable DP System for a Full Bridge Real Time Simulator. Proceedings of the International Conference on Offshore Mechanics and Arctic Engineering - OMAE, v. 1, 92014.

FOSSEN, T. I. Marine Control Systems. [S.l.: s.n.], 2002.

GIBSON, R.; CHRISTOU, M. Metocean Criteria for the Fatigue Analysis of Subsea Pipelines. [S.l.], 2019.

GONG, X.; RICHMAN, M. B. On the Application of Cluster Analysis to Grwing Season Precipitation Data in North America East of the Rockies. Journal of Climate, v. 8, 1995. 
HASTIE, T.; TIBSHIRANI, R.; FRIEDMAN, J. The Elements of Statistical Learning. 2nd. ed. New York: Springer-Verlag, 2008. 745 p.

HUANG, A. S.; MOREnO, F. M.; TANNURI, E. A.; CÂMARA, J. G. A. Equilibrium Position Analysis for Offloading Operations With Turret-Moored FPSO. Journal of Offshore Mechanics and Arctic Engineering, ASME International, v. 141, n. 5, p. 1-9, 10 2019.

KAnNER, S.; AUBAUlT, A.; PEIFFER, A.; YU, B. Efficient Algorithm for Discretization of Metocean Data Into Clusters of Arbitrary Size and Dimension. In: 36th International Conference on Ocean, Offshore and Arctic Engineering. Trondheim: ASME, 2017. p. 10.

KANNER, S.; AUBAULT, A.; PEIFFER, A.; YU, B. Maximum Dissimilarity-based Algorithm for Discretization of Metocean Data Into Clusters of Arbitrary Size and Dimension. [S.1.], 2018. Disponível em:〈https://proceedings.asmedigitalcollection.asme. org $\rangle$.

KAUFMAN, L.; ROUSSEEUW, P. J. Finding Groups in Data: An Introduction to Cluster Analysis. [S.1.]: Wiley-Interscience, 2005. 342 p. ISBN 9780471735786,0-47-1-73578-7.

LECKEBUSCH, G. C.; WEIMER, A.; PINTO, J. G.; REYERS, M.; SPETH, P. Extreme wind storms over Europe in present and future climate: a cluster analysis approach. Meteorologische Zeitschrift, Schweizerbart Science Publishers, Stuttgart, Germany, v. 17, n. 1, p. 67-82, 9 2008. Disponível em:〈http://dx.doi.org/10.1127/0941-2948/2008/0266〉.

LEWIS, E. V. Principles of Naval Architecture-Second Revision. 3. ed. Jersey City: The Society of Naval Architects and Marine Engineers, 1989.

LIU, Y.; WEISBERG, R. H. Patterns of ocean current variability on the West Florida Shelf using the self-organizing map. Journal of Geophysical Research: Oceans, v. 110, n. C6, 2005. Disponível em:〈https://agupubs.onlinelibrary.wiley.com/doi/abs/10.1029/ 2004JC002786〉.

LYRA, G. B.; OLIVEIRA-JÚNIOR, J. F.; ZERI, M. Cluster analysis applied to the spatial and temporal variability of monthly rainfall in Alagoas state, Northeast of Brazil. International Journal of Climatology, 2014. ISSN 10970088.

MA, M. Wind Rose. 2020. Disponível em:〈https://www.mathworks.com/matlabcentral/ fileexchange/17748-wind \_rose $\rangle$.

MAZZILLI, F.; TANNURI, E. Técnicas de ajuste de ganhos de controle para Sistemas de Posicionamento Dinâmico. In: $23^{0}$ Congresso Nacional de Transporte Aquaviário, Construção Naval e Offshore. Rio de Janeiro: [s.n.], 2010. p. 11.

MOLLAND, A.; TURNOCK, S. Marine Rudders and Control Surfaces. Elsevier, 2007. ISBN 9780750669443. Disponível em:〈https://linkinghub.elsevier.com/retrieve/pii/ B9780750669443X50008>.

MOREnO, F. M.; SOUZA, F. L. D.; TANNURI, E. A. Metocean Data Clustering For Real-Time Maneuvering Simulations. In: MARSIM. Halifax: [s.n.], 2018. 
PALIWAL, K. K.; AGARWAL, A.; SINHA, S. S. A Modification Over Sakoe and Chiba's Dynamic Time Warping Algorithm for Isolated Word Recognition. [S.l.], 1982. v. 4, 329-333 p.

PREVOSTO, M.; FORRISTALL, G. Z.; JEANS, G.; HERRY, C.; HARTE, G.; HARRINGTON-MISSIN, L.; DOOLEY, P. Worldwide Approximations Of Current Profiles For Steel Riser Design. In: 31st International Conference on Ocean, Offshore and Arctic Engineering. Rio de Janeiro: [s.n.], 2012.

SANTANA, J. P. L. d. Recordes mantêm Suape entre os cinco maiores portos públicos do país. 2018. Disponível em:〈http://www.suape.pe.gov.br/pt/noticias/ 1085-recordes-mantem-suape-entre-os-cinco-maiores-portos-publicos-do-pais .

TANNURI, E. A. Desenvolvimento De Metodologia De Projeto De Sistema De Posicionamento Dinâmico Aplicado A Operações Em Alto-Mar. São Paulo: [s.n.], 2002.

TANNURI, E. A.; MELLO, P. C. de; DOTTA, R.; OSHIRO, A. T.; DIEDERICHS, G. R.; CRUZ, D. F.; FERREIRA, M. D.; NUNES, L. M. P.; MAEDA, K. Drift-Off Study in Drilling Vessels Comparing Numerical Model and Full-Scale Field Measurements. Journal of Offshore Mechanics and Arctic Engineering, v. 142, n. 4, 8 2020. ISSN 0892-7219. Disponível em:〈https://asmedigitalcollection.asme.org/offshoremechanics/ article/doi/10.1115/1.4046195/1074098/DriftOff-Study-in-Drilling-Vessels-Comparing .

TANNURI, E. A.; RATEIRO, F.; FUCATU, C. H.; FERREIRA, M. D.; MASETTI, I. Q.; NISHIMOTO, K. Modular Mathematical Model for a Low-Speed Maneuvering Simulator. In: 33rd International Conference on ocean, Offshore and arctic Engineering. San Francisco: [s.n.], 2014. p. 10.

TPN. Tanque de Provas Numérico. 2019. Disponível em:〈http://tpn.usp.br/〉.

VALE, M. N. do. Agrupamentos de Dados: Avaliação de Métodos e Desenvolvimento de Aplicativo para Análise de Grupos. Tese (Doutorado) - PUC-RJ, 2005.

VOGEL, M.; HANSON, J.; FAN, S.; FORRISTALL, G.; LI, Y.; FRANTANTONIO, R.; JONATHAN, P. Efficient Environmental and Structural Response Analysis by Clustering of Directional Wave Spectra. p. 2-5, 2016.

WATAI, R. A.; RUGGERI, F.; TANNURI, E. A. Estudo Hidrodinâmico e de Condições Metaoceanográficas para área de fundeio próxima ao Porto de Suape (PE). 2017. 34 p.

ZHANG, H.; SINGER, B. H. Recursive Partitioning and Applications. 2. ed. New York: Springer, 2010. 259 p. ISBN 978-1-4419-6823-4.

ZHANG, Z.; TANG, P.; DUAN, R. Dynamic time warping under pointwise shape context. Information Sciences, Elsevier Inc., v. 315, p. 88-101, 9 2015. ISSN 00200255. 